\title{
Natural and Accelerated Bioremediation Research
}

\section{N A B I R}

\section{Program Plan}

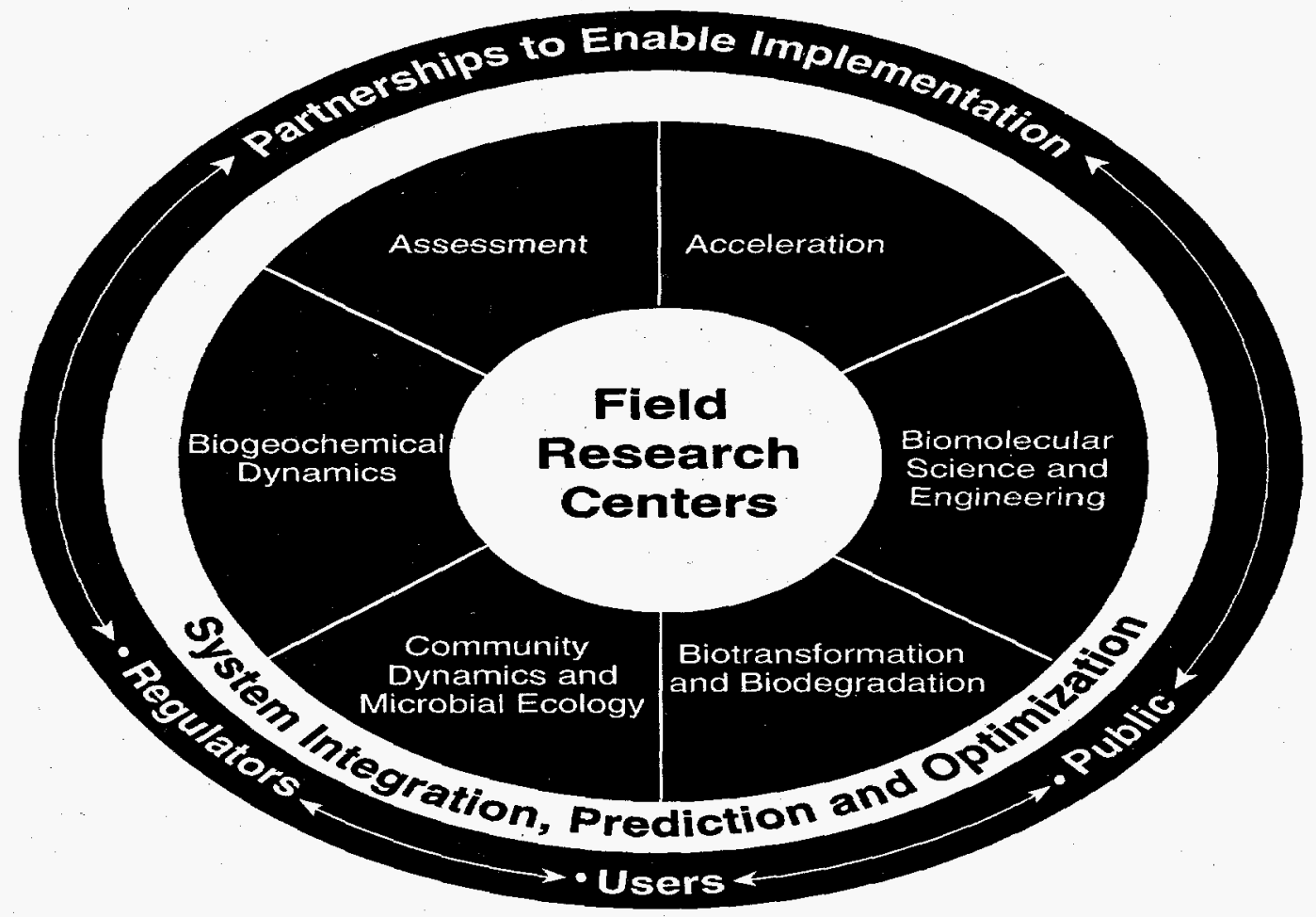

\section{September 1995}

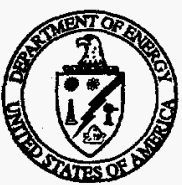

U.S. Department of Energy

Office of Energy Research

Office of Health and Environmental Research

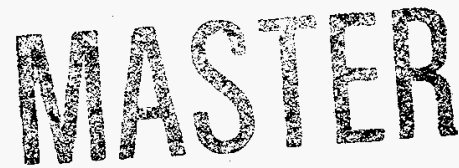




\section{DISCLAIMER}

Portions of this document may be illegible in electronic image products. Images are produced from the best available original document. 


\section{Foreword}

Bioremediation is unique among remediation technologies in that it degrades or transforms hazardous contaminants through the use, possibly with manipulative enhancement, of indigenous microorganisms. Bioremediation can be used in many waysdegradation of concentrated organic contaminants near their source, as a secondary remediation strategy following physical or chemical methods, for sequestration of metals and radionuclides through microbially mediated transformation processes, and for remediating large plumes of dilute contaminants that are broadly dispersed in the environment. Thus, bioremediation has the potential to be one of the most cost-effective technologies for dealing with environmental remediation problems.

The U.S. Department of Energy (DOE), Office of Environmental Management (EM) is responsible for the environmental management of 130 sites and facilities in 30 states and territories (DOE, 1995). Activities associated with nuclear weapons production have left many of these sites contaminated with complex mixtures of organic and radioactive chemicals. Bioremediation has the potential to be of great utility in the restoration of such sites, and the Natural and Accelerated Bioremediation Research (NABIR) program, described in this document, focuses on such DOE problems. Results produced under NABIR, however, will also be applicable to the remediation of pollution caused by a wide variety of industrial activities across the nation.

DOE's Office of Health and Environmental Research (OHER) has a long tradition of supporting fundamental research in the life and environmental sciences. NABIR builds on OHER's foundation to develop a body of knowledge that will support environmental restoration of DOE's facilities. It is one part of the Office of Energy Research's (OER's) commitment to help address DOE's environmental management problems.

OHER is committed to ensuring that the scientific results from this program are used. To achieve this, we are committed to developing productive communication with the EM problem-holders, with regulatory agencies, and with the research community. Scientific research must be focused where it has the biggest potential to impact 
remediation activities. Scientific results must be communicated effectively and quickly. Ethical, legal, and social issues must be identified and dealt with to the satisfaction of the public and regulatory agencies. The NABIR program is designed to address all of the above.

Scientists and engineers from the DOE national laboratories worked together to prepare the Natural and Accelerated Bioremediation Research program plan with help and advice from DOE staff, university researchers, and the private research and development (R\&D) sector. The plan was written for several audiences-academic and national laboratory researchers who will participate in the program, program managers from DOE and other federal agencies whose programs will benefit from these activities, and private-sector research organizations. We believe that this integrated, multidisciplinary program will provide the fundamental scientific and technological foundation needed to realize the potential of bioremediation.

Michelle S. Broido, Ph.D.

Acting Director

Environmental Sciences Division

Office of Health and Environmental

Research 


\section{Mission, Scope, and Goals}

MISSION

The mission of the Natural and Accelerated Bioremediation Research (NABIR) program is to provide the scientific understanding needed to harness natural processes and to develop methods to accelerate these processes for the bioremediation of contaminated soils, sediments, and groundwater at DOE facilities.

\section{SCOPE}

The program will focus on in situ bioremediation of complex mixtures of contaminants present at DOE facilities. Primary contaminants of concern include mixtures of halogenated compounds, organic acids, chelating agents, heavy metals, and radionuclides. Scientific understanding will be gained by performing fundamental laboratory and field research on biotransformation and biodegradation processes, community dynamics and microbial ecology, biomolecular science and engineering, biogeochemical dynamics, and innovative methods for accelerating and assessing in situ biogeochemical processes. Field research centers and the supporting infrastructure will be established to facilitate long-term, interdisciplinary research. Computational models will be developed as integrating tools, as well as to provide methods for predicting and optimizing the effectiveness of bioremediation.

DOE has a 50-year legacy of environmental problems resulting from the production of nuclear weapons. Among the most serious are widespread contamination of soils, sediments, and groundwater. The total life-cycle cost of remediating these sites is not known (DOE, 1995). Moreover, many of the contaminated soils, sediments, and groundwater are believed to be impossible to remediate with existing technology. Examples of such intractable problems include the Snake River Aquifer in Idaho, contaminated groundwater at the " 100 " and " 200 " areas at Hanford, Washington, contaminated sediments in the Columbia River, and groundwater at the Nevada Test Site (DOE, 1995). The huge cost, long duration, and technical challenges associated with 
remediating DOE facilities present a significant opportunity for science to contribute cost-effective solutions.

While some of DOE's environmental remediation problems are shared by other federal agencies and the private sector, DOE faces a unique set of challenges associated with complex mixtures of contaminants, especially those mixtures that contain radioactive elements. The Environmental Management Program's Office of Technology Development has embarked on an ambitious path to develop innovative technologies for solving many of its problems. However, they and others have recognized that, in many cases, the fundamental scientific information needed to develop effective technologies is lacking. Natural and accelerated bioremediation, which has potential to play an important role in DOE's environmental restoration program, is one area where advances in scientific understanding could make a significant contribution.

\section{GOALS}

Over a ten-year period, the scientific knowledge needed to harness natural biogeochemical processes and develop methods to accelerate these processes will be achieved by meeting the following goals:

- Develop interdisciplinary teams and focus them on gaining the fundamental knowledge necessary to overcome the obstacles facing current technologies for remediating complex contaminant mixtures in natural environments.

- Establish field research centers for long-term research on the scientific foundations underpinning bioremediation.

- Develop the scientific knowledge, computational methods, and monitoring techniques needed to implement and predict the effectiveness of bioremediation of contaminant mixtures in a wide variety of natural environments.

- Train a new generation of scientists and engineers to address interdisciplinary problems related to biogeochemical processes in complex environments.

- Identify opportunities for using knowledge gained from this program for other applications such as ex situ waste treatment, pollution prevention, and ecosystem monitoring.

- Develop effective partnerships to address ethical, legal, and social issues as well as to use and share the knowledge acquired from the program for optimal application of bioremediation at DOE sites. Partners will include intra- and inter-agency representatives, state and federal regulators, the public, and the research and development community. 


\section{Executive Summary}

This draft plan describes a ten-year program to develop the scientific understanding needed to harness and develop natural and enhanced biogeochemical processes to bioremediate contaminated soils, sediments and groundwater at DOE facilities. The Office of Health and Environmental Research (OHER) developed this program plan, with advice and assistance from DOE's Office of Environmental Management (EM). The program builds on OHER's tradition of sponsoring fundamental research in the life and environmental sciences and was motivated by OHER's and Office of Energy Research's (OER's) commitment to supporting DOE's environmental management mission and the belief that bioremediation is an important part of the solution to DOE's environmental problems.

\section{NATURAL AND ACCELERATED BIOREMEDIATION}

-Bioremediation is defined by the American Academy of Microbiology as "the use of living organisms to reduce or eliminate environmental hazards resulting from accumulations of toxic chemicals or other hazardous wastes" (Gibson and Sayler, 1992). The program addresses both natural bioremediation, which relies on naturally occurring microbial and plant processes, and accelerated bioremediation, which seeks to accelerate desirable processes through the addition of amendments (e.g., nutrients, electron acceptors) or microorganisms (including GEMs), or by manipulating physical, chemical, or hydrological processes. Bioremediation has been implemented successfully for degradation of petroleum hydrocarbons and, to a limited extent, degradation of explosives and chlorinated hydrocarbons, as well as for immobilization of toxic trace metals. However, the effectiveness of bioremediation cannot always be predicted reliably, due to numerous factors ranging from lack of basic scientific knowledge to engineering limitations. More importantly, few if any investigations have addressed bioremediation of the contaminants present at DOE sites, where mixtures containing chlorinated hydrocarbons, metals, radionuclides, PCBs, and inorganic contaminants are common. Finally, there is general agreement among the research community that field-based research is needed to realize the full potential of bioremediation. 


\section{THE SCIENTIFIC PROGRAM}

The program was shaped by a team of scientists after a thorough review of recommendations for research published over the past five years and an analysis of related programs in DOE and other federal agencies. Several key themes guided the scientific approach:

- Fundamental research is required to advance our understanding of the biological, chemical, and physical processes important for natural and accelerated bioremediation.

- Integration of scientific ideas across disciplines is essential for the development of the knowledge needed to predict and optimize bioremediation rates and processes.

- Field research centers are the best vehicles for integrating research, identifying crucial research needs, and focusing the program on DOE's most significant problems.

- Access to R\&D shared infrastructure will be required to advance measurement and diagnostic techniques.

- To realize the enormous potential that this program has to contribute to remediating DOE's sites, the goals must be identified clearly and used to focus the program.

- Ethical, legal, and social issues associated with bioremediation, especially with regard to genetically engineered organisms (such as GEM), must be identified and addressed immediately.

- Linkages to other, related programs must be established and maintained.

The key themes will be implemented through the seven interrelated program elements described below.

\section{Biotransformation and Biodegradation}

Fundamental research in microbiology to elucidate the mechanisms of biotransformation and biodegradation of complex contaminant mixtures.

\section{Community Dynamics and Microbial Ecology}

Fundamental research in ecological processes and interactions of biotic and abiotic components of ecosystems to understand their influence on the degradation, persistence, and toxicity of mixed contaminants. 


\section{Biomolecular Science and Engineering}

Fundamental research in molecular and structural biology to enhance our undestanding of bioremediation and improve the efficacy of bioremedial organisms and identify novel remedial genes.

\section{Biogeochemical Dynamics}

Fundamental research in the dynamic relationships among in situ geochemical, geological, hydrological, and microbial processes.

\section{Assessment}

Fundamental research in measuring and validating the biological and geochemical processes of bioremediation.

\section{Acceleration}

Fundamental interdisciplinary research in flow and transport of nutrients and microorganisms, focused on developing effective methods for accelerating and optimizing bioremediation rates.

\section{System Integration, Prediction, and Optimization}

Fundamental research to develop conceptual and quantitative methods for describing community dynamics, biotransformation, biodegradation, and biogeochemical dynamics processes in complex geologic systems.

\section{MANAGEMENT STRUCTURE AND IMPLEMENTATION}

The program will be managed by OHER, with assistance from a program office. The program office will be responsible for day-to-day management, scientific coordination within and among program elements, scheduling of major activities at the test sites, communication and data base management, and facilitating access to the R\&D shared infrastructure. Each field research center will have an on-site manager who will be responsible for obtaining permits, developing and implementing a site safety plan, day-to-day scheduling of field activities, and site operations. Instrument managers will be identified for major laboratory measurement facilities. Final management approval and oversight for all activities will be retained by OHER. The program will also be supported by an interagency steering committee to ensure coordination with complementary programs and identify opportunities for leveraging scientific and infrastructure investments.

Research projects will be carried out by a science team consisting of DOE laboratory scientists, academic investigators, researchers from other federal agencies, and industry researchers. The scientific program will be funded primarily by competitive proposals, regardless 
of the status of the principal investigator, be it university, DOE laboratory, or industry. The program will seek to get the best talent available to address the goals identified in the program elements.

The activities described above will be funded by OHER. As proposed by the team developing this program, the approximate total budget over the life of the ten-year program is $\$ 417 \mathrm{M}$, of which $75 \%$ supports scientific effort and the remainder is divided equally among equipment and operating expenses.

The startup and implementation of the program will begin in FY96. FY96 activities will include: (1) broad announcement of the program to the research community and DOE sites, (2) selection of the scientific team leaders, (3) formation of the initial scientific team through a competitive process, (4) selection of the first field research center, (5) evaluation of $R \& D$ shared infrastructure requirements, (6) identification of ethical, legal, and social issues that must be addressed immediately, and (7) identification of the interagency steering committee members.

Two types of peer review will be incorporated into the program management plan-programmatic peer review and project peer review. Programmatic peer review will be used to evaluate the overall effectiveness of the program and how well the program is achieving its goals. Project peer review will consist of conventional scientific peer review of individual projects proposed by the principal investigators of the program.

In addition to peer review, other performance measures will be used to evaluate whether the program is successful. These will include quantity and quality of new knowledge generated by the program, effectiveness of the interdisciplinary teams, timely accomplishments of programmatic goals, application of knowledge or techniques to bioremediation or to otherwise help solve DOE problems, and spin-off to other areas such as, pollution prevention, ecosystem studies, biomedical applications, ecotoxicity, and human genome studies. 


\section{Contents}

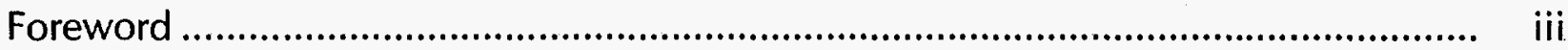

Mission, Scope, and Goals .................................................................................. v

Executive Summary .................................................................................................... vii

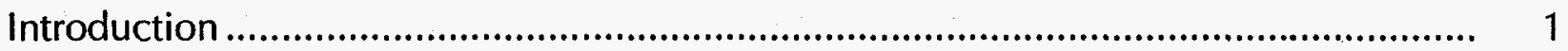

The Legacy of the Cold War and DOE's Unique Set of

Remediation Challenges................................................................................... 7

Biogeochemical Processes: The Foundation for In Situ

Bioremediation .............................................................................................. 11

Bioremediation Research Needs ................................................................. 14

Bioremediation and Related Programs in DOE ................................................ 22

Bioremediation in Other Departments and Agencies........................................ 29

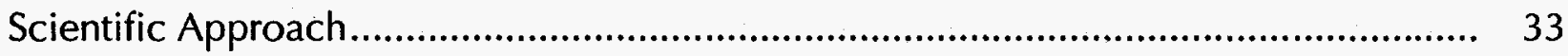

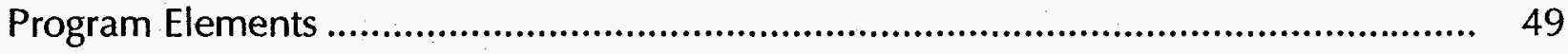

Program Element 1: Biotransformation and Biodegradation............................ 49

Program Element 2: Community Dynamics and Microbial

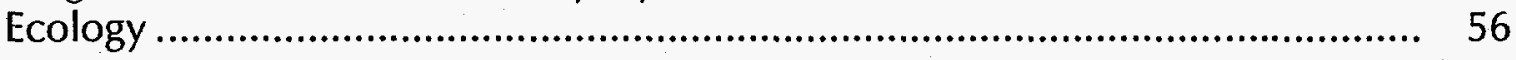

Program Element 3: Biomolecular Science and Engineering .............................. 65

Program Element 4: Biogeochemical Dynamics ................................................ 71

Program Element 5: Assessment ................................................................... 76

Program Element 6: Acceleration ........................................................... 83

Program Element 7: System Integration, Prediction, and

Optimization ......................................................................................... 89

Program Management, Partnerships, ELSI Issues, and Implementation Plan.................. 95

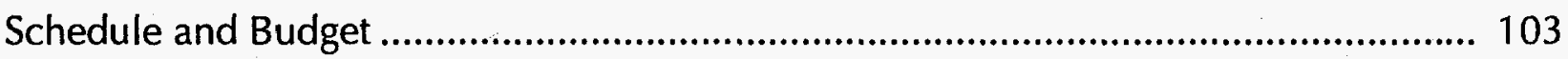

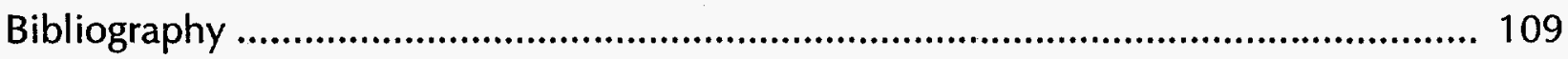

Appendix A: Acronyms and Initialisms.................................................................. 115

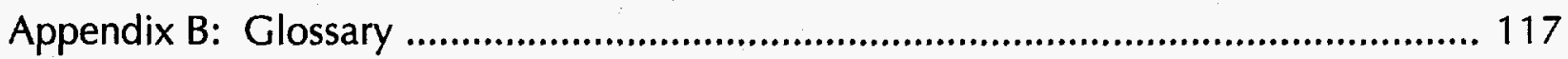

Appendix C: Developers and Reviewers of the Program Plan.................................... 125 


\section{Introduction}

\section{THE DOE MISSION}

Environmental management and cleanup of the DOE facilities is one of the five primary missions of the Department of Energy (Fig. 1). To accomplish this mission, DOE must find new and more cost-effective remedies for protecting human health and the environment, particularly because of the unique composition and large quantities of hazardous and radioactive wastes that are broadly dispersed in the environment at DOE's facilities. DOE's Office of Energy Research (OER) is committed to developing fundamental scientific knowledge in support of this mission.

\section{THE OFFICE OF HEALTH AND ENVIRONMENTAL RESEARCH}

To support the environmental management mission, OER's Office of Health and Environmental Research (OHER) will initiate a new program in Natural and Accelerated Bioremediation Research (NABIR). The program plan was prepared with assistance and cooperation from DOE's Office of Environmental Management (EM) and is intended to complement EM's ongoing technology development programs by improving scientific understanding of the biogeochemical processes that provide the foundations for bioremediation.

OHER has a long tradition of sponsoring fundamental research in the life and environmental sciences. OHER investigates problems of complexity and scale that are expected to significantly change the way we think about a field of scientific inquiry. Such problems require the long-term commitment of interdisciplinary teams to develop breakthroughs in scientific understanding and new scientific methods and instruments. Examples of such programs include the Human Genome Project, the Atmospheric Radiation Measurement Program, and the Subsurface Science Program (see Table 1).

NABIR builds on this tradition and is motivated by the belief that bioremediation is an important part of the solution to DOE's environmental problems. 


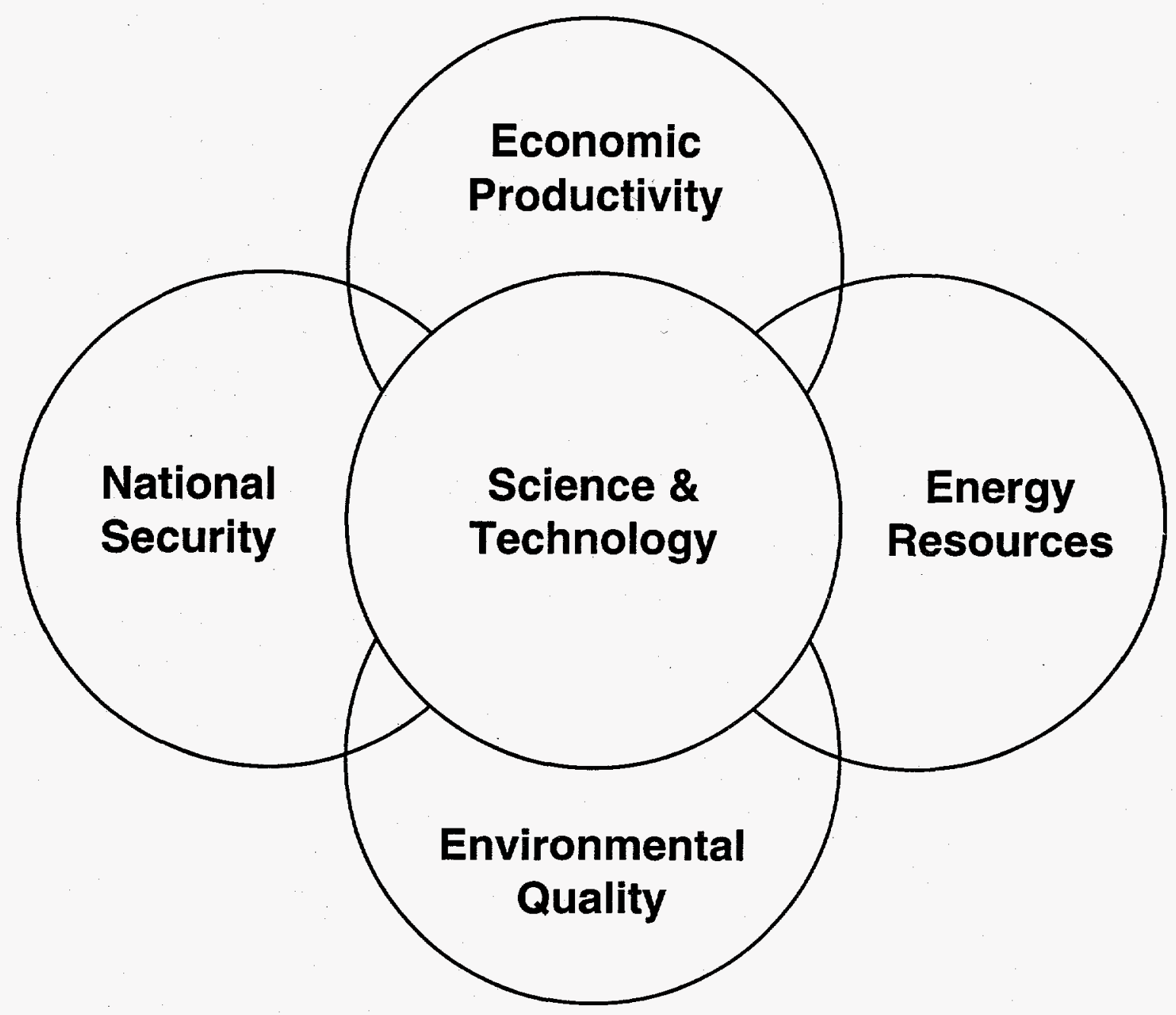

Figure 1. The strategic plan of the DOE identifies five primary mission areas. (From the Performance Agreement petween The President of the United States and The Secretary of Energy, Fiscal Year 1995.) 
Table 1. Representative OHER accomplishments.

\begin{tabular}{ll}
\hline Area of Research & Accomplishments \\
\hline Global change research & $\begin{array}{l}\text { First agency to develop a } \\
\text { program in global change }\end{array}$ \\
research (1978); emphasis on \\
improving capability to predict \\
regional and global climate \\
change.
\end{tabular}


Bioremediation is defined by the American Academy of Microbiology (AAM) as "the use of living organisms to reduce or eliminate environmental hazards resulting from accumulations of toxic chemicals and other hazardous wastes" (Gibson and Sayler, 1992). Other options for remediation of soils, sediments, and groundwater include physical and chemical methods or a combination thereof. The optimal strategy for any given problem will depend on the nature and concentration of the contaminant(s), the characteristics of the hydrogeologic environment, and the extent of contamination. At the present time, bioremediation is often the preferred method for remediation of petroleum hydrocarbons because it is cost effective, and it converts the petroleum hydrocarbons into harmless by-products such as carbon dioxide and water.

Over the past decade, opportunities for applying bioremediation to a much broader set of contaminants have been identified. Indigenous and enhanced organisms have been shown to degrade industrial solvents, polychlorinated biphenyls (PCBs), explosives, and many different agricultural chemicals. Pilot, demonstration, and full-scale applications of bioremediation have been carried out on a limited basis. Equally importantly, microorganisms that transform and sequester heavy metals and radionuclides have been identified and employed, to a limited extent, for in situ bioremediation. However, the full benefits of bioremediation have not been realized because processes and organisms that are effective in controlled laboratory tests are not always equally effective in full-scale applications. The failure to perform optimally in the field setting stems from a lack of predictability due, in part, to inadequacies in the fundamental scientific understanding of how and why these bioremediation processes work.

The advantages of in situ bioremediation compared to or in combination with other remediation technologies include, but are not limited to, the following.

1. In situ bioremediation can be used to completely degrade and detoxify some organic contaminants, thereby permanently removing liability for the contaminants.

2. For deep, widely dispersed plumes of heavy metals and radionuclides, in situ biosequestration and immobilization may be the only viable solution for addressing DOE's remediation needs.

3. For some types of contaminants, physical and chemical methods of remediation may not completely remove the contaminants, leaving residual concentrations that are above regulatory guidelines. Bioremediation can be used as a cost-effective secondary treatment scheme to decrease the concentration of 
contaminants to acceptable levels. In other cases, bioremediation can be the primary treatment method, and followed by physical or chemical methods for final site closure.

4. In some cases, natural attenuation (including natural bioremediation) of the contaminant plumes may be the only cost effective solution (DOE, 1995). Natural biogeochemical processes that degrade organic contaminants, convert nitrate to nitrogen gas, and sequester heavy metals and radionuclides will play major roles in natural attenuation. These biogeochemical processes must be adequately understood before regulatory agencies and the public accept natural attenuation as an alternative to more aggressive remediation methods.

5. For radionuclides and heavy metals broadly dispersed in surface soils, phytoremediation (bioremediation using plants) may be the only practical way to concentrate and collect the contaminants. Alternatively, plants that do not accumulate radionuclides or heavy metals can be planted to prevent wildlife exposure to contaminated sources of food.

6. In highly heterogeneous geologic environments, physical or chemical methods that rely on advective transport of remediation agents to the contaminants may be ineffective. However, in such environments, in situ remediation schemes that rely on diffusive transport of remediation agents (e.g., nutrients) to indigenous microorganisms for degrading or transforming the contaminants may be more effective.

7. For complex mixtures of contaminants requiring a combination or sequence of physical and chemical remediation methods, bioremediation techniques that use microbial consortia to concurrently address all contaminants may be faster and more cost-effective.

NABIR will support fundamental research on natural and accelerated bioremediation. Both are expected to significantly reduce the cost and improve the effectiveness of remediation of DOE's contaminated sites. Although this program emphasizes fundamental research on in situ bioremediation of soils and groundwater, knowledge applicable to $e x$ situ waste treatment schemes will be learned and transferred. Similarly, this program will focus on microbial bioremediation, compared to phytoremediation, because the majority of DOE's contaminants are below the rhizosphere. However, when appropriate, phytoremediation research will also be sponsored.

\section{THE NABIR PROGRAM PLAN}

The NABIR program plan covers a ten-year period beginning in FY 1996. The plan presented here describes the motivation for and 
structure of the scientific program, the scientific goals and objectives, and the plans for partnering with EM, regulatory agencies, and the public to facilitate implementation of the scientific knowledge gained. A management structure, implementation plan, schedule, and budget are also provided.

\section{WHO WILL PARTICIPATE IN THE NABIR PROGRAM?}

Participants in the NABIR program will include the national research community, the EM problem holders, and federal officials with management and oversight responsibilities. The national research community will be engaged in the broadest sense, including academic, DOE laboratory, other federal agency, and industrial researchers.

Research projects will be carried out by teams of laboratory scientists and engineers, academic researchers, postdoctoral fellows, graduate students, and field technicians. The scientific teams will be selected through a competitive process, and research projects will be formally peer-reviewed biannually. Periodic scientific forums will be held to stimulate the transfer of ideas and information between researchers and to help guide the direction of the scientific program. Programmatic peer reviews will be conducted prior to critical decision points in the program. The scientific direction of the program and its projects will be adjusted in response to these two types of peer review and broader input from the scientific community. In addition, a multiagency steering committee will be established to provide coordination between complementary research and technology development programs.

Integration of the scientific research among the investigators will be key to the success of the program. Three field research centers will be established for performing long-term, interdisciplinary, multiinvestigator research and will be the primary integrating vehicles for the research program. Large-scale, multi-investigator field experiments will be conducted to bring together researchers from a variety of scientific and engineering disciplines. In addition, the field research centers will be available for investigator-initiated research by scientists funded from this and other programs.

The field research centers also will be critical for ensuring that the knowledge gained from NABIR will be used to help solve DOE's environmental management problems. Locating the field research centers at DOE facilities will provide ongoing opportunities for a twoway transfer of information between the EM problem holders and the research community. Researchers will learn more about site-specific needs for fundamental and applied research. Site personnel responsible for the cleanup will keep abreast of the latest scientific developments and new opportunities for applying bioremediation. 


\section{The Legacy of the Cold War and DOE's Unique Set of Remediation Challenges}

The U.S. Department of Energy faces environmental remediation and waste management problems resulting from over 50 years of nuclear weapons production. More than 10,500 individual hazardoussubstance-release sites have been identified-sites that must be safely managed until treatment and disposal options mature.

In situ approaches to restoration and containment, including bioremediation, are methods of choice over excavation and pump-andtreat because contamination is often widely dispersed, dilute, or otherwise inaccessible.
The volume, extent, broad distribution, and complexity of DOE's contaminated soils and groundwater pose a unique and formidable challenge: to develop scientifically sound characterization, remediation, performance assessment, and long-term monitoring technologies that are cost-effective and result in acceptable risk to human health and the environment. In situ approaches to restoration and containment, including bioremediation, are methods of choice over excavation and pump-and-treat because much of the contamination is widely dispersed in the environment, is present in relatively dilute concentration, or is otherwise inaccessible because of its depth or its location beneath structures.

Environmental restoration is complicated by the diversity of subsurface environments at contaminated sites across the DOE complex. ${ }^{*}$. These sites are located in arid, non-arid, cold, and hot climates and include a diversity of geological settings and depositional environments with unique conditions that must be understood and managed for bioremediation or other restoration methods to be effective. In addition, DOE's history of developing, manufacturing, and managing

\footnotetext{
*DOE is responsible for waste management and cleanup of more than 130 installations totaling approximately $7280 \mathrm{~km}^{2}$ in 30 states and territories. Collectively, these installations contain more than 2500 billion liters of contaminated groundwater and more than $\mathbf{2 0 0}$ million cubic meters of contaminated soil. Soils in approximately 5000 other properties are contaminated with uranium tailings (DOE, 1995).
} 
More than half of the DOE sites are contaminated with mixtures of two or more compound classes. nuclear materials and weapons resulted in environmental contamination with complex and exotic mixtures of compounds. Management practices over the 50-year period resulted from direct disposal of wastes into cribs and trenches or by deep injection and indirect contamination following the loss of integrity of landfills and leaking underground storage tanks (Fig. 2). The costs associated with remediating many of DOE's largest plumes of contaminated groundwater and sediments have not been determined, but estimates to clean up DOE's contaminant soils, sediments, and groundwater range from tens to hundreds of billions of dollars (DOE, 1995).

DOE created the Office of Environmental Management (OEM) in response to legal and ethical requirements to resolve this legacy of environmental contamination at 130 DOE sites. OEM's major responsibilities include waste management, environmental restoration, and relevant technology development. DOE must overcome myriad technical challenges to enable efficient waste management and environmental restoration at its sites. Scientific breakthroughs and technology development are important to enable implementation of cost-effective technologies that can meet the performance standards. OEM has implemented a new management approach that is designed to ensure that DOE's environmental $R \& D$ programs remain focused on OEM's most pressing remediation and waste management needs (DOE, 1994). Five major remediation and waste management focus areas have already been identified:

- Contaminant plume containment and remediation.

- Mixed-waste characterization, treatment, and disposal.

- High-level waste tank remediation.

- Landfill stabilization.

- Facility transitioning, decommissioning, and final disposition.

The NABIR program will include leaders from the contaminant plume containment, remediation, and landfill focus areas in an advisory capacity. It will coordinate its efforts to ensure the two-way transfer of information and knowledge.

Classes of chemical contaminants present in sediments and groundwater at more than half of all DOE facilities include fuel hydrocarbons, chlorinated hydrocarbons, metals, and radionuclides. Compound classes most frequently detected at DOE sites are metals and chlorinated hydrocarbons, radionuclides, anions, fuel 
क
$\frac{0}{0}$
$\frac{0}{3}$
$\frac{0}{0}$
$\frac{1}{0}$
0
0
0

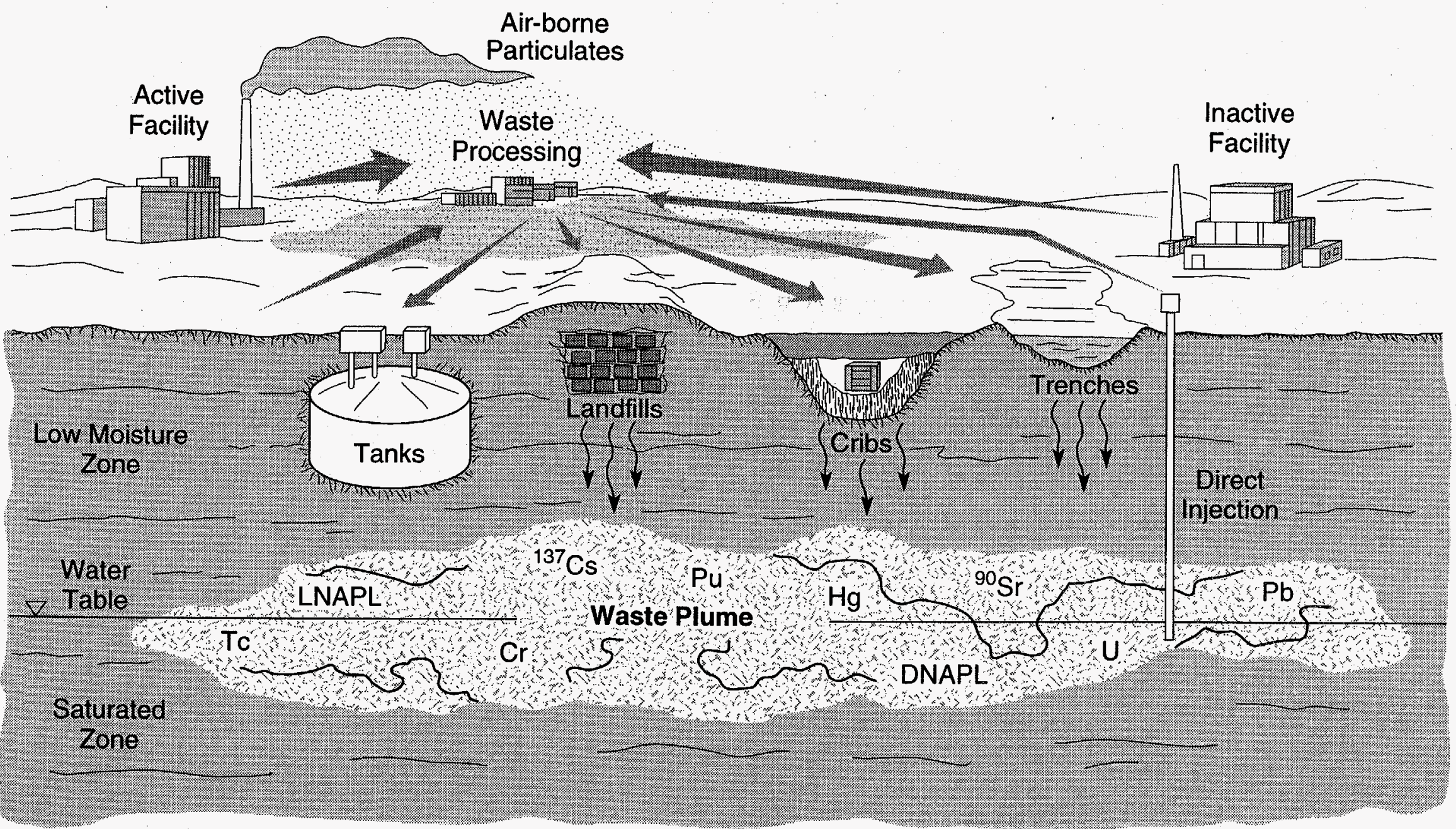

Figure 2. The DOE legacy of contaminant plumes: 2500 billion liters of contaminated groundwater and 200 million cubic meters of contaminated soil. 
Successful in situ treatment of contaminant mixtures in diverse settings requires an understanding of the interrelation of the physical, chemical, and biological processes that effect chemical reactions. hydrocarbons, and ketones. Organic acids, phthalates, explosives, alkyl phosphates, complexing agents (i.e., EDTA, DTPA, and NTA), and pesticides are also significant contaminants at individual sites. More than half of the DOE sites evaluated by Riley et al. (1992) were contaminated with mixtures of two or more compound classes. The most common mixtures reported were metals and radionuclides. Codisposal mixtures of compounds has resulted in modified transport and toxicity properties that can increase ecological or health risk. For example, complexation with ligands enhances the mobility of metals and radionuclides, alters behavior at mineral surfaces, and affects availability to microorganisms.

Successful treatment of contaminant mixtures in diverse settings by in situ biological, chemical, or physical methods or a combination of these methods requires a fundamental understanding of the interactions and interdependence of physical, chemical, and biological processes that effect chemical reactions. Developing this basic understanding, as it applies to bioremediation technology development and performance assessment, requires integrated, interdisciplinary research.

Acquisition of this knowledge base must be accompanied by parallel advances in the development of effective performance assessments and advanced computational methods, identification of acceptable cleanup end points, and research in ethical, legal, and social impacts (ELSI). Researchers must identify and address stakeholders' issues and coordinate their efforts with other federal agencies and industry.

A full understanding of the natural processes involved in natural and accelerated bioremediation depends on the ability to build on laboratory experimentation by directly investigating phenomena in the field and conducting field experiments. Many of the scientific and technical results from a bioremediation R\&D program on in situ treatment will also be applicable to waste management and minimization efforts-such as the design and operation of bioreactors to treat a broad spectrum of dilute and concentrated waste streams from ongoing and past DOE operations. 


\section{Biogeochemical Processes: The Foundation for In Situ Bioremediation}

Over the past two decades, it has become widely accepted that microorganisms, and to a lesser extent plants, have the ability to transform and degrade many types of contaminants. Transformation and degradation processes differ depending on physical environment, microbial communities, and contaminants; but the fate of many contaminants, from petroleum hydrocarbons to radionuclides, is

Transformation and degradation processes differ; but the fate of many contaminants, from petroleum hydrocarbons to radionuclides, is influenced by microbial activity. influenced by microbial activity. These processes form the foundation for bioremediation - both natural bioremediation, which relies on intrinsic rates and processes, and accelerated bioremediation, which seeks to enhance desirable processes through the addition of amendments.

Microorganisms degrade or transform contaminants by a variety of mechanisms. Petroleum hydrocarbons, for example, are converted to carbon dioxide and water or are used in generating new cells by aerobic bacteria. In this case, microorganisms use the petroleum hydrocarbons as a primary food source. Chlorinated hydrocarbons can be degraded, but the degradation takes place as a secondary or cometabolic process. Enzymes created during aerobic utilization of carbon sources such as methane fortuitously degrade the chlorinated solvents. Under anaerobic conditions, chlorinated solvents such as trichloroethylene (TCE) are degraded through a sequence of steps, where some of the intermediary by-products may be more hazardous than the parent compound (e.g., vinyl chloride). Inorganic contaminants such as nitrate can also be degraded by microbial activity and plants. Depending on environmental conditions, nitrate can be converted to nitrogen gas or used as a nutrient to support cell production.

While metals and radionuclides cannot be degraded by biological activity, they can be transformed from one chemical form to another or transported from soils to above- and below-ground plant tissues. Fungi, for example, can convert dissolved arsenic and selenium to gaseous forms through methylation. Bacteria similarly have been 


Because of the
impressive
capabilities of
microorganisms
to degrade and
transform
contaminants,
systematic
attempts to
understand and
harness these
capabilities will
provide
tremendous
benefits.

shown to reduce mercury to its volatile elemental form. Bacteria have been shown to change the oxidation state of some heavy metals (e.g., chromium, selenium, and mercury) and radionuclides (e.g., uranium) by using them as electron donors or acceptors. In some cases, the solubility of the altered species will increase and consequently the altered species will more easily be flushed from the geologic host material. In other cases, the opposite will occur, and the contaminant will be immobilized in situ. The immobilization (or sequestration) of chemical and radioactive contaminants through in situ biological processes can make an important contribution to site remediation.

In light of the impressive capabilities of microorganisms and plants to degrade and transform contaminants, systematic attempts to understand and harness these abilities should provide tremendous benefits. In fact, these remediation ideas are not new: they have provided the foundation for many ex situ waste treatment processes (including sewage treatment) and a host of in sit $u$ bioremediation methods that are in practice today (Hinchee et al., 1994). For example, bioremediation technologies such as bioventing and land farming have become accepted practice for remediating petroleum hydrocarboncontaminated soils and sediments (CISB, 1993). In addition, several projects, including one at DOE's Savannah River Site, have demonstrated that TCE can be co-metabolically degraded in situ by providing methane as a carbon source. Explosives and polychlorinated biphenyls (PCBs) have been biodegraded in field-scale experiments (Harkness et al., 1993). Bacterial transformation and immobilization of trace metals such as selenium also have been implemented on a limited basis (Benson et al., 1993). Technologies to promote volatilization and dissipation of selenium have been demonstrated in surface water and soils (Frankenberger and Benson, 1994).

Over the last decade, progress has been made in expanding the number and type of contaminants to which bioremediation can be applied. Significant progress has also been made in the number of practical methods for implementing in situ bioremediation. For example, alternative strategies have been developed for delivering chemical additives, such as oxygen. Chemical additives for increasing the bioavailability of recalcitrant organics have been identified. Techniques such as hydrofracturing have been developed for improved delivery of nutrients or microorganisms in low-permeability geologic media. In addition, methods have been developed for creating passive treatment systems such as biofilters (Taylor et al., 1993). Novel concepts for using microbially produced biopolymers as in situ plugging agents have also been explored ( $\mathrm{Li}$ et al., 1994). These advances are important steps towards establishing bioremediation as one of the viable solutions for in situ remediation of contaminant mixtures in a wide range of complex environments. And of great importance, data are now available that can demonstrate the 
cost-effectiveness of bioremediation in comparison to physical and NABIR will build chemical remediation methods (Saaty and Booth, 1994; Wijesinghe et al., 1992; Atlas, 1995).

on all recent

activities and

advances in

bioremediation and

NABIR will build on all recent activities and advances in bioremediation and will focus on filling existing knowledge gaps. As described in the next section, significant work must be done to build a more robust scientific foundation to support widespread application of bioremediation, especially of contaminant mixtures, metals, and will focus on filling the existing knowledge gaps. radionuclides. In addition, NABIR will identify the ethical, legal, and social impacts that must be addressed before natural and accelerated bioremediation at DOE facilities is acceptable to both the public and the regulatory authorities. 


\section{Bioremediation Research Needs}

\begin{tabular}{l} 
"Predictability of \\
bioremediation \\
process \\
performance \\
cannot be made \\
with a high level \\
of confidence." \\
(Gibson and \\
Sayler, 1992) \\
\hline
\end{tabular}

The foundation of bioremediation has been the natural ability of microorganisms to degrade organic compounds (Atlas, 1995). Bioremediation is defined by the American Academy of Microbiology as "the use of living organisms to reduce or eliminate environmental hazards resulting from accumulations of toxic chemicals and other hazardous wastes" (Gibson and Sayler, 1992). "This technology is based on the use of naturally occurring or genetically engineered microorganisms (GEMS) to restore contaminated sites and protect the environment" (Miller and Poindexter, 1994).

Bioremediation is not a panacea but rather a "natural process" alternative to such methods as incineration, catalytic destruction, the use of adsorbents, and the physical removal and subsequent destruction of pollutants (AgBiotech, 1991). The cost of moving and incinerating pollutants is at least ten times that of in situ biological treatment (Atlas, 1995). By integrating proper utilization of natural or modified microbial capabilities with appropriate engineering designs to provide suitable growth environments, bioremediation can be successful in the field (Skladany and Metting, 1992). However, a gap exists between advances in laboratory research and commercial field applications (Sayler, 1995). Two major factors responsible for this gap are the lack of (1) a sufficient knowledge base to accurately predict pollutant degradation rates and fates and (2) sites designated as field research centers for bioremediation research and technology demonstrations. Laboratory and microcosm studies have documented the potential use of microorganisms for bioremediation. However, the physiologic potential of microbial populations to remediate environments of relevant size, heterogeneity, and variability has not been adequately tested (Miller and Poindexter, 1994; Skladany and Metting, 1992). Successful application of bioremediation techniques must address both the heterogeneous nature of many contaminated waste sites and the complexity of using living organisms.

There has been progress in overcoming some of the barriers that have impeded bioremediation from being successfully applied in the field (Atlas, 1995). Scientists have begun to search for organisms with better 
Nine assessments

have been

conducted over the

past four years to

identify

bioremediation

RED needs. biodegradation kinetics for a variety of contaminants within broad environmental habitats. Studies examining extremophiles could result in using organisms in situ that have a high tolerance for organic solvents and alkaline soils or waters, and that function at high temperatures for more efficient $e x$ situ activity in bioreactors.

In addition, more often scientists are using molecular biology to optimize bioremediation. For example, molecular engineers are constructing starvation promoters to express heterologous genes needed in the field for survival and adding additional bioremediation genes that code for enzymes able to degrade a broader range of compounds present in perturbed and stressed environments (Atlas, 1995). Genes such as the lux gene are being inserted as monitors for specific enzyme activities such as naphthalene degradation. Much of this work is being accomplished through transposon vectors, multimer resolution system vectors, and alternative nonantibiotic selection determinants such as resistance to herbicides and heavy metals, and nutritional markers (growth on lactose only) (de Lorenzo, 1992, 1993). All are efforts to make genetically modified organisms with potential for field bioremediation more acceptable to the general public and more predictable in terms of performance and ecological behavior. However, most of this work is still conducted at the bench level, and technical gaps remain with respect to designing recombinant bacteria that are stable enough for use by process engineers in both in situ and ex situ applications.

Summarized below are the R\&D needs expressed by academic, industrial, and government participants at workshops on bioremediation sponsored by universities, federal granting agencies, and institutions since 1991. Essentially, the take-home message of all these reports is the need to better understand how bioremediation works in the field. Unless there is a concerted effort to apply bench technologies for evaluation, implementation, and assessment in field sites containing contaminants, bioremediation will not reach its full potential as a proven technology. And unless field engineers and bioengineers get involved in the early stages of $R \& D$ for field applications, bioremediation will not advance as rapidly as it should as an alternative to other, more costly methods.

At a workshop organized by Rutgers University in 1991, scientists and engineers reviewed the current state of bioremediation, addressed the difficulties in making bioremediation a successful applied technology, and suggested approaches for resolving these difficulties (AgBiotech, 1991). Eight major problems were identified:

1. Bioremediation assessment and implementation need more integrated, cross-discipline effort. 
2. Initial site characterizations, due to site heterogeneity, can be inadequate to evaluate or employ bioremediation as a treatment alternative.

3. To assess biotreatability, widely accepted methods and criteria need to be established.

4. Factors limiting degradation rates in bioremediation applications need to be adequately identified and addressed.

5. To ensure that bioremediation is not prematurely discarded, the full range of treatment options needs to be considered.

6. More adequate information and enhanced modeling principles are needed for rational scale-up from the laboratory to the field.

7. Techniques for monitoring progress and utilizing mass balance concepts in the field need to be further developed.

8. Bioremediation needs an accessible, expanded, and welldocumented database.

In 1992, the Environmental Protection Agency (EPA) issued a report recommending five key research program areas that were to provide a balanced transition of bioremediation research from the laboratory bench to technology applications in the field (BTDP, 1992). These research program areas, listed below, could lead to a fundamental understanding of how to apply bioremediation technologies to engineering activities.

1. Improve site characterization technology.

2. Create a "Bioremediation Field Initiative" to expand field experiments and collect and disseminate bioremediation performance data.

3. Develop new approaches to performance evaluation in order to better determine the extent and rate of cleanup.

4. Research processes to identify microbial capability of biotransformation and develop methods for delivery.

5. Develop better models of bioremediation through exploitation of field results to predict and guide future applications.

The American Academy of Microbiology in 1992 evaluated the scientific foundations of bioremediation, its current status, and its future needs (Gibson and Sayler, 1992). The workshop panelists 
"There is a need to orient aspects of bioremediation research to modern biotechnologically integrated science and engineering efforts using field site demonstrations as vehicles for integration." (Gibson and Sayler, 1992) concluded that solid biochemical, molecular, and ecological foundations of bioremediation existed and that environmental biotechnology has expanded the knowledge base of on-going processes with bioremediation. The report lists examples of bioremediation process performance and credibility, such as land farming and soil slurry reactors. It addresses concerns regarding information needs to advance current technology, parameters for successful bioremediation (site characterization, biodegradability of the contaminants, microbiology, and environmental and nutritional factors) that should be included in the engineering framework, and limitations of current knowledge. There are opportunities for enhanced technology if improvements can be made in process performance, degradative capacity via molecular engineering, predicting the outcome of multicomponent substrate biodegradation, and understanding the regulation of microbial enzyme production for simultaneous degradation of several compounds that are all present at low concentrations. Bioremediation can be developed as a technology if the exploratory research base is exploited. There is a need to better understand and define the following: the roles and applications of microbial biofilms and activities at interfaces, the microbial responses to multipollutant mixtures, the dynamics of microbial community structure and function, site characterization, process monitoring and optimization, and integration of molecular genetics and physiology with environmental needs. The report also recommends that kinetic models be developed and coupled to existing and emerging hydrogeochemical transport models to predict the potential success of bioremediation and that this technology be evaluated and verified in the field. Finally, the report concludes that there is a lack of wellcharacterized field sites that could be used for understanding the natural events that occur and for demonstrating feasibility of the laboratory-demonstrated technology. Only under environmental conditions and by using an interdisciplinary approach can bioremediation be applied and verified.

In 1993, the American Academy for Microbiology held a follow-up workshop to the 1992 workshop. The resulting report documented the critical need for field research in environmental bioremediation by addressing strategies and mechanisms for field research in environmental bioremediation (Miller and Poindexter, 1994). Criteria for field site selection and use are described, as well as use of components of scientific disciplines in conducting field research in environmental bioremediation. The report recaps some of the technologies already developed that have applications for field use, such as physical and chemical analysis and microbiological and genetic methods. Now, concludes the report, is the time for bioremediation to move into field sites, where the necessary information can be obtained to predict efficacy and determine the duration of treatment, costs, and safety. 
The National Research Council's 1993 report "In Situ Bioremediation: When Does It Work?" discusses the future prospects for bioremediation and three limiting factors that restrict the use of field applications of the variety of microbial processes well documented in the laboratory (CISB, 1993). These factors are the lack of understanding of how microorganisms behave in the field, the difficulties associated with stimulating microbial growth in the field, and making the contaminant bioavailable to the microbial community. To overcome these limitations, it was recommended that research focus on the following:

1. Understand microbial processes in nature, such as anaerobic versus aerobic reactions, and how they are interrelated within a microniche.

2. Examine the effect of stimulating materials for increased microbial growth such as gas sparging.

3. Promote more efficient contact between the contaminant and the microorganism through high-pressure fracturing of the subsurface matrix or solubilization of the contaminants via steam injection, addition of surfactants, or through improved dispersal methods.

4. Evaluate protocols for the range of chemical contaminants and site characteristics in the field and document the loss of these contaminants from the field.

5. Develop innovative site characterization techniques that are rapid, reliable, and inexpensive.

6. Improve mathematical models to link the understanding of chemical, physical, and biological activities occurring in the field.

7. Demonstrate that bioremediation is working in the field at fastenough rates and in multiple locations to ensure that cleanup goals are met.

The American Chemical Society sponsored a symposium entitled "Bioremediation through Rhizosphere Technology" in 1993. The published papers from this symposium indicate that the rhizosphere provides a complex and dynamic microenvironment where bacteria and fungi associated with plant roots can degrade, mineralize, and stabilize toxicants, thus offering a potentially important treatment strategy for bioremediation of numerous classes of hazardous chemicals in the environment (Anderson and Coats, 1994). Radionuclides and heavy metals were not discussed. However, the recommendations of the participants indicate that an understanding of the fundamental biochemical, physiological, and ecological interactions 
in the rhizosphere will facilitate the successful use of vegetation to remediate chemically contaminated soils.

In 1994, the Department of Energy held a workshop to discuss the current status and the basic and applied research needs of phytoremediation (DOE, 1994b). Phytoremediation uses the natural attributes of plants for applications in site remediation efforts. Useful attributes of plants include their roots, which have enormous surface area to bioaccumulate and concentrate contaminants such as heavy metals and other inorganic compounds, and their diverse genetic adaptations to handle toxic levels of contaminants and mineralize toxic organic compounds. In addition, there is a positive synergy between microorganisms in the rhizosphere, in that the numbers and activities of microorganisms are increased due to the nutrient and energy sources provided by the plant. In many instances these microbial activities are bioremedial. Overall, plant cultivation and management is cost-effective and in many ways more easily accepted by the general public, since it is a solar energy driven process. Even though phytoremediation is considered a viable technology for some contaminants, certain research and development needs exist:

1. To better understand and utilize the physiological, biochemical, and genetic mechanisms of uptake, transport, and accumulation of pollutants.

2. To genetically evaluate those plants that are hyperaccumulators of metals and other pollutants.

3. To better understand the interactions occurring in the rhizosphere between the plant root system and surrounding biota.

4. To implement field evaluations and validation of phytoremediation technologies.

A workshop held by the European Community and the U.S. government in 1994 focused on the potential of microorganisms to solve environmental problems (Economidis and Palmisano, 1995). Three areas of research were discussed: anaerobic biotransformations of pollutants, biodegradability testing using microcosm and mesocosm approaches, and tailor-made microorganisms for the treatment of toxic waste. The participants concluded that future research on the use of microorganisms to solve environmental problems should focus on the need to:

1. Examine bioremedial catalytic systems of microorganisms that have not previously been well studied.

2. Focus on the diverse metabolic pathways exhibited by microorganisms when grown in the absence of oxygen. 
3. Explore use of combined aerobic/anaerobic or anaerobic/aerobic systems for biodegradation of pollutants.

4. Assess the bioavailability of contaminants and catalysis in the nonaqueous phase of contaminant biotransformation in multiplephase systems.

5. Develop biological-based methods for the containment, control, and monitoring of microbial populations in reactors and field sites.

6. Further explore inoculation for bioremediation in contained and uncontained systems.

In 1995, the National Science and Technology Council's Biotechnology Research Subcommittee reported that several priorities for research in bioremediation are needed to further advance the field (BRS, 1995). These priorities are:

1. Develop an understanding of the structure of microbial communities and their dynamics in response to normal environmental variation and novel anthropogenic stresses.

2. Develop an understanding of the biochemical mechanisms, including enzymatic pathways, involved in aerobic and particularly anaerobic degradation of pollutants.

The take-home message of all these

3. Extend the understanding of microbial genetics as a basis for enhancing the capabilities of microorganisms to degrade pollutants.

to better

understand how

bioremediation

works in the field.

4. As a standard practice, conduct microcosm $/$ mesocosm studies of new bioremediation techniques to determine, in a cost-effective manner, whether they are likely to work in the field, and establish dedicated sites where long-term field research on bioremediation technologies may be conducted.

5. Develop, test, and evaluate innovative biotechnologies, such as biosensors, for monitoring bioremediation in situ; models for the biological processes at work in bioremediation; and reliable, uniform methods for assessing the efficacy of bioremediation technologies.

Over a ten-year period, NABIR will address most if not all of the research and development needs compiled over five years by international scientists and engineers working in the bioremediation field. In reports written since 1991 on the research needs for bioremediation, all agree that the real question that needs to be answered is whether or not in situ bioremediation can be an efficient, 
cost-effective technology. There is a growing body of evidence that various bioremediation processes can often provide a clean, natural, and cost-effective method for treatment of pollutants (Atlas, 1995). Yet bioremediation is described as an innovative but unproven technology and is often not even considered as an alternative technology by field engineers (Grimes, 1995; Sayler, 1995). One way to answer this question of feasibility is to provide a systematic long-term integrated program of field research focused on testing and optimizing the potential of bioremediation as a major environmental technology for recovery of contaminated sites, and assessing its safety. The following pages describe such a program. 


\section{Bioremediation and Related Programs in DOE}

Research directly or indirectly related to bioremediation is funded by several programs in the DOE. While a small fraction of this work is focused on developing the scientific foundations for bioremediation, the vast majority is directed towards developing new applications for biotechnology. The total annual budget currently expended in DOE on bioremediation and related research is about $\$ 40 \mathrm{M}$. These research programs are described briefly below. An ongoing dialogue will be maintained with all of these programs to ensure coordination and timely transfer of scientific knowledge among the researchers involved in these efforts.

\section{OFFICE OF ENERGY RESEARCH}

While there is significant effort focused toward bioremediation in DOE, many research needs are not being addressed by the current programs.
The research programs funded by the Office of Energy Research seek to develop the scientific foundations underpinning a host of chemical, physical, and biological processes. Some of these research programs, such as OHER's Subsurface Science Program, are directly relevant to bioremediation. Others, such as use of computer modeling to design molecules known as crown ethers to bind to highly radioactive pollutants such as cesium and strontium, contribute less directly, but nevertheless provide important scientific knowledge in specific research areas. Examples of indirectly related programs include research on degradation of biopolymers and physiological mechanisms in extreme environments, as well as the microbial genome project.

\section{Subsurface Science Program: Heterogeneity}

This research deals with one of the fundamental problems in implementing bioremediation, the variability in microbial populations and environmental conditions in the subsurface. At arid Western sites and at humid Eastern sites, field-oriented research is being directed toward characterization of microbial heterogeneity and the relationship of microbial heterogeneity to geochemical and physical heterogeneity. 
A second stage is examining how this underlying heterogeneity affects stimulation of the microbial populations in bioremediation.

\section{Subsurface Science Program: Bacterial Transport}

This research focuses on basic research applicable to the bioaugmentation approach to bioremediation. Basic processes controlling bacterial transport are being investigated in the laboratory and in ongoing field experiments at an uncontaminated field site where natural physical and chemical heterogeneity are reasonably well understood. The coarse-grained, sandy sediments at the site have stringers of high iron content, and the hypothesis for the field experiment deals with the effect of the iron on bacterial transport. Microbial characteristics and microbial interactions controlling transport are key questions being addressed.

\section{Subsurface Science Program: Co-Contaminant Chemistry}

This research deals most directly with bioremediation-related issues by addressing the increased mobility of radionuclides in the subsurface due to chelation with organic matter. This mobility may be reduced to prevent movement of the radionuclides by degradation of the organic chelator or displacement of the radionuclides from the chelator. Issues such as sorption of the radionuclides, chelators, and the complex are being addressed.

\section{Subsurface Science Program: Deep Microbiology}

This research focuses on the deep biosphere, including deep aquifers, sediments and lithologies, where in situ bioremediation may be the only feasible remediation option. Emphasis is being given to deep microbial ecology and to the origins of microbiota found at depths of hundreds of meters or more. For origins research, the two main hypotheses are the in situ hypothesis-that the origin of the microorganism is associated with the original depositional environment-and the transport hypothesis-that microorganisms have been transported into the current geological environment from elsewhere. Aspects related to bioremediation include survival characteristics of bacteria in the subsurface, long-term and longdistance transport of bacteria, acquisition of microorganisms with new degradative and survival capabilities, and enhanced understanding of the unusual environmental factors that control the presence and distribution of deep microbial populations.

\section{Basic Energy Sciences: Geosciences Program}

The BES Geosciences Program supports a wide variety of fundamental research in geophysics, geochemistry, geomechanics, and subsurface flow and transport. Many of the projects are developing knowledge 
relevant to bioremediation, including subsurface imaging, thermodynamic and kinetic behavior of complex mixtures of chemicals, and transport of reactive chemicals in heterogeneous environments.

\section{Basic Energy Sciences: Chemical Sciences Program}

The BES Chemical Sciences Program supports a wide variety of fundamental research in combustion, solar photoconversion, catalysis, separation and analysis, and fundamental research to support environmental restoration and waste management. Many of these projects may be indirectly related to bioremediation, especially those investigating radiochemistry, advanced analytical and spectroscopic methods, and major R\&D facilities.

\section{Basic Energy Sciences: Material Sciences}

The BES Material Sciences Program supports a wide variety of fundamental research in the chemistry of materials, including the chemical and crystalline structure of liquids and solids; polymers and organic materials, including superconductors, magnetic materials, semiconductors, and conductors; and surfaces, interfaces, and surface chemistry. They also support research in solid-state physics, including the mechanical and acoustic properties of liquids and solids, phase transition and thermodynamics, and thin films. Many of these projects are indirectly related to bioremediation, especially those involving interfaces and surface chemistry and new methods for characterizing materials.

\section{Basic Energy Sciences: Energy Biosciences}

The BES Energy Biosciences Program supports research in energyrelated microbiology, metabolic diversity, photosynthesis, and plant cell walls. Many of these programs are indirectly related to bioremediation, especially those applicable to phytoremediation.

\section{ENVIRONMENTAL MANAGEMENT}

Bioremediation-related technology development programs in Environmental Management are focused on developing or adapting bioremediation technologies for solving site-specific remediation problems at DOE facilities. Specific projects currently under way or recently completed include the following.

\section{Adsorption/Desorption Processes and Bioavailability}

Research in this area focuses on developing the technology necessary to accelerate rates of in situ biological remediation of sorbed contaminants. Two approaches are to use surfactants/biosurfactants to enhance the bioavailability of contaminants, and to isolate adhesion- 
deficient bacteria as a biocatalyst for trichloroethylene (TCE) degradation.

\section{Biomass Remediation}

The goal of this research project is to demonstrate the feasibility of using terrestrial and aquatic plants to remediate soils, sediments, and surface waters contaminated by heavy metals and radionuclides. Feasibility is evaluated by investigating the accumulation of contaminants in plants grown on contaminated soils relative to the concentration of the contaminant in the soil, and by using the Ukrainian fractionation separation technology (FST) to establish the distribution of the contaminants in the plant biomass.

\section{PCB Bioremediation}

This research deals with developing and demonstrating a bioremediation technology for polychlorinated biphenyl (PCB) contaminated soil and sludge. General Electric Company (GE) has provided a microbial culture that is known to degrade PCBs. The development of new ways to stimulate PCB degradation by this microbial culture will ultimately result in complete mineralization of the PCBs.

\section{Biosorption of Uranium}

The focus of this research is to develop a biosorbent technology (sorptive biomass) that selectively removes uranium or other selected metals present at low concentrations in surface or groundwater. Biosorbents immobilized in permeable beads are used in flow-through bioreactors to achieve waste fixation and volume reduction (ppm levels reduced to $\mathrm{ppb}$ levels).

\section{Co-Metabolic Techniques for Biodegradation of TCE}

The co-metabolic bioremediation of mixed organics at DOE sites is the focus of this research. Field-scale bioreactors are used to demonstrate degradation of compounds not used as a carbon or energy source by microorganisms. Microorganisms used include methanotrophs and pseudomonads which degrade toluene.

\section{In Situ Microbial Filters}

The goal of this research is to develop and evaluate an in situ microbial filter of methanotrophic bacteria to remediate contaminated plumes at their expanding boundaries. Contaminated groundwater that flows through the microbial filter will be decontaminated to regulatory limits by the microorganisms, and clean water will be produced. 
An ongoing

dialogue will be

maintained with

all of these

programs to

ensure

coordination and

timely transfer

of scientific

knowledge among

the researchers

involved in these

efforts.

\section{Vadose Zone Bioremediation of Chlorinated Solvents}

The objective of this research is to develop and evaluate the effectiveness of various classes of microorganisms to degrade chlorinated solvents in groundwater and to test methods to control the metabolic activity of multiple populations of microorganisms in the subsurface.

\section{Optimization Strategies for In Situ Remediation}

The goal of this work is to recommend effective designs of chemical delivery, mixing schemes, and strategies for improving in situ bioremediation. This will be accomplished by conducting laboratory work, evaluating field data, and investigating processes of solute transport and fate.

\section{Field Demonstration of In Situ Biodegradation of TCE and PCE Using Methane}

This project has three approaches to the degradation of TCE and PCE using methane. One approach is to use horizontal wells to inject air or an air/methane mixture into soil, which stimulates indigenous microorganisms to degrade the TCE and PCE. Another approach is to pump contaminated groundwater through a fermenter containing methane. The indigenous methanotrophic bacteria in the groundwater are thus stimulated to degrade the contaminants. The third approach is to use microorganisms already present in the roots of trees and plants (rhizospheres containing methanotrophs) to degrade TCE and PCE.

\section{Biodegradation of Carbon Tetrachloride at Hanford}

Studies are being conducted to identify optimal strategies for cometabolic degradation of carbon tetrachloride, including evaluation of acetate, glycerol, methanol, and ethanol as agents for biostimulation.

\section{Bioremoval of Metals with Algae}

Studies are being conducted on the ability of algae to remove metals from water while embedded in polyurethane foam. This bioremoval technology could be used to remediate groundwater and surface water impoundments contaminated with heavy metals.

\section{Bioremediation of Petroleum-Contaminated Soil in a Prepared Bed}

This full-scale bioremediation system for petroleum-contaminated soil consists of a cement trough $400 \mathrm{ft}$ long by $40 \mathrm{ft}$ wide with four cells. Each cell is being used to test different nutrient amendments for stimulating indigenous microbes to degrade petroleum contaminants. 


\section{In Situ Bioremediation of Groundwater at a Sanitary Landfill}

Air and gaseous nutrient injection to accelerate bioremediation are being demonstrated at two sites in a large sanitary landfill. The groundwater is contaminated with chlorobenzenes, vinyl chloride, and trichloroethylene.

\section{Passive Bioventing of Petroleum-Contaminated Vadose Zones}

Demonstrations of barometric pumping (passive gas flow) are being done for vadose zones contaminated with petroleum hydrocarbons or chlorinated solvents.

\section{Active Bioventing/Biosparging of Petroleum- Contaminated Vadose Zones}

Air is being extracted and injected at several sites to demonstrate bioremediation of petroleum hydrocarbons in vadose zones.

DOE's Fossil Energy Program, in concert with the Petroleum Environmental Research Fund (PERF), has a new program related to bioremediation of environmental problems associated with the petroleum industry. Current research is focused on three areasintrinsic bioremediation, toxicity testing, and bio-barriers. The intrinsic bioremediation effort is documenting how naturally available bacteria change soil quality over time in various types of soils and contaminants. Toxicity researchers are attempting to assess toxicity of contaminated soils from a physiological perspective, e.g., considering digestive rather than purely chemical extraction of toxins from soil, and conducting in vitro testing with human cells. Bio-barriers research focuses on enhancing bioremediation by changing conditions in the path of the contaminant plume, e.g., by creating impermeable barriers.

Other indirectly related programs include research in bioconversion of coal, bioprocess engineering to develop new technologies for alcohol fuels and pollution prevention technology for waste streams, methods of microbially enhancing recovery from oil reservoirs, and microbial and enzymatic methods to remove sulfur from petroleum.

\section{ENERGY EFFICIENCY}

DOE's Energy Efficiency Program sponsors two large biotechnology research programs geared towards pollution prevention and biomass conversion. The Alternative Feedstocks Program seeks to identify new 
feedstocks for biofuels, including agricultural crop residues, forest products, and municipal solid waste streams. The Biofuels Program seeks to develop effective and low-cost methods to convert cellulose to ethanol, methanol, and biodiesel.

\section{OFFICE OF CIVILIAN RADIOACTIVE WASTE MANAGEMENT}

The Office of Civilian and Radioactive Waste Management (OCRWM) Yucca Mountain program has recently initiated investigations to evaluate the influence of microbial activity on the fate and transport of radionuclides in the geologic formations surrounding the potential repository horizon. 


\section{Bioremediation in Other U.S. Departments and Agencies}

Several other departments and agencies in the U.S. government are sponsoring bioremediation research programs or projects. The major programs are briefly described below. None of these programs, however, sponsor research or use bioremediation techniques to clean up radionuclides and complex mixtures of contaminants-the central remediation issue facing the $\mathrm{DOE}$.

\section{DEPARTMENT OF AGRICULTURE}

The goal of the U.S. Department of Agriculture's environmental research is to acquire knowledge that will improve the management and protection of natural resources. The program addresses all aspects of agriculture, including forestry and aquaculture, with the aim of improving operational efficiency while minimizing negative environmental impacts. The research ranges from understanding the function of both natural and managed ecosystems to using bioremediation to degrade toxic pesticides.

\section{DEPARTMENT OF COMMERCE}

The Department of Commerce (DOC) sponsors research on bioremediation through the National Institute of Standards and Technology (NIST) and the National Oceanic and Atmospheric Administration (NOAA). NIST has a new program concentrating on the use of cytochrome-producing microorganisms to dehalogenate hazardous compounds in contaminated soil or water. Bioremediation research, as well as research in many other fields, is also supported by NOAA through the National Marine Fisheries Service and the National Sea Grant College Program. 


\section{DEPARTMENT OF DEFENSE}

The Department of Defense (DOD) supports research on bioremediation through the Office of Naval Research (ONR), the Army Research Office, and the Air Force Office of Scientific Research. The goal is the bioremediation of petroleum hydrocarbons, explosives, propellants, and organophosphates. Research has led to the cleaning of contaminated soils and sediments at military installations by biodegradative processes.

\section{DEPARTMENT OF HEALTH AND HUMAN SERVICES}

The Department of Health and Human Services supports basic and applied research in environmental biotechnologies through one of its institutes, the National Institute for Environmental Health Science (NIEHS). Areas of interest include the mechanisms of degradation and transformation of toxic chemicals mediated by microorganisms, bioremediation technologies, and biomarkers of toxic chemical interaction with humans and other animals.

\section{DEPARTMENT OF INTERIOR}

The Department of Interior (DOI), through its Bureau of Mines and Geological Survey, awards specific contracts to examine the efficacy of bioremediation in addressing DOI needs. Primary emphasis is on metals and groundwater contamination.

\section{ENVIRONMENTAL PROTECTION AGENCY}

The Environmental Biotechnology Program of the Environmental Protection Agency (EPA) is researching bioremediation and engineering activities to clean up hazardous waste in the environment. Their research explores factors limiting biodegradation in the field and seeks to define the impact of waste characterization on biotreatment and the mechanisms controlling the rate and extent of biodegradation. The program also conducts research to translate biodegradation process concepts into well-engineered biosystems, develop in situ biostimulation and bioaugmentation delivery systems, and develop tools to assess performance and ecological and human health effects.

In addition to bioremediation research, the Agency also serves in an advisory function for States and EPA Regions that have technical questions related to bioremediation of specific hazardous waste sites. The Agency also has several partnership programs with industry and other Federal Agencies to develop commercial bioremediation technologies such as the Superfund Innovative Technology Evaluation Program (SITE) and the Federal Remediation Technologies Roundtable. 


\section{AGENCY FOR INTERNATIONAL DEVELOPMENT}

The Agency for International Development (USAID) supports several small-scale research projects involving bioremediation. Examples include using petroleum dispersants in Jamaica and exploring bioremediation techniques to remove heavy-metal contamination of soil and water in Bulgaria.

\section{NATIONAL SCIENCE FOUNDATION}

The National Science Foundation (NSF) funds research on bioremediation through its Engineering, Biological Science, and Biological Oceanography directorates. Most of this research is focused on the fundamental biology, genetics, and ecology of microorganisms used in bioremediation. NSF also supports targeted efforts that combine basic research with field testing in cooperation with private industry, such as research conducted at the Center for Microbial Ecology at Michigan State University.

\section{STRATEGIC ENVIRONMENTAL RESEARCH AND DEVELOPMENT PROGRAM}

The EPA, DOD, and DOE have developed the Strategic Environmental Research and Development Program (SERDP) to address problems of mutual concern. Bioremediation is one of a number of topics addressed in research programs funded by SERDP. In particular, SERDP sponsors the National Center for Integrated Bioremediation Research and Development. The Center is operated by the University of Michigan and is located at Wurtsmith Air Force Base in Oscoda, Michigan. At this national center, integrated research is conducted on bioremediation of mixtures of contaminants common to DOD and many industrial facilities, including petroleum hydrocarbon mixtures, solvents, heavy metals, and PAHs. 


\section{Scientific Approach}




\section{Scientific Approach}

The scientific approach for NABIR was developed with the assistance of a team of scientists and engineers from the national laboratories, and input from academic institutions and the private-sector $R \& D$ community. Three considerations guided development of the program. First, as summarized in the previous section "Legacy of the Cold War and DOE's Unique Set of Remediation Challenges," opportunities for applying bioremediation at DOE sites were identified, along with some of the unique remediation challenges faced by DOE. Second, reports from nine recent assessments of $R \& D$ needs for bioremediation were reviewed, and subsequent discussions were held with some of the participants (see "Bioremediation Research Needs"). Finally, related R\&D programs in DOE and other agencies were evaluated to determine which R\&D needs were not being met by the existing programs (see "Bioremediation and Related Programs in DOE" and "Bioremediation in Other Departments and Agencies"). NABIR is designed to fill these research gaps and complement other ongoing programs.

\section{KEY THEMES OF THE NABIR PROGRAM}

The scientific approach of NABIR is characterized by several key ideas which are highlighted and discussed below.

Fundamental research is required to advance scientific understanding of the biological, chemical, and physical processes important for natural and accelerated bioremediation. Research is needed in many disciplines, such as microbiology, structural and molecular biology, genomics, geochemistry, and hydrology and transport processes. But more importantly, interdisciplinary research involving two or more of these disciplines is likely to achieve breakthroughs in scientific understanding. Finally, fundamental research should be focused on the behavior of complex systems that include mixtures of contaminants and multiple organisms, and this research must account for the natural spatial and temporal variability of geologic environments.

Integration of scientific ideas across disciplines is essential for development of the knowledge needed to predict and optimize bioremediation rates and processes. An advance in any one aspect of 
Overcoming the traditional walls that inhibit integration of disciplines is one of the keys to the success of NABIR. bioremediation, such as development of microorganisms with enhanced degradative capabilities, is unlikely to make an impact unless other factors, such as how to introduce the microorganisms into the soil, are also improved. Scientific advances in many key aspects of bioremediation must be coordinated and integrated at every step of the way.

Field research centers are the best vehicles for promoting and coordinating cooperation among research teams; identifying crucial fundamental, interdisciplinary research needs; achieving the integration described above; and focusing the research program on DOE's most significant problems. In addition, performing research at a contaminated site will facilitate the two-way transfer of information needed to ensure that the scientific results of this program will be integrated into site remediation strategies. Other opportunities, such as co-locating a bioremediation technology demonstration nearby, would allow for a host of synergistic interactions between technology development and fundamental research programs.

Access to RED shared infrastructure will be required to advance measurement and diagnostic techniques for understanding, quantifying, and enhancing biotransformation processes and rates. Examples of the facilities required could include:

- Dedicated beamlines and end stations at the DOE synchrotrons, e.g., National Synchrotron Light Source (NSLS), Stanford Synchrotron Radiation Laboratory (SSRL), Advanced Light Source (ALS), Advanced Photon Source (APS) for applications in metal speciation, crystallography, and structural biology.

- High throughput sequencing facilities.

- Analytical chemistry facilities, e.g., gas chromatography/mass spectroscopy (GC/MS), high-pressure liquid chromatography/mass spectroscopy (HPLC/MS).

- Advanced methods for imaging such as nuclear magnetic resonance spectroscopy (NMR) and high-resolution microscopy (e.g., confocal microscopes, electron microscopy).

In addition to instrumentation, a set of shared computational models and shared strategies for mathematically representing and visualizing biogeochemical processes will be required. Networks to efficiently link researchers to databases and models will facilitate rapid transfer of knowledge among the team and to other interested parties. One of the first tasks of the program will be to develop a set of specific recommendations on the nature and location of scientific infrastructure needed to support this program. Instrumentation and communication infrastructure needs will be evaluated on an ongoing basis, and recommendations will be made for developing new capabilities. 
The goals of the research program and the interrelationships between the goals of program elements must be clearly identified. In the following sections, the research program is described in terms of program goals at three, five, and ten years.

Linkages to related research and technology development programs will be established and maintained to ensure that NABIR builds on knowledge gained from other programs, fills in key gaps in scientific understanding, focuses on DOE's most important environmental problems, and leverages funds and shares resources when possible. In particular, NABIR will work closely with OEM's Contaminant Plumes and Landfill focus teams to facilitate the seamless integration of knowledge between these complementary programs.

These themes will be implemented through the seven program elements shown in Fig. 3 and described below.

\section{THE SEVEN PROGRAM ELEMENTS OF NABIR}

The NABIR program consists of seven interrelated program elements:

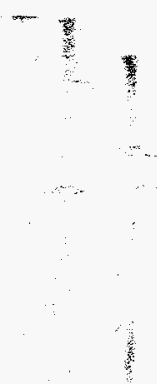

- Biotransformation and Biodegradation

- Community Dynamics and Microbial Ecology

- Biomolecular Science and Engineering

- Biogeochemical Dynamics

- Assessment

- Acceleration

- System Integration, Prediction, and Optimization.

A schematic diagram illustrating the analysis and synthesis leading to selection of the scientific program elements for NABIR is provided in Fig. 4, and detailed supporting information derived from recent R\&D needs assessments is provided in Table 2.

The rationale for selecting these seven interrelated program elements is provided below:

Biotransformation and Biodegradation. More knowledge is needed about mechanisms and pathways for biotransformation and biodegradation, especially for metals, radionuclides, and mixtures of contaminants. Moreover, the role of microbial consortia and how organisms work together to degrade or transform contaminants must be understood better. 


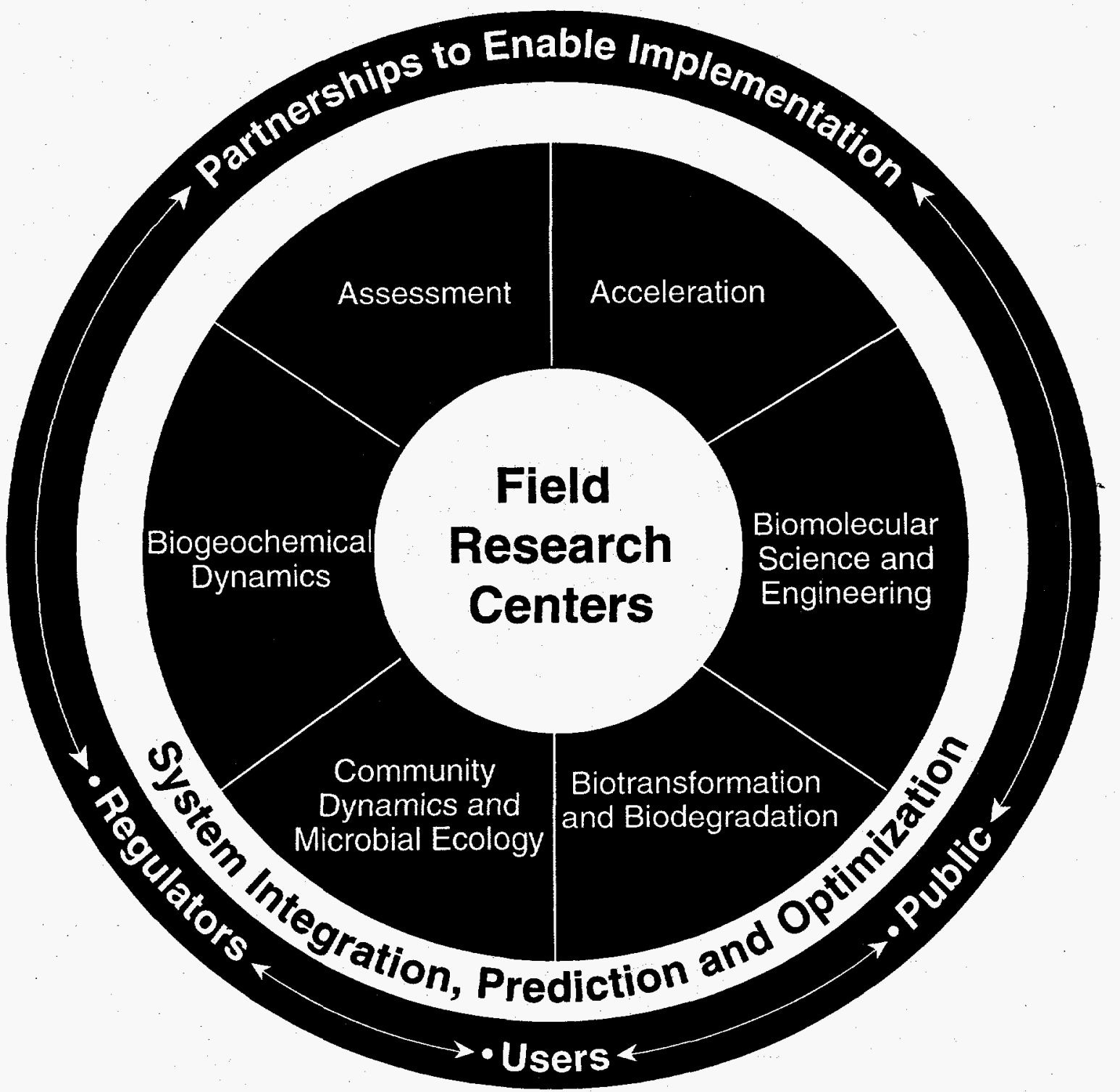

Figure 3. A schematic diagram showing the seven program elements of the NABIR Program, the integrating role of the field research centers, and the partnerships to enable implementation of new bioremediation technologies. 


\section{Recent Reviews}

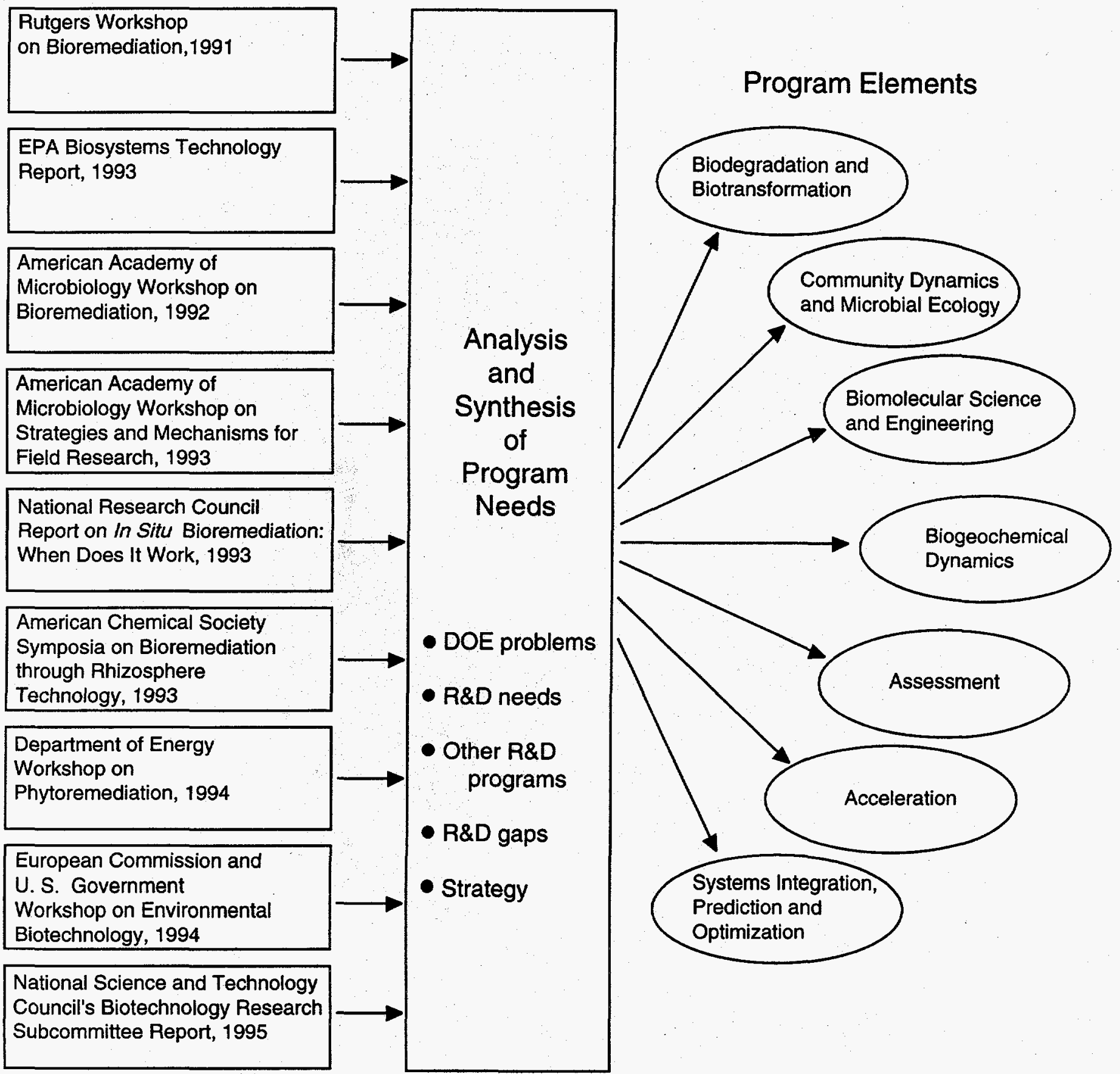

Figure 4. Analysis and synthesis of NABIR Program needs. 
Table 2. Bioremediation research and development needs as identified in recent reviews and addressed by NABIR Program Plan.

\begin{tabular}{|c|c|c|c|c|c|c|c|}
\hline & \multicolumn{7}{|c|}{ NABIR PROGRAM ELEMENTS } \\
\hline & $\begin{array}{l}\text { Biotransformation } \\
\text { and } \\
\text { Biodegradation }\end{array}$ & $\begin{array}{l}\text { Community } \\
\text { Dynamics and } \\
\text { Microbial Ecology }\end{array}$ & $\begin{array}{l}\text { Biomolecular } \\
\text { Science and } \\
\text { Engineering }\end{array}$ & $\begin{array}{l}\text { Biogeochemical } \\
\text { Dynamics }\end{array}$ & Assessment & Acceleration & $\begin{array}{l}\text { Systems } \\
\text { Integration, } \\
\text { Prediction, and } \\
\text { Optimization }\end{array}$ \\
\hline $\begin{array}{l}\text { Rutgers } \\
\text { Bioremediation } \\
\text { Workshop, } 1991\end{array}$ & & & & $\begin{array}{l}\text { Identify and } \\
\text { address factors } \\
\text { limiting bioremedia- } \\
\text { tion applications. }\end{array}$ & $\begin{array}{l}\text { Need better site } \\
\text { characterization } \\
\text { and development } \\
\text { of techniques for } \\
\text { monitoring progress } \\
\text { and utilizing mass } \\
\text { balance concepts in } \\
\text { the field. }\end{array}$ & ? & $\begin{array}{l}\text { Need accessible, } \\
\text { expanded, and } \\
\text { well-documented } \\
\text { database and } \\
\text { enhanced modeling } \\
\text { principles for } \\
\text { rational scale-up } \\
\text { from lab to field. }\end{array}$ \\
\hline $\begin{array}{l}\text { EPA Biosystems } \\
\text { Technology } \\
\text { Report, } 1992\end{array}$ & $\begin{array}{l}\text { Identify microbial } \\
\text { capability of } \\
\text { biotransformation. }\end{array}$ & & & & $\begin{array}{l}\text { Improve site } \\
\text { characterization } \\
\text { technology and } \\
\text { develop new } \\
\text { approaches to } \\
\text { performance } \\
\text { evaluation of } \\
\text { cleanup rates. }\end{array}$ & $\begin{array}{l}\text { Develop methods } \\
\text { for delivery. }\end{array}$ & $\begin{array}{l}\text { Collect and dissem- } \\
\text { inate bioremediation } \\
\text { performance data } \\
\text { and develop better } \\
\text { models to predict } \\
\text { and guide future } \\
\text { applications. }\end{array}$ \\
\hline $\begin{array}{l}\text { AAM } \\
\text { Bioremediation } \\
\text { Workshop, } 1992\end{array}$ & $\begin{array}{l}\text { Understand and } \\
\text { define the microbial } \\
\text { response to multi- } \\
\text { pollutant mixtures. }\end{array}$ & $\begin{array}{l}\text { Understand and } \\
\text { define the dynamics } \\
\text { of microbial com- } \\
\text { munity structure } \\
\text { and function, and } \\
\text { the role and appli- } \\
\text { cation of microbial } \\
\text { biofilms and activi- } \\
\text { ties at interfaces. }\end{array}$ & $\begin{array}{l}\text { Understand } \\
\text { regulation of } \\
\text { microbial enzyme } \\
\text { production for } \\
\text { simultaneous } \\
\text { degradation of } \\
\text { several compounds } \\
\text { present at low } \\
\text { concentrations. }\end{array}$ & & $\begin{array}{l}\text { Improve site } \\
\text { characterization } \\
\text { technology. }\end{array}$ & $\begin{array}{l}\text { Advance under- } \\
\text { standing of param- } \\
\text { eters that affect } \\
\text { biodegradation } \\
\text { rates. }\end{array}$ & $\begin{array}{l}\text { Develop kinetic } \\
\text { models and couple } \\
\text { to existing hydro- } \\
\text { geochemical trans- } \\
\text { port models to } \\
\text { predict potential } \\
\text { success of } \\
\text { bioremediation. }\end{array}$ \\
\hline $\begin{array}{l}\text { AAM } \\
\text { Bioremediation } \\
\text { Workshop, } 1993\end{array}$ & & $\begin{array}{l}\text { Study microbial, } \\
\text { physical, and } \\
\text { genetic ecology, } \\
\text { microbial com- } \\
\text { munity structure } \\
\text { and function in } \\
\text { contaminated } \\
\text { sites, and fate } \\
\text { of introduced } \\
\text { microorganisms. }\end{array}$ & $\begin{array}{l}\text { Integrate molecular } \\
\text { biology and } \\
\text { physiology with } \\
\text { environmental } \\
\text { needs. }\end{array}$ & & $\begin{array}{l}\text { Characterize solids, } \\
\text { liquids, gases, and } \\
\text { perturbations. }\end{array}$ & $\begin{array}{l}\text { Improve process } \\
\text { performance. }\end{array}$ & $\begin{array}{l}\text { Collect and analyze } \\
\text { data in a three- } \\
\text { dimensional } \\
\text { mathematical model } \\
\text { that integrates } \\
\text { hydrodynamic, } \\
\text { microbial, and geo- } \\
\text { chemical processes. }\end{array}$ \\
\hline
\end{tabular}


Table 2. (continued)

\begin{tabular}{|c|c|c|c|c|c|c|c|}
\hline & \multicolumn{7}{|c|}{ NABIR PROGRAM ELEMENTS } \\
\hline & $\begin{array}{l}\text { Biotransformation } \\
\text { and } \\
\text { Biodegradation }\end{array}$ & $\begin{array}{l}\text { Community } \\
\text { Dynamics and } \\
\text { Microbial Ecology }\end{array}$ & $\begin{array}{l}\text { Biomolecular } \\
\text { Science and } \\
\text { Engineering }\end{array}$ & $\begin{array}{l}\text { Biogeochemical } \\
\text { Dynamics }\end{array}$ & Assessment & Acceleration & $\begin{array}{l}\text { Systems } \\
\text { Integration, } \\
\text { Prediction, and } \\
\text { Optimization }\end{array}$ \\
\hline $\begin{array}{l}\text { NRC In-Situ } \\
\text { Bioremediation } \\
\text { Report, 1993 }\end{array}$ & & $\begin{array}{l}\text { Understand both } \\
\text { aerobic and anaer- } \\
\text { obic biodegradative } \\
\text { processes and how } \\
\text { they interact in the } \\
\text { community. }\end{array}$ & & & $\begin{array}{l}\text { Develop innovative } \\
\text { site characterization } \\
\text { methods and } \\
\text { monitor loss of } \\
\text { contaminants. }\end{array}$ & $\begin{array}{l}\text { Improve contact } \\
\text { between contami- } \\
\text { nants and micro- } \\
\text { organisms and } \\
\text { augment bioremedial } \\
\text { activity using } \\
\text { chemical or physical } \\
\text { means. }\end{array}$ & $\begin{array}{l}\text { Improve mathe- } \\
\text { matical models to } \\
\text { understand the links } \\
\text { between chemical, } \\
\text { physical, and } \\
\text { biological activities } \\
\text { in the field. }\end{array}$ \\
\hline $\begin{array}{l}\text { ACS Rhizosphere } \\
\text { Symposium, } 1993\end{array}$ & . & $\begin{array}{l}\text { Understand } \\
\text { fundamental } \\
\text { biochemical, } \\
\text { physiological, } \\
\text { and ecological } \\
\text { interactions in the } \\
\text { rhizosphere. }\end{array}$ & & & & & \\
\hline $\begin{array}{l}\text { DOE Phyto- } \\
\text { remediation } \\
\text { Workshop, } 1994\end{array}$ & $\begin{array}{l}\text { Understand and } \\
\text { utilize physiological, } \\
\text { biochemical, and } \\
\text { genetic mechanisms } \\
\text { for uptake, trans- } \\
\text { port, and accumu- } \\
\text { lation of pollutants. }\end{array}$ & $\begin{array}{l}\text { Understand inter- } \\
\text { actions between } \\
\text { plant root systems } \\
\text { and surrounding } \\
\text { biota. }\end{array}$ & $\begin{array}{l}\text { Genetically evaluate } \\
\text { metal hyperaccumu- } \\
\text { lator plants. }\end{array}$ & & & & \\
\hline $\begin{array}{l}\text { EC-US } \\
\text { Environmental } \\
\text { Workshop, } 1994\end{array}$ & $\begin{array}{l}\text { Examine those } \\
\text { biodegradative } \\
\text { pathways not } \\
\text { previously well } \\
\text { studied. }\end{array}$ & $\begin{array}{l}\text { Examine anaerobic } \\
\text { and aerobic degra- } \\
\text { dative systems; } \\
\text { develop inocula for } \\
\text { bioremediation ex } \\
\text { situ and in situ. }\end{array}$ & & $\begin{array}{l}\text { Assess bio- } \\
\text { availability of } \\
\text { contaminants. }\end{array}$ & $\begin{array}{l}\text { Monitor microbial } \\
\text { populations in } \\
\text { reactors and field } \\
\text { sites. }\end{array}$ & & \\
\hline $\begin{array}{l}\text { NSTC } \\
\text { Biotechnology } \\
\text { Report, } 1995\end{array}$ & $\begin{array}{l}\text { Understand aerobic } \\
\text { and anaerobic } \\
\text { mechanisms and } \\
\text { pathways for } \\
\text { biodegradation. }\end{array}$ & $\begin{array}{l}\text { Understand } \\
\text { bioremedial } \\
\text { interactions within } \\
\text { the community } \\
\text { dynamics. }\end{array}$ & $\begin{array}{l}\text { Extend genetics as a } \\
\text { basis to enhance } \\
\text { bioremediation. }\end{array}$ & & $\begin{array}{l}\text { Develop biosensors } \\
\text { for monitoring and } \\
\text { assessing efficacy } \\
\text { of bioremediation. }\end{array}$ & & $\begin{array}{l}\text { Develop models for } \\
\text { biological processes } \\
\text { in the field. }\end{array}$ \\
\hline
\end{tabular}


Community Dynamics and Ecology. More knowledge is needed to understand the composition, structure, and function of the large number of organisms present in natural systems. Advanced molecular and biochemical methods should be applied to identify populations, evaluate evolution in response to exposure to contaminants, and understand the influence of a variety of environmental factors on biodegradation and biotransformation rates and processes. In addition, better understanding of the factors influencing the survival and effectiveness of introduced organisms needs to be developed.

Biomolecular Science and Engineering. The potential of molecular manipulation to enhance bioremediation remains untapped. To realize this potential, more information is needed to analyze genes, proteins, and regulatory elements of critical molecules for bioremediation. Knowledge of structure and function relationships is also needed to understand the enzymatic mechanisms for detoxification. Building on this foundation, organisms could be engineered with superior degradative capabilities. However, ethical, legal, and social issues associated with the development and utilization of engineered biodegradative organisms must be addressed to the satisfaction of the public and regulatory agencies before they can be used.

Biogeochemical Dynamics. Better methods are needed for measuring the in situ distribution of organisms with potential for biodegradation, and for understanding the environmental factors that control these distributions. In addition, the important role of interfaces as it affects the nature and rate of biogeochemical processes needs to be understood better, especially the role of solid-liquid interfaces, liquidgas interfaces, and the interface between two immiscible liquids. Bioavailability of contaminants and nutrients is another key issue that must be better understood.

Assessment. Advanced and real-time measurement tools are required to understand and monitor the processes responsible for bioremediation and assessing how effective they are. Key needs include developing new methods for assessing biodegradation rates and activities, developing noninvasive or minimally invasive techniques for characterizing a site and monitoring loss of contaminants from the site, developing diagnostic techniques for interpreting measurements, and determining a scientifically defensible strategy for identifying bioremediation end points.

Acceleration. Better understanding of the factors that limit the rate of in situ bioremediation is needed so that effective methods for accelerating biogeochemical processes can be developed. Better methods should be developed for supplying nutrients and microorganisms for in situ bioremediation, and for increasing the bioavailability of contaminants. To achieve this, the underlying transport processes need to be better understood, innovative 
biostimulation and bioaugmentation methods as well as better methods for delivering acceleration agents to the subsurface should be developed.

System Integration, Prediction, and Optimization. More knowledge is required to predict and optimize the effectiveness of bioremediation. Mechanistic models that quantitatively describe biotransformation and biodegradation processes, community dynamics, and biogeochemical dynamics must be improved and then linked together to develop engineering models for field-scale design, optimization, and assessment of bioremediation. Systems to integrate and disseminate new information are also needed.

Close coordination and interaction among researchers investigating topics in these program elements will be required to overcome the traditional barriers to cross-fertilization and integration of knowledge and ideas. The field research centers described below, as well as information systems, shared models, and R\&D shared infrastructure will be the major vehicles for achieving this interaction.

\section{FIELD RESEARCH CENTERS}

There is broad agreement among the R\&D community about the need for dedicated research sites where the biogeochemical processes that contribute to bioremediation can be investigated. Field research centers will also be the vehicles for identifying applied research needs. NABIR will establish three field research centers where such site-based investigations can be carried out. The field research centers will be selected to address a range of hydrogeologic environments and contaminant mixtures that are important to DOE. The concept for operating these field research centers is illustrated in Fig. 5. The centers will support four types of activities:

1. Small-scale, investigator-driven experiments related to community dynamics of soil microbiota and ecology, biotransformation and biodegradation processes, the survival and effectiveness of bioengineered organisms, biogeochemical dynamics, new methods of assessment, and acceleration strategies.

2. Large-scale interdisciplinary assessment of the rates and processes influencing natural bioremediation.

3. Large-scale manipulative experiments where methods of accelerating bioremediation and the underlying scientific foundations can be evaluated.

4. Pilot-scale evaluation of manipulative methods of accelerating bioremediation. 

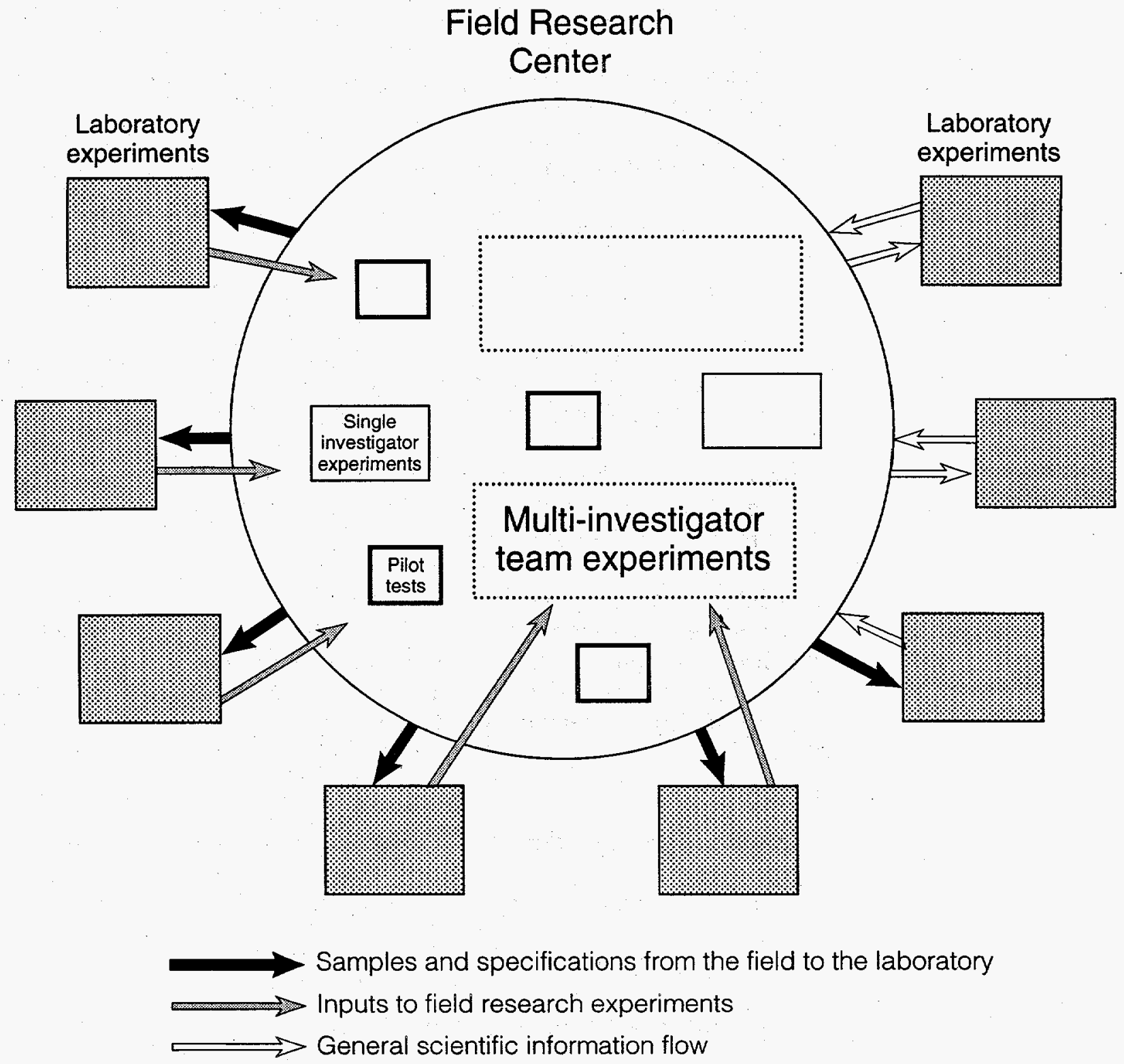

Figure 5. Field research center concept. 
In addition, samples of soil, sediment, groundwater, and biota will be made available for researchers performing laboratory experiments. Thus each field research center will offer the opportunity for iterative and synergistic laboratory and field-based research. The ability to test hypotheses derived from either field or laboratory-based research in an iterative manner will make this program unique.

Selected scientific investigators will be asked first to participate in the characterization of all aspects of the field site, including:

- Assessment of natural degradation and transformation processes

- Evaluation of community dynamics and microbial ecology

- Structure and function analysis of key bioremediative organisms

- Evaluation of the spatial and temporal heterogeneity of the microbial community, contaminant distribution, hydrogeologic settings, and environmental factors.

Building on the characterization activities, concepts for accelerating bioremediation rates will be tested in the laboratory and, if successful, used for pilot or field-scale evaluation.

At each field research center, experimental work will proceed in the three phases illustrated in Fig. 6 and described below. Development of the three field research centers will be staged over the first four years of the program. The location of the first field research center will be selected in the first year of the program.

\section{Phase I}

The focus of Phase I, scheduled over the first two years, will be to

- Define programmatic criteria for the DOE field research center.

- Select, permit, and review data on the field site.

- Develop infrastructure support.

- Notify the scientific community of opportunities for research at the field research center.

- Initiate additional site and biogeochemical characterization of the site (to be continued in Phases II and III in parallel with field experiments). 


\begin{tabular}{|c|c|c|c|c|c|c|c|c|c|c|}
\hline \multirow[b]{2}{*}{ Program Years } & \multicolumn{2}{|c|}{ Phase I } & \multicolumn{3}{|c|}{ Phase II } & \multicolumn{4}{|c|}{ Phase III } & \\
\hline & $\begin{array}{l}\bar{\nabla} \\
1\end{array}$ & $\begin{array}{l}\vec{\nabla} \\
2\end{array}$ & $\begin{array}{l}\nabla \\
3\end{array}$ & $\overline{4}$ & $\begin{array}{l}\bar{\nabla} \\
5\end{array}$ & $\overline{6}$ & $\begin{array}{l}7 \\
7\end{array}$ & $\begin{array}{l}\nabla \\
8\end{array}$ & 9 & $\begin{array}{c}\vec{\gamma} \\
10\end{array}$ \\
\hline Activities & $\begin{array}{l}\text { - Site } \\
\text { - Pern } \\
\text { - Dat } \\
\text { and } \\
\text { char }\end{array}$ & ation & $\begin{array}{l}\text { - Ass } \\
\text { bio } \\
\text { - Pre } \\
\text { exp } \\
\text { - Invv }\end{array}$ & $\begin{array}{l}\text { tion } \\
\text { acc }\end{array}$ & & $\begin{array}{l}\text { - Cont } \\
\text { proc } \\
\text { - Opti } \\
\text { - Inve }\end{array}$ & acce & ex & & \\
\hline
\end{tabular}

Figure 6. Phase I, II, and III for the first field research center. 


\section{Phase II}

The focus of Phase II, scheduled for years three through five, will be to

- Conduct interdisciplinary, multi-investigator experiments to assess the rates and processes influencing natural bioremediation.

- Conduct a large-scale multi-investigation experiment on accelerated bioremediation using existing approaches to accelerating bioremediation rates.

- Conduct small-scale, investigator-driven experiments including but not limited to community dynamics of soil microbiota and ecology, biotransformation and biodegradation processes, survival and effectiveness of bioengineered organisms, biogeochemical dynamics, new methods of assessment, and acceleration strategies.

\section{Phase III}

In Phase III, following year five, the focus will be to

- Conduct a large-scale, multi-investigator experiment on accelerated bioremediation using new, optimized acceleration methods developed from this program.

- Continue small-scale, investigator-driven experiments including but not limited to community dynamics of soil microbiota and ecology, biotransformation and biodegradation processes, survival and effectiveness of bioengineered organisms, biogeochemical dynamics, new methods of assessment, and acceleration strategies.

- Continue interdisciplinary multi-investigator evaluation of natural bioremediation rates and processes.

General attributes of sites suitable for the field research centers are summarized in Table 3. A discussion of the selection procedure for the field research centers is provided in the "Program Management, Partnerships, and Implementation Plan" section of this plan. 
Table 3. Site selection criteria for field research centers.

\begin{tabular}{|c|c|}
\hline $\begin{array}{l}\text { Attributes of the } \\
\text { field research site }\end{array}$ & $\begin{array}{l}\text { - Human and ecological hazards are not } \\
\text { imminent. } \\
\text { - Unlikely to be restored using available } \\
\text { technology. } \\
\text { - Heterogeneous geological and microbial } \\
\text { environment. } \\
\text { - Can be partitioned into multiple matched } \\
\text { subsites for replication. } \\
\text { - Secure from vandalism and other activities } \\
\text { that could interfere with research projects. }\end{array}$ \\
\hline Status & $\begin{array}{l}\text { - Characterized with respect to general site } \\
\text { features and the nature and extent of } \\
\text { contamination. } \\
\text { - Characterized with respect to social, cultural, } \\
\text { and environmental justice issues. } \\
\text { - Available for long-term research. } \\
\text { - Community is amenable to establishing a } \\
\text { cooperative stakeholder involvement group. }\end{array}$ \\
\hline
\end{tabular}

\section{STRATEGIES FOR SCIENTIFIC INTEGRATION}

One of the major scientific challenges facing bioremediation is that its development for the solution of complex environmental problems requires an interdisciplinary approach. Successful bioremediation requires information from technical specialists such as microbiologists, hydrogeologists, geochemists, and engineers and nontechnical factors such as the public, land-use planners, and manufacturers. Overcoming the traditional walls between these disciplines is one of the keys to the success of NABIR.

NABIR will employ several strategies to achieve the integration of the scientific research activities:

1. The field research centers will be a major vehicle for integrating research activities and promoting cooperation among research teams. Databases containing a wide variety of site-specific information will be shared, and large-scale experiments will be jointly conceived, designed, and implemented by multiple investigators.

2. Scientific projects teams that include a variety of disciplines will be encouraged to submit proposals to the program. Proposals submitted by individual investigators will be integrated into 
larger programs involving a number of investigators. The peerreview process will be designed to facilitate formation of these teams.

3. The System Integration, Prediction, and Optimization program element will support projects to develop computational models that describe the dynamic interaction among microbial, geochemical, and hydrogeological processes. Participation of scientists from many disciplines and research projects will be required to achieve this goal. Engineers will be involved in scaling up these models to develop tools that accurately incorporate these processes but can also be used to design, optimize, and evaluate full-scale bioremediation efforts.

4. Through the use of shared R\&D infrastructure, information flow will occur rapidly as new experimental data is gathered and interpreted.

5. Research projects that include investigators from more than one discipline will be favored over those involving only one discipline.

6. Regular scientific and public forums will be held where the results of research in progress can be shared among the research community and include technology developers and those involved in technology transfer. These will stimulate rapid exchange of ideas and help keep the project focused on the most important scientific issues. 
Program Elements 


\section{Program Element 1: Biotransformation and Biodegradation}

Fundamental research in microbiology to elucidate the mechanisms of biotransformation and biodegradation of complex contaminant mixtures.

PROGRAM OBJECTIVE

To understand the mechanisms and pathways for biotransformation and biodegradation of contaminant mixtures in order to improve the performance of bioremediation in the field.

\section{BACKGROUND}

The current understanding of biotransformation and biodegradation pathways and mechanisms in the field is incomplete.
The goal of all bioremediation efforts is to reduce the potential toxicity of chemical contaminants in the field by using microorganisms, plants, and animals to transform, degrade, or immobilize toxicants. There is already a significant base of knowledge about many pathways for organic degradation, and several important contaminant degradation mechanisms are presently under detailed investigation. Fundamental knowledge of biodegradation and biotransformation mechanisms has already contributed significantly to improving the performance of bioremediation in the field. Bioremediation strategies employing cometabolism, anaerobic biotransformations of highly chlorinated solvents, and alternate electron acceptors which are in use today resulted in large part from fundamental investigations of the mechanisms used by microorganisms to transform contaminants.

Despite the successful contributions of existing knowledge about biodegradation and biotransformation mechanisms, there is still much that research can contribute. At present, the understanding of biotransformation and biodegradation pathways and mechanisms in the field is incomplete. Although the degradation of many organics and the biotransformation of some inorganic compounds in laboratory cultures have been well described, it is unclear how this information relates to bioremediation processes under field conditions. In addition, 
research is needed to understand recently discovered biotransformation processes such as metal biotransformations and biosequestration, coupled aerobic and anaerobic processes, cometabolism, biotransformations in the presence of alternative electron donors/acceptors, and biotransformations catalyzed by consortia (Ehrlich, 1990; Francis, 1990; Lovley, 1993; Macaskie, 1991).

In both the short and long term, a sound understanding of the fundamental mechanisms of biotransformation and detoxification will lead to improved prediction, control, and assessment of bioremediation performance, facilitate the selection and prioritization of contaminated sites for bioremediation, and result in the transfer of improved bioremediation processes for cleanup of contaminated sites.

\section{APPROACH}

An important
challenge will be
to find new ways
to investigate
molecular and
cellular processes
under field
conditions.

An important challenge will be to find new ways to investigate molecular and cellular processes conditions.
Identifying and understanding the biotransformation and biodegradation of organic and inorganic contaminants will require close integration of laboratory and field experiments. Research areas include aspects of microbial physiology, enzymology, biochemistry, chemistry, microbial ecology, and plant-microorganism interactions. This program element will emphasize metal and radionuclide biotransformations and contaminant biotransformations under field conditions. The role of consortia in contaminant biotransformations will be an explicit component of both laboratory and field investigations. Research carried out under this program element will include all members of soil and water communities, including plants, rhizosphere members, eukaryotes, and prokaryotes. Although the goal of this element is the understanding of biodegradation and biotransformation under field conditions, attaining this understanding will require experiments with pure contaminants and pure cultures under defined conditions. Achieving the goals of this program element will require development of improved experimental laboratory microcosms that qualitatively and quantitatively reflect field mechanisms and processes. The scientific focus of this element is the field and not the laboratory microcosm, and an important challenge will be to find new ways to investigate molecular and cellular processes under field conditions.

Investigations and the expected results will integrate closely with those of the other program elements. Examples of important linkages with the other elements include: identifying rate-limiting enzymatic steps and enzymes as potential targets for the Biomolecular Science and Engineering element; developing the understanding of contaminant transformations required to better assess bioremediation endpoints and performance in the Assessment element; and providing fundamental kinetic data required for the System Integration, Prediction and Optimization element and the Acceleration element. 
The Biotransformation and Biodegradation element will focus on four subelements:

1. Biotransformations of metals and radionuclides.

2. Pathways, processes, and molecules for degradation of mixtures of organic contaminants.

3. Interactions between metals and radionuclides, and organics.

4. Kinetics of biotransformation and biodegradation processes under field conditions.

\section{Subelement 1.1: Mechanisms for Biotransformation of Metals and Radionuclides}

Fundamental research on those mechanisms that affect the speciation, bioavailability, mobilization, immobilization, and transport of metals and radionuclides in the environment.

Objective

To understand biotransformation of metals and radionuclides in sufficient detail to improve the bioremediation of toxic metals and radionuclides in the environment.

Goals

Three-Year

Identify the dominant redox processes catalyzed by microorganisms and other biota that affect metal speciation, toxicity, and mobility in soils, sediments, and waters. Achieving this goal will involve initial characterization of mechanisms for microbially mediated metal redox reactions and estimation of the importance and potential applicability of these redox reactions in the field. Results obtained will help to identify systems for more detailed study in subsequent years.

Identify and initially characterize biomineralogical processes which affect the mobility and toxicity of toxic metals and radionuclides in soils, sediments, and waters. As with the first goal in this subelement, these results will be used to identify important systems and scientific questions for future study.

Identify those biological processes involving complexation and bioaccumulation of toxic metals and radionuclides that either immobilize or mobilize metals and radionuclides in the environment. This area of research encompasses extracellular metal complexation, 
complexation to cell surfaces, and intracellular processes for bioaccumulation.

\section{Five-Year}

Isolate and characterize enzymes or other molecules responsible for oxidation or reduction of metals and radionuclides and their mobilization or immobilization.

Characterize the role of microbial action on the formation and transport of colloids containing toxic metals and radionuclides in the environment. Because of the multiple mechanisms potentially involved in colloid formation and transport, achieving this goal will require collaboration with other subelements within the Biotransformation and Biodegradation element (complexation with extracellular products and with cell surfaces) and with the Biogeochemical Dynamics element.

\section{Ten-year}

Be able to apply the knowledge of biologically mediated redox reactions to improve the management of toxic metal and radionuclide contamination in the environment.

\section{Subelement 1.2: Identification of Pathways, Processes, and Molecules for Degradation of Mixtures of Organic Contaminants}

Fundamental research in identifying and characterizing the pathways, processes, and molecules responsible for biotransformations of contaminants that are relevant to field conditions.

Objective

To elucidate the novel and diverse biological mechanisms applicable to degradation of mixtures of organic contaminants, and to identify important biodegradation processes and molecules for other program elements.

Three-Year

Conceive and initiate investigations of combinations of biological, chemical, and physical processes to degrade mixtures of recalcitrant contaminants in situ or $e x$ situ in reactors. Identify the scientific challenges to application of these methods in the field.

Identify promising targets for biomolecular engineering. Achieving this goal will involve identifying rate-limiting steps in the 
biodegradation of contaminants and developing methods for identifying and purifying the enzymes or other molecules catalyzing those steps. This goal will include characterization of the catalytic mechanism involved in order to aid in the rational modification of molecules for enhanced activity.

Identify pathway end products and intermediates produced during biodegradation that can be used to measure or assess activity. The purpose is to discover and develop strategies for better measurement of bioremediation activities in the field.

Five-Year

Develop and test one or more strategies, based on fundamental understanding of biodegradation mechanisms, for enhanced biodegradation of organic contaminants in field experimental centers.

\section{Ten-Year}

Utilize the understanding of biodegradation mechanisms to improve bioremediation practices and performance in the field.

\section{Subelement 1.3: Interactions between Toxic Metals, Radionuclides, and Organic Contaminants}

Fundamental research on the biologically mediated interactions between toxic metals, radionuclides, and organics.

Objective

To understand how and why the presence of toxic metals or radionuclides at a site affects the biodegradation of organics and how biodegradation of contaminants and other organics affects the speciation and mobility of metals and radionuclides.

Goals

Three-Year

Identify and characterize mechanisms whereby biota modify the speciation, mobility, and toxicity of toxic metals and radionuclides during biodegradation of organic contaminants or organic matter. These mechanisms include, for example, the biodegradation of organic complexing agents and the modification of soil organic matter.

Identify and characterize radiological and chemical toxicity and mechanisms for mediation of this toxicity to microorganisms catalyzing beneficial biotransformations of contaminants. 
Five-Year

Develop sufficient understanding of the interactions between organic biodegradation, metal and radionuclide toxicity, speciation and mobility, and soil and water biota to test new concepts for control of metal toxicity and mobility in field experimental centers.

Ten-Year

Understand the ways that microorganisms, toxic metals, and radionuclides interact with organic contaminants and organic soil matter to guide bioremediation practices at sites where there are mixtures of metals and organics.

\section{Subelement 1.4: Kinetics of Biotransformation and Biodegradation Processes under Field Conditions}

Fundamental research in the kinetics of multi-step, multi-component biodegradation and biotransformation pathways.

Objective

To obtain data describing the rates and extents of contaminant biotransformations relevant to field conditions. These data will be used to develop improved numerical models to elucidate the complex interactions important during bioremediation in the field.

Goals

\section{Three-Year}

Initiate studies on the kinetics of coupled biological processes (e.g., cell transport, enzyme transformations of contaminants, cell growth, competition and predation, and feedback inhibition) for the biotransformation of mixtures of contaminants. Although the kinetics of biological processes will be emphasized in this subelement, thermodynamics and reversibility of relevant biotransformations will also be considered. The results of these studies will be used in collaboration with the System Integration element to develop mechanistic models for biodegradation and biotransformation processes at field sites. These studies are directed at identifying (in concert with the Systems Integration, Biogeochemical Dynamics, and Acceleration elements) those processes that have the most value for predicting and improving the performance of bioremediation under field conditions. Therefore, studies of nutrient and substrate limiting conditions, field temperatures, consortia, and other conditions particularly relevant to the field will be emphasized. 
Five-Year

Extend investigations of the kinetics of coupled biological processes to field experimental centers and to a more comprehensive collection of contaminants and environmental conditions.

Test the validity, applicability, and ability of the models to predict bioremediation based on the interrelationships of biological, chemical, and physical processes at field experimental centers. Uncertainties of model predictions and sensitivity to accuracies of measured parameters will also be addressed.

\section{Ten-Year}

Attain a quantitative and mechanistic understanding of the kinetics and thermodynamics of biodegradation and biotransformation processes to improve bioremediation practices and performance in the field. 


\section{Program Element 2: Community Dynamics and Microbial Ecology}

Fundamental research in ecological processes and interactions of biotic and abiotic components of ecosystems to understand their influence on the degradation, persistence, and toxicity of mixed contaminants.

PROGRAM OBJECTIVE

To further the understanding of the structure and function of the microbial and plant community and interactions of components in natural and amended soil and subsurface habitats containing mixed contaminants and to elucidate their role in bioremediation.

BACKGROUND

Fundamental

research is needed

in community

dynamics and

microbial ecology

at both the

molecular and the

organismal level to

better understand

bioremediation

processes.
Fundamental research in community dynamics and microbial and plant ecology at both the molecular and the organismal level is needed to better understand the natural intrinsic processes of bioremediation in mixed contaminant sites. The taxonomic scope of soil ecology includes viruses, prokaryotes, eukaryotic microorganisms (such as fungi, protozoa, and microalgae), and metazoans including nematodes, earthworms, and other microinvertebrates and their interactions with plant roots. Carbon and electron flow through biological communities facilitates degradation and transformation of organic and inorganic wastes. Our understanding of these reactions must transcend taxonomic characterization and single-species study from microorganisms through lower invertebrate communities populating subsurface systems. A more complete understanding of energetics and biogeochemical transformation at the community level may ultimately provide the ability to control or stimulate communities capable of transformation and to channel carbon flow (particularly of polluting organic compounds) through these communities or populations. It is essential to understand the roles and interactions of diverse communities in order to understand how and to what extent the structure of the biological community influences the course of 
bioremediation and to what extent the environmental factors influence community dynamics in sites containing mixed contaminants. As this issue is addressed, then the Acceleration program element can determine how to best augment and sustain the microbial activity involved in remediation.

Genetic and phenotypic information is needed to better assess community members. Traditional methods for identifying microorganisms and assessing their activity in soil, such as plating and most probable number (MPN) techniques, have limited applicability for bioremediation (Metting, 1992). DNA and RNA molecular probes, polymerase chain reaction (PCR) amplification of DNA, and genomic sequencing of ribosomal RNA are being used to identify microorganisms or populations. In addition, fluorescence stains and antibodies, microautoradiography, enzyme-linked immunosorbent assay (ELISA), and microscopy are employed to monitor changes in population types and numbers. Although these techniques can identify a larger number of phenotypes present in a soil sample than direct plating, they do not account for biodiversity with respect to function of the organisms under environmental stress, competition, or seasonal changes. Both radioactive and stable isotope technologies are being applied to measuring soil community respiration activity along with methods to measure enzymatic activity. Specific patterns of phospholipid ester-linked fatty acids (PLFA) and formation of polyhydroxy butyrate (PHB) can indicate physiological stress within the microbial community (Tunlid and White, 1992). However, we are still far from understanding or having the tools and methods to provide cost-effective, real-time evaluation of metabolic activities and physiology associated with bioremediation or to examine in detail changes in soil populations over time to assess bioremediation activity. Even the modeling used to predict microbial activity has been developed more for bioreactors that function as closed (batch) and open (continuous) systems than for applications in soils (Lynch and Hobbie, 1988).

\section{APPROACH}

In open systems, such as those found at mixed-contaminant sites or in continuous-flow bioreactors, organisms selectively take in substances, usually in solution, process these substances, and return products to the surrounding environment. Often the focus on bioremediation has been from an engineering point of view, i.e., to determine the mass balance (CISB, 1993). However, in nature this continuous process of "substrates in" and "end products out" is dynamic, and members of the community are continuously changing in numbers and types. Current approaches to bioremediation focus on mass balance, providing quantitative descriptions of initial and final concentrations as well as intermediates in selected cases. This gives rise to the "black box" perception of bioremediation (Miller and Poindexter, 1994). Basic 


Understanding
the complex
relationships and
interactions of all
the organisms
involved will
improve
prediction,
assessment, and
optimization of
bioremedial
processes.

research into community dynamics will provide a more complete understanding of the path of carbon and electron flow through degrading and transforming populations. This information will identify and quantify the signals and switches at the molecular, cellular, and community level that lead to successional changes required to induce and control bioremediation processes. The approach of this program element is to build upon the previous laboratory studies on bioremedial capabilities of organisms and transfer this knowledge to study communities in field research centers where mixed contaminants exist in a variety of types and concentrations. In the field research center it can be determined whether organisms capable of bioremediation are widely dispersed, concentrated where the contaminant levels are not toxic and diluted, or present where the contaminants are concentrated. Information is also needed to assess what organisms can degrade the contaminants irrespective of their ability to be isolated or counted (Miller and Poindexter, 1994). Other factors that may influence community bioremedial activities also need to be elucidated at both the molecular and the organismal level, such as rates and mechanisms of molecular evolution of expressed bioremedial genes and environmental factors influencing bioavailability and rates of biotransformation and biodegradation and the partitioning of contaminants within the geologic medium.

Research in the Community Dynamics and Microbial Ecology program element will be integrated with research in several other elements. With respect to Biomolecular Science and Engineering, Community Dynamics will identify important prokaryote and eukaryote bioremedial populations present within one or more damaged sites that may have greater potential for bioremedial activity and genes for cloning or biological molecules for overexpression. Similarly, for the Biotransformation and Biodegradation element, Community Dynamics will provide organisms to examine for poorly understood or novel enzymatic pathways. In collaboration with the Assessment element, Community Dynamics will provide the basic data that need to be monitored and assessed for soil community bioremedial activity of the consortia as a whole in situ and $e x$ situ and for the maintenance of the community in relation to structure and function of the consortia. Finally, for the System Integration, Prediction, and Optimization element, Community Dynamics will provide information on bioremedially active members of the community to design and calibrate the models.

Community Dynamics and Microbial Ecology will use molecular and macro approaches to identify the individual species of the community and detect variations within the species and differences in species composition at different sites. It will characterize the consortia which may, through molecular evolution, become a robust community that utilizes and/or detoxifies mixed contaminants. It will also explore 
interrelationships between organisms in the community, evaluate the community as a whole system in remediating the individual components of the mixed contaminants in the presence of geologic and hydrogeologic factors, and correlate the presence of metabolic genes with effective bioremedial processes. By understanding the complex multi-organismal relationships of each of the populations involved and their interactions, the overall goal to improve bioremedial activity in the field research center should be achieved. Community Dynamics and Microbial Ecology will focus on four subelements to meet the overall goals described above. These subelements are:

1. Community identification using molecular and biochemical techniques.

2. Molecular evolution and gene transfer within the community.

3. Community structure and function relationships.

4. Influence of environmental factors.

\section{Subelement 2.1: Community Identification Using Molecular and Biochemical Techniques.}

Fundamental research in using molecular and biochemical techniques to identify members of the community existing in sites containing mixed contaminants.

Objectives

Use molecular biology tools and biochemical techniques to characterize pristine and damaged-site biological communities and to establish with high reliability the spatial and temporal diversity of populations that make up natural communities of microbiota.

Goals

\section{Three-Year}

Develop strategies to identify important transient and permanent bioremedial members of the community and monitor their natural changes or shifts with respect to the impact of various contaminants on the community structure, and compare to similar unpolluted sites by use of molecular biology, genomic sequencing, and biochemical analysis of metabolites.

\section{Five-Year}

Characterize populations to identify isolates that are resistant to or are utilizers of toxic components. 
Identify and verify presence and activity of specific genes responsible for biodegradation and biotransformation activity on mixed contaminants and integrate information with Biomolecular Science and Engineering and Biotransformation and Biodegradation program elements.

Based on information obtained from molecular biology and biochemistry techniques, develop new isolation procedures that will enable the non-culturables to be cultured for kinetics studies on biochemical capabilities as defined in the program element Biotransformation and Biodegradation.

Determine the fate of introduced organisms that have demonstrated superior bioremedial activity and compare their numbers and types to those of competitive intrinsic populations.

Ten-Year

Compare populations throughout a ten-year period for changes due to environmental parameters including concentrations of contaminants that may either optimize or enhance the bioremedial activity of the community as a whole.

\section{Subelement 2.2: Molecular Evolution and Gene Transfer within the Community}

Fundamental research in identifying how genes are transferred in mixed-waste contaminated habitats to understand how the community evolves to utilize the organic contaminants as substrates and/or tolerate high concentrations of toxic compounds.

Objective

To genetically and molecularly evaluate how the microbial community as a whole deals with contaminants by using the experimental field research center to examine consortia that have through molecular evolution become a robust community that utilizes and/or detoxifies mixed-waste contaminants.

Goals

Three-Year

Determine whether the frequency of genetic transfer of various elements such as phage and plasmids present in prokaryotic and eukaryotic members of the community at sites containing mixed contaminants is greater or lesser due to environmental stress than at clean sites of similar geological characteristics. 
Identify the regulatory elements of genes responsible for bioremedial activity of various populations within the community.

Within sites containing mixed contaminants, begin to identify signaling mechanisms of plant-microorganism communication such as the chemical signal in root exudates to induce microbial metabolic response and determine whether this relationship could favor bioremedial activity between the two groups of organisms.

Five-Year

Use a consortium isolated from one or more sites containing mixed contaminants as a nursery and inoculate other similar mixedcontaminant sites to see how information is transferred and/or used for bioremedial activities.

Understand how different members of the community, including rhizosphere populations, work together in the presence of mixed contaminants to handle the individual components, and link this information to the Biotransformation and Biodegradation program element.

Identify key species and metabolic dynamics, including stress recognition and response, and interactions that are critical to the remediation capabilities of the communities.

Determine the minimal amount of redundancy of similar, identical, or different genes of degradative enzymatic pathways needed within the community for bioremedial activity of mixed contaminants.

Determine whether microbial bioremedial genes and species boundaries are maintained in a highly contaminated mixed-waste site.

Determine how genes and plasmids are being transferred (horizontal gene transfer, transduction, conjugation, or transformation), selected (cryptic or spontaneous mutations), or rearranged to produce naturally occurring variants in the field research center and/or generate novel genotypes, and determine whether this transfer is retained in the autochthonous population even when the original organism (natural or genetically engineered) can no longer be detected.

\section{Ten-Year}

Begin to determine the long-term effect of molecular evolution on the stability of community bioremediation of mixed wastes.

Evaluate the consortium under different environmental conditions such as diverse geologic and hydrologic conditions and geochemical matrices, different concentrations of mixed contaminants, and temporal as well as spatial variations. 
Identify and utilize the robust populations for applications in bioremediation.

\section{Subelement 2.3: Community Structure and Function Relationships}

Fundamental research in examining principles and dogmas of ecology that may influence the overall ability of the community to remediate mixed contaminants.

Objective

To examine and understand ecological theories with respect to bioremedial structure and function activities of the community within one or more soil and subsurface samples containing mixed contaminants.

Goals

Three-Year

Determine range of changes in the community structure and function of populations in response to different environmental parameters, including different morphological types exhibited in the presence of mixed contaminants.

Examine the role of and tendency toward biofilm formation by community members and its influence on bioremedial activity.

Examine and compare community structure and function of biodegradation and biotransformation activities found in contaminated sites containing mixed wastes to other, similar samples collected from more than one site and correlate this data with the Biodegradation and Biotransformation and Biogeochemical Dynamics program elements.

In collaboration with the Biotransformation and Biodegradation program element, examine the rate and degree of utilization of the mixed contaminants as substrates supporting microbial growth to that of co-metabolism where the substrate is only partially metabolized and does not support growth.

\section{Five-Year}

Determine the ecological significance of biological behavior in mixedcontaminant sites in terms of cell replication, nutrition, and response; e.g., bacterial chemotaxis and chemotropism in eukaryotic microorganisms, phototaxis and phototropism, orientation to gravity and magnetism, responses to contact, pressure, heat, and other factors. 
Examine the effects of bioremediation activity on microbial developmental processes; e.g., differentiation; secondary metabolism; sporulation of bacteria, actinomycetes, and fungi; heterocyst formation of cyanobacteria; cell starvation; and survival of non-sporulating eubacteria and archaebacteria.

Apply the understanding of successional cues to induce and control biodegradation activity in field research center experiments.

\section{Ten-Year}

Determine the direct or indirect effects bioremediation activity has on interactions with other cells, such as parasitism, predation, amensalism, mutualism, and commensalism.

Apply tested and validated ecological principles to further enhance bioremedial activities of communities present in sites containing mixed contaminants.

\section{Subelement 2.4: Influence of Environmental Factors}

Fundamental research on the response of microbial and rhizosphere communities to in situ physical and chemical factors that affect the survival, growth, and active bioremediation of contaminant mixtures.

\section{Objective}

To understand the relative importance and interactive influences of in situ physicochemical parameters such as $\mathrm{pH}$, Eh, ionic strength, temperature, water activity, and other factors on properties of microbial populations and communities responsible for biodegradation and biotransformation activity in soil material containing mixed contaminants.

\section{Goals}

\section{Three-Year}

Identify and evaluate key physicochemical parameters that influence microbial community structure and function in environments containing mixed contaminants.

\section{Five-Year}

Understand and demonstrate those physicochemical parameters that support or interfere with biodegradation and biotransformation under controlled conditions in situ and ex situ. 
Develop a knowledge base sufficient for the design and implementation of laboratory and field experiments to understand how physicochemical processes, in the presence of mixed contaminants, interact at the soil community level, including plants, under hydrological flow regimes and in natural heterogeneous environments.

\section{Ten-Year}

Understand the interactions and relative importance of key physical and chemical variables that influence or control microbial community dynamics and how these can be manipulated to optimize biodegradation and biotransformation activities of the community. 


\section{Program Element 3: Biomolecular Science and Engineering}

Fundamental research in molecular and structural biology to enhance our understanding of bioremediation and improve the efficacy of bioremedial organisms and identify novel remedial genes.

\section{PROGRAM OBJECTIVE}

To use molecular biology to enhance our understanding of bioremediation and to genetically modify molecules and organisms to improve bioremedial activities.

\section{BACKGROUND}

The potential of molecular manipulation to enhance bioremediation in the field remains untapped.
It is generally accepted that the great diversity of organisms living in soil and ground water have evolved the biochemical tools to detoxify many anthropogenic contaminants of concern to DOE. The enzymatic pathway which degrades trichloroethylene (TCE) is one example. At some contaminated sites, resident organisms lack critical enzymes for degradative processes or are inhibited by some component of the mixed contamination. Selection techniques in genetics that modify organisms have been used to improve remedial affects on the environment, for example, bacterial-enhanced oil recovery. No molecular manipulations have yet been applied to bioremediation in the field, and the real potential of this methodology remains untapped.

The use of genetically engineered organisms in the environment has been limited by public perception and the concerns of regulatory agencies about the potential risks of releasing genetically altered organisms into the environment. In addition, engineered organisms' inability to compete with natural soil populations is an issue that must be addressed. Accordingly, the technology associated with the regulation and containment of such organisms and the direct use of biomolecules extracted or removed from cell-free systems are critical areas for research. 
Molecular

biologists can isolate and characterize genes and gene products that will enhance the bioremediation of mixed contaminants.
Using the information and data gained from the program elements on Community Dynamics and Biotransformation and Biodegradation, scientists will gain a better understanding of the active, critical resident soil and subsurface populations. They will identify the molecules, enzymes, and pathways most effective for bioremediation of mixed contaminants and determine how techniques in molecular and structural biology can improve the effectiveness of these organisms. Molecular biologists can isolate and characterize genes and gene products that will enhance the bioremediation of mixed contaminants. They will conduct structural studies of bioremedial enzymes and other molecules to build a basis for understanding and manipulating molecular activities for bioremediation purposes. They will also develop expression systems for remedially active molecules for pathway engineering, structure and function studies, and large-scale, cell-free systems. In addition, molecular biologists will use rational design and random mutagenesis techniques to modify activity and substrate binding specificity once the structural aspects of molecules with remedial potential are identified and characterized. All of these efforts combined should lead to the application, testing, and evaluation of improved bioremedial activity with respect to the stability, efficacy, and safety of recombinant organisms and new or engineered molecules in the field research center.

Accordingly, the biomolecular engineering program will concentrate on five areas:

1. Analysis of genes and regulatory elements for critical molecules in bioremediation.

2. Structure and function of bioremedial molecules.

3. Genetic selection and engineering of improved bioremedial molecules and organisms.

4. Pathway engineering.

5. Cell-free systems for bioremediation.

\section{Subelement 3.1: Analysis of Genes, Proteins, and Regulatory Elements for Critical Molecules in Bioremediation}

Fundamental research to identify genes and promoters that affect bioremedial activity. 
Objective

Identify, clone, and sequence novel genes and promoters important to the bioremediation of mixed contaminants.

Goals

Three-Year

Identify and characterize the important bioremedial genes and proteins by cloning and sequencing.

Identify critical promoter elements that induce or regulate bioremedial activity of mixed contaminants.

Five-Year

Develop expression systems, including transformation systems of soil organisms, for bioremedial genes and proteins.

Identify gene products, including substances that enhance the ability of organisms to live under contaminated conditions, that affect the survivability of bioremedially active organisms in mixed contaminants.

Ten-Year

Evaluate and compare recombinant organisms against natural populations for bioremedial efficacy in the field research center.

\section{Subelement 3.2: Structure and Function of Bioremedial Molecules}

Fundamental research to determine the three-dimensional structure and critical components of molecules of bioremedial value for sites with mixed contaminants.

Objective

Obtain structure and function information pertinent to bioremediation that will, for example, facilitate the design and expression of improved molecules and our understanding of enzymatic mechanisms for the detoxification of contaminants.

Goals

\section{Three-Year}

Develop strategies for overproduction of bioremedial molecules by prokaryotes and eukaryotes for structural analyses of these molecules. 
Five-Year

Study the structural information about bioremedial molecules provided by x-ray diffraction patterns, and nuclear magnetic resonance. Use structural information to predict and test rational strategies for improvements in bioremedial molecules.

\section{Ten-Year}

Test designed bioremedial molecules for their efficacy in situ and ex situ.

\section{Subelement 3.3: Genetic Selection and Engineering of Improved Bioremedial Molecules and Organisms}

Fundamental research in microbiology to genetically engineer and enhance molecules and organisms for bioremediation.

Objective

Generate molecules and organisms through mutagenesis and selection with improved bioremedial activity.

Goals

Three-Year

Generate and choose mutants for improved bioremedial activity through mutagenesis, directed evolution, and other means.

Examine robust members of the contaminated soil community for their potential as hosts and carriers for horizontal gene transfer and for developing alternative transformation systems.

Five-Year

Design and develop, in genetically modified organisms, survival selection pressure systems for expression of heterologous remedial genes in the field.

Develop genetically modified organisms that are more predictable in terms of performance and ecological behavior in sites containing mixed contaminants by using alternative, nonantibiotic selection and suicide determinants. 
Ten-Year

Test useful, predictive, and competitive genetically modified organisms for applications in the field and for large scale bioprocessing engineering.

\section{Subelement 3.4: Pathway Engineering}

Fundamental research to identify, isolate, and mix genes involved in bioremedial pathways.

Objective

To construct ("quilt") or enhance a bioremedial pathway by identifying actives genes from different prokaryote and eukaryote organisms and then inserting those genes into one of more organisms.

Goals

Three-Year

Identify genes from different organisms that can work together to transform the intermediate compounds in a bioremediation pathway from toxic contaminants to nontoxic endpoints.

Five-Year

Create improved enzymatic pathways for bioremediation by combining optimized genes from different sources into a single organism.

Combine activities from different (engineered) organisms to create extracellular enzymatic pathways.

Ten-Year

Evaluate genetically engineered organisms for their effectiveness in the field and their ability to outperform natural organisms.

\section{Subelement 3.5: Cell-Free Systems for Bioremediation}

Fundamental research to evaluate the use of cell-free systems (enzymes and biochelators) for bioremedial activity.

Objective

Examine cell-free systems that may have an application or delivery advantage over whole cells. 
Goals

\section{Three-Year}

Identify molecules that have potential for bioremediating mixed contaminants in cell-free systems.

Using information from other program subelements, identify, express, and evaluate the applicability for in situ bioremediation of mixed contaminants.

\section{Five-Year}

Design experiments to test how well cell-free molecules perform in the soil matrix and in bioreactors.

Develop methods to produce high yields of these molecules to test their efficacy, durability, reproducibility, and economy as bioremedial agents.

Investigate the feasibility for large-scale production and recovery of these molecules.

Ten-Year

Test cell-free bioremedial molecules for their efficacy in situ and ex situ. 


\section{Program Element 4: Biogeochemical Dynamics}

Fundamental research in dynamic relationships among in situ geochemical, geological, hydrological, and microbial processes.

\section{PROGRAM OBJECTIVE}

To provide a mechanistic understanding of how microorganisms and contaminants are transported under coupled and interactive physical, geochemical, and microbial processes and how underlying molecular and interfacial phenomena and natural heterogeneities control contaminant and nutrient availability and microbial and rhizosphere activity in contaminated environments.

\section{BACKGROUND}

Many bioremedial processes that are effective in smallscale laboratory experiments fail in field applications.
Many microbial and geochemical processes that are effective in smallscale laboratory experiments fail in field applications. This can be attributed to factors such as geochemical and hydrogeological heterogeneity, spatial variability in the distribution of contaminants, difficulty in characterizing and interpreting the geological and hydrological setting, lack of control of nutrient or contaminant availability and moisture content of the soil, or the lack of sufficient populations or activity of microbial consortia able to biotransform, biodegrade, or detoxify the contaminants. Recent experience suggests that successful bioremediation depends on three factors:

1. The presence of microbial consortia and plants that can biotransform, biodegrade, and detoxify contaminants of interest.

2. The availability of nutrients and contaminants to the microbiota and plants.

3. Environmental conditions that are conducive to survival, growth, and activity such that the desired biotransformations occur at a sufficient rate. 
Scientists must

evaluate how

environmental

factors interact

to enhance or

interfere with the

survival, growth,

and activity of the

microbial

community needed

for bioremediation.
All of these factors depend on the complex and dynamic interplay of hydrological, geochemical, and biological processes within a geological medium that is spatially and temporally heterogeneous. Knowledge of these coupled processes-based on a fundamental understanding at the molecular, interfacial, and microbiological scales-is necessary to assess natural biogeochemical processes and to harness them for either intrinsic or enhanced bioremediation.

Over the past several decades, scientists have made significant progress toward understanding these processes and their interrelationships. For example, the important role that speciation and complexation of metals and radionuclides play in their bioavailability and transport properties is now recognized. Similarly, it is now recognized that geologic environments are heterogeneous on many scales: individual mineral grains, coatings on their surfaces, aggregates of several grains, and the macroscopic variations associated with varying depositional environments and post-depositional events (such as fracturing, faulting, and diagenetic alteration). A basic understanding of the geochemistry of specific mixtures of organic chemicals and radionuclides, multiphase flow, transport and surface interactions of colloids/biocolloids, factors influencing bacterial transport, and the microbiology of deep geologic formations is also emerging. Progress over the past decades provides an excellent foundation for future research in this area-focused on issues crucial to bioremediation.

To improve the effectiveness of bioremediation, critical research is needed to:

1. Develop methods to evaluate the spatial and temporal distribution at appropriate scales of microorganisms and specific microbial and rhizosphere communities that can biotransform, biodegrade, or detoxify contaminants of interest.

2. Understand the processes and factors that contribute to the availability of nutrients and contaminants to the microbiota.

3. Evaluate how environmental factors interact to enhance or interfere with survival, growth, and activity of the microbial community required to biodegrade, biotransform, or detoxify contaminant mixtures on a field scale.

\section{APPROACH}

To meet these critical research needs, the Biogeochemical Dynamics program is closely tied to research in Community Dynamics and Microbial Ecology, Biotransformation and Biodegradation, Assessment, Acceleration, and System Integration, and will focus on three areas of scientific research: 
1. Interfacial Phenomena. Biogeochemical processes at liquidliquid, liquid-solid, and gas-liquid interfaces.

2. Contaminant and Nutrient Availability. Chemical, physical, and biological factors affecting contaminant and nutrient availability.

3. Spatial and Temporal Heterogeneity. In situ spatial and temporal heterogeneity in microbial populations and communities, and physical and geochemical parameters and their interrelationships.

Field and laboratory experiments will take place in parallel, using an iterative process to identify key issues and track progress toward a field-scale understanding of these processes and their role in bioremediation. Intermediate-scale facilities will be used for experiments to investigate processes not manifested at the laboratory scale, such as hydrologic flow regimes and scaled heterogeneities. The goals of these experiments are (1) to provide a mechanistic understanding of coupled physical, hydrological, geochemical, and microbiological processes and how underlying molecular and interfacial phenomena and heterogeneities control contaminant transport and availability and microbial movement at the field scale; and (2) to develop a knowledge base sufficient to predict and manipulate the influence of interfacial phenomena, contaminant and nutrient availability, and in situ heterogeneities on the effectiveness of intrinsic and enhanced bioremediation. Information and results from these experiments will be closely linked to the System Integration, Prediction, and Optimization element.

\section{Subelement 4.1: Interfacial Phenomena}

Fundamental research in thermodynamic, mechanistic, and molecular phenomena that operate at interfaces in the subsurface, including mineral and cell surfaces and immiscible fluid boundaries.

Objective

To understand coupled geological, geochemical, and biological mechanisms at interfaces and how these mechanisms influence or control microbial behavior, biotransformation, and transport.

Goals

Three-Year

Identify the key mechanistic processes operating at mineral, cell, liquid, and gas interfaces that control or significantly influence microbial adhesion, transport, and metabolism. 
Five-Year

Identify which interfacial phenomena are important for understanding and predicting the field-scale behavior of complex contaminant mixtures.

\section{Ten-Year}

Develop an extensive body of knowledge that will enable measuring and interpreting of the field-scale biogeochemical processes that affect bioremediation.

\section{Subelement 4.2: Contaminant and Nutrient Availability}

Fundamental research in geochemistry, microbiology, and transport processes focusing on the sequestration and recalcitrance of contaminants and the availability of nutrients that can limit or enhance the effectiveness of bioremediation.

\section{Objective}

To understand the fundamental processes responsible for physical inaccessibility (contaminant sequestration), chemical speciation and complexation, nutrient availability, and the inherent recalcitrance of complex contaminant mixtures and how these phenomena influence bioremediation processes.

Goals

\section{Three-Year}

Identify the mechanisms by which nutrients and compounds that are biodegradable in culture are sequestered by the solid phase or other mechanisms (i.e., interlayer and microaggregate transfer, solid phase molecular diffusion, reversible/irreversible adsorption, precipitation/ dissolution).

\section{Five-Year}

Understand the fundamental mechanisms of contaminant sequestration and the inherent recalcitrance of the key components of complex mixtures, and identify methods for predicting the extent to which these phenomena influence important contaminant mixtures in the subsurface.

\section{Ten-Year}

Identify microbial, physical, and chemical mechanisms to overcome or minimize sequestration and recalcitrance phenomena to enhance bioremediation potential. 


\section{Subelement 4.3: Spatial and Temporal Heterogeneity}

Fundamental research in microbiology, geochemistry, geology, and hydrology, focusing on the spatial and temporal variability observed in soils, sediments, and aquifers and how the variability of one parameter is coupled to others and reflected at different scales.

\section{Objective}

To develop a fundamental understanding of the influence of physical and chemical heterogeneity and hydrological dynamics on microbial distribution and community structure and activity, and how these factors influence the effectiveness of bioremediation.

Goals

Three-Year

Develop the knowledge and methods required to measure and understand spatial variability in physical, chemical, and biological properties in soils and aquifers based on laboratory and intermediatescale scientific research.

Five-Year

Determine which parameters (i.e., physical, chemical, and/or biological heterogeneities) must be measured and at what scales to predict the field-scale effects of heterogeneity on contaminant transport processes and microbial communities.

\section{Ten-Year}

Understand how to use information on natural heterogeneity in space and time and geochemical transport processes in the effective design and deployment of in situ bioremediation strategies. 


\section{Program Element 5: Assessment}

Fundamental research in measuring and validating the biological and geochemical processes of bioremediation.

\section{PROGRAM OBJECTIVES}

To expand and validate innovative methods for measuring biodegradation rates, biotransformation processes, microbial community dynamics, electron flow, contaminant distributions, and hydrogeological and geochemical factors-and to understand the implications of these measurements. The methods developed will focus on characterizing, monitoring (for process control), and defining end points essential to implementing biodegradation in the field, particularly those methods relevant to the transformation of metals and radionuclides.

\section{BACKGROUND}

Current methods

for measuring and evaluating the

effectiveness of bioremediation are inadequate and, in most cases, undeveloped.
Understanding the relationships between microbial community dynamics and the resulting biodegradation and transformation is key to evaluating and predicting the microbial processes that can be harnessed for bioremediation. However, current methods for measuring and evaluating the effectiveness of bioremediation are inadequate and, in most cases, undeveloped. The recently published evaluation by CISB (1993) suggests that "... demonstrating that in situ bioremediation is working should include three types of evidence:

1. Document[ed] loss of contaminants from the site,

2. Laboratory assays showing that microorganisms in site samples have the potential to transform the contaminants under expected site conditions, and

3. One or more pieces of evidence showing that the biodegradative potential is actually realized in the field." 
Techniques that

measure the

electron flow

critical to all the

bioremediation

processes are

particularly

important.
Other appropriate evidence would include documented product accumulation and detoxification. The strongest case is made by having multiple lines of evidence that include documentation of electron flow towards bioremediation pathways.

In today's practice, biological technologies applied during full-scale remediation rely on measuring the disappearance of parent compounds and analyzing the status of electron acceptors $\left(\mathrm{O}_{2}, \mathrm{NO}_{3}\right.$, and $\mathrm{SO}_{4}$ ), selected nutrients, and microbial numbers. Research is needed to develop measurement tools to assess the transformation of complex wastes containing radionuclides and organic compounds and to interpret measurements of bioremediation. Techniques that measure the electron flow that is critical to all the bioremediation processes are particularly important. Environmental microbiology uses techniques largely adapted from clinical microbiology and chemical techniques designed to measure total chemical concentrations. Although useful, these techniques cannot adequately describe the identity, function, physiology, and activity of in situ organisms. Most importantly, populations, communities, and activities involving anaerobic environments, mixtures of contaminants, and in situ measurements of environmental conditions have not been examined. DNA probes and polymerase chain reaction (PCR) to amplify DNA have been used to assess the responses of individual biodegradative strains or various genera involved in bioremediation processes. But even these processes are limited when measuring community function under stress or competition.

Current chemical methodologies for assessing contamination rates and residuals are labor intensive, expensive, and provide indirect measures of in situ processes. They may also inaccurately relate total chemical measurements to bioavailability and risk to human health. This may be true even when the concentration of chemicals, e.g., metals, radionuclides, or chemical mixtures such as total petroleum hydrocarbons, are above statutory levels as commonly determined by analytical chemistry. Research is needed to determine the short- and long-term bioavailability of contaminants to the soil community at the micro and macro level. The limitations of existing techniques are most apparent when interpreting the results of end points of bioremediation for human health risk assessment. Leaching and other harsh methods for extracting chemical constituents from the soil for analytical determination may not adequately measure availability to human or ecological receptors. Surrogate methods that represent receptors, such as simulated gastrointestinal fluids, do exist, but they have not been validated for contaminant mixtures or residual environmental concentrations following bioremediation. Surrogate end points such as molecular, genetic, cellular, and other in vitro assays also exist, but they have not been validated against whole animal standards nor have they been applied to bioremediation. 
Interference from physical or chemical components in the environment also constrains assessment methodologies. Techniques for documenting the loss of contaminants from a site have been confounded by a host of problems, including natural geologic heterogeneity, variable and unpredictable distributions of contaminants, and the practice of measuring total elemental compositions of soil, sediment, or groundwater samples. Improved methods for detecting the location of contaminants, both directly and indirectly, are needed. Moreover, the influence of geologic heterogeneity and contaminant transport processes on the distribution of contaminants needs to be better understood so that optimal strategies can be developed for locating sampling and monitoring sites. Improved methods for efficiently measuring the chemical form of metals and radionuclides (e.g., redox status, complexation, and sorption) are required to more effectively evaluate bioremediation potential and document biotransformation processes.

\section{APPROACH}

The Assessment element will focus on developing techniques for assessing the bioremedial activities of individual strains and functional groups within a community. It will validate existing and emerging laboratory and field techniques (diagnostics) and include data quality and utility. The element will also develop a suite of reliable, reproducible, timely, and economical monitoring techniques for evaluating bioremediation under laboratory and field conditions, and will examine issues in evaluating environmentally acceptable end points for bioremediation.

Solving the technical issues related to measuring, monitoring, and quantifying end points for bioremediation will require the integration of ecological, chemical, hydrogeological, geophysical, engineering, and information management disciplines. For assessing communities and biodegradation rates of parent compounds and intermediates, the emphasis must be on techniques that yield information on activities of consortia or on specific strains of bioremedial groups within the consortia. When assessing bioremediation end points, the focus must be on techniques that accurately reflect the impact on human and environmental health. In addition, an emphasis on near-real-time analysis and data acquisition will provide feedback and support to other program elements on complex reactions in heterogeneous matrices.

The Assessment element, therefore, will involve efforts at the field research centers and at appropriate satellite sites and will focus on these four subelements:

1. Structure rate and activity. Development of quantitative techniques for assessing bioremediation indicators relating to 
community structure rates of activity and types of microbial activity.

2. Geophysical, geochemical, and hydrogeological characterization. Development of techniques for measuring the geochemical and hydrogeologic factors that influence bioremediation.

3. Interpretive diagnostics. Development of innovative diagnostic tools for managing and interpreting bioremediation measurement information, including fatal-flaw-analysis methods.

4. Bioremediation end points. Development of surrogate methods that accurately reflect the effects of the residual products of bioremediation on human and environmental health.

\section{Subelement 5.1: Structure, Rate, and Activity}

Fundamental research in designing, developing, and measuring techniques to assess bioremediation activity, including community structure, biotransformation rates, and types of microbial and rhizosphere activity.

\section{Objective}

Develop a proven toolbox of measurement techniques for microbial activity, degradation rates, movement, community structure, degradative populations, and biotransformation products in situ that can provide timely information critical to the design, control, and evaluation of bioremediation efforts, including real-time measurement methods.

Goals

\section{Three-Year}

Adapt and improve existing molecular and biochemical techniquessuch as DNA and RNA molecular probes, bioreporters, biosensors, fluorescent stains, PCR techniques, and DNA and RNA fingerprinting analyses of gene products-for application to field and laboratory measurements of microbial activity, community structure, and electron flow.

Initiate characterizations at field research centers using novel and conventional techniques. 
Five-Year

Develop and evaluate new techniques-such as isotopes of carbon, oxygen, and chloride to distinguish abiotic and biotic processes (e.g., to address mass balance and fate issues)-for application to environmental in situ and ex situ measurements of microbial activity and community structure.

\section{Ten-Year}

Evaluate innovative techniques for cost-effective, real-time efficient laboratory field-monitoring capabilities and reliability.

Provide critical assessment of the degradative capabilities of microbial communities that degrade and transform complex mixtures of contaminants.

\section{Subelement 5.2: Geochemical, Geophysical, and Hydrogeologic Characterization}

Fundamental research in developing techniques for measuring important geological, hydrological, and geochemical parameters that influence the bioremediation of contaminants.

Objective

Develop tools and techniques that enable an accurate description of hydrogeologic and geochemical factors influencing bioremediation. These factors include the spatial distribution of key chemical species (e.g., electron acceptors and essential nutrients), the nature of the geological matrix (e.g., lithology, porosity, mineralogy, clay contact), and the mobility of the water, dissolved contaminants, nutrients, gases, and colloidal particles.

Goals

\section{Three-Year}

Evaluate the effectiveness of geophysical techniques, such as highresolution seismic and electrical methods, for identifying contaminants, biodegradable products, and physical properties controlling fluid transport.

Identify and apply a suite of geophysical, geochemical, hydrological, and geological characterization techniques to describe the heterogeneity of the first field site. 
Five-Year

Develop a suite of noninvasive geophysical techniques for locating contaminants and documenting losses.

Develop geophysical methods for monitoring biodegradation or biotransformation byproducts.

Develop hydrological methods for better characterization of transport properties for water, dissolved contaminants, and colloids, including bacteria-sized particles.

\section{Ten-Year}

Develop cost-effective and reliable geophysical technologies for designing and monitoring long-term bioremediation processes. Couple these technologies with new diagnostics tools to develop an approach to post-closure monitoring that complies with regulatory issues.

\section{Subelement 5.3: Interpretive Diagnostics}

Fundamental research in developing the diagnostics to interpret complex data sets, including temporal and spatial variability, in support of effective remediation management.

Objective

Develop innovative methods for analyzing data from in situ microbial biomass, biotransformation, and biodegradation activity, and other tools (including statistical methods) for analyzing bioremediation processes, in collaboration with the Biogeochemical Dynamics and System Integration, Prediction, and Optimization elements.

Goals

\section{Three-Year}

Review, evaluate, and develop methods and techniques for compiling, organizing, and analyzing data using analytic and statistical techniques.

Five-Year

Incorporate novel measurement techniques of community interaction and activity into an existing data-acquisition framework.

Develop methods for measuring and interpreting spatial heterogeneity in concentration and species of target compounds, biological communities; and hydrogeologic parameters in collaboration with the Biogeochemical Dynamics element. 
Improve and validate mathematical and statistical methodologies for interpretation of data from the surveillance of large areas affected by complex contaminant mixtures over long time periods in collaboration with the System Integration, Prediction, and Optimization element.

\section{Ten-Year}

Develop diagnostic feedback models with associated hardware and software systems that can monitor bioremediation processes and provide feedback for the successful management of remediation systems.

\section{Subelement 5.4: Bioremediation End Points}

Fundamental research in developing surrogate methods that reflect the bioavailability and stability of contaminants, to help development of performance standards for remediation.

\section{Objective}

Assess the stability and bioavailability of the residual end products of bioremediation of complex contaminant mixtures.

Goals

Three-Year

In partnership with the Environmental Protection Agency (EPA) and other organizations sponsoring work on alternative end-points (e.g., GRI), develop methods and tools for estimating the bioavailability of residual contaminant mixtures.

Five-Year

Establish long-term monitoring programs to monitor the stability of sequestered or immobilized contaminants.

\section{Ten-Year}

Through collaborative efforts with the EPA, validate environmentally acceptable end points and performance standards for the bioremediation of complex contaminant mixtures. 


\section{Program Element 6: Acceleration}

Fundamental interdisciplinary research in flow and transport of nutrients and microorganisms, focused on developing effective methods for accelerating and optimizing bioremediation rates.

\section{PROGRAM OBJECTIVES}

To develop effective methods for accelerating and optimizing in situ bioremediation processes, and where applicable, transfer this knowledge to ex situ waste treatment.

\section{BACKGROUND}

Methods for
accelerating
bioremediation
must overcome a
variety of physical,
chemical, and
biological
limitations.

Methods for

accelerating

bioremediation

must overcome a

chemical, and

biological

limitations.
Many microbial isolates and consortia are capable of transforming or degrading a wide range of environmental pollutants. Similarly, various species of plants can be used to transport, transform, and degrade contaminants. However, these processes may take too long to significantly decrease contaminant levels due to a variety of physical, chemical, and biological limitations. Thus, mechanisms to address these limitations and accelerate biodegradation and biotransformation rates are needed. Biotransformative rates can be accelerated by (1) biostimulation-increasing the number of microorganisms in the contaminated region by addition of chemical amendments, (2) bioaugmentation-active introduction of microorganisms to the subsurface, or (3) increasing the availability of contaminant compounds to organisms. Each of these approaches has been investigated at the bench and pilot scale, and some have been implemented at full scale. For example, addition of nutrients and electron donors/acceptors required for the growth or activity of endogenous microbiota and plants has been examined. To a limited extent, field tests of the bioaugmentation approach have also been conducted. Chemical additives such as surfactants have been added to increase the bioavailability of pollutants to native or introduced degradative organisms. And, to a very limited extent, bioengineered microbial isolates and plants have been introduced to accelerate cleanup. 
Successful use of technologies to accelerate bioremediation rates has been limited by a lack of understanding of both scientific and engineering factors.
Successful use of technologies to accelerate bioremediation rates has been limited due to a lack of understanding of both scientific and engineering factors. For example, although a good deal is known about biodegradation pathways for organic compounds, little is known about the overall interactions of the organisms carrying out these transformations within complex communities, within geological media, or under field conditions at contaminated sites. Moreover, in many natural and engineered systems, biological processes are limited by mass transfer processes, such as molecular diffusion, that are independent of the organisms, and by an incomplete understanding of how geologic properties of the subsurface influence bioremediation. Deficiencies of engineered systems for delivering nutrients and microorganisms to various geological media have also restricted the use of bioremediation.

A combination of scientific and engineering investigations aimed at achieving accelerated bioremediation rates is needed to overcome these limitations. Building on new knowledge about community dynamics, biotransformation and biodegradation processes, biomolecular engineering, and phytoremediation, research is needed to address questions such as:

- What is the optimal rate and formulation for delivery of nutrients?

- Are nutrients delivered more effectively at a constant rate, or are cyclic rates more effective?

- What are the most effective strategies for introducing nonendogenous organisms into aquifers and the vadose zone?

- Under which circumstances are liquid or gas nutrient delivery systems more effective?

- How can bioremediation rates be accelerated in low-permeability materials such as clay or sparsely fractured rock?

- Can aerobic environments be effectively converted to anaerobic environments or vice versa? What is required to do so?

\section{APPROACH}

To answer questions such as these, research will focus on three topics:

1. Microbial and chemical transport processes.

2. Biostimulation and bioaugmentation processes.

3. Delivery strategies for chemicals and microorganisms. 
These research activities will build upon and synthesize information gained from all of the program elements and focus on transferring this information from the bench to the field.

Research efforts will initially focus on identifying critical processes and microorganisms necessary for promoting acceleration of bioremediation in laboratory experiments that mimic in situ conditions. Coordinated field and laboratory experiments will also be initiated. Subsequent development will include obtaining a sufficient scientific understanding of microbial and delivery processes to design meaningful field-scale experiments on accelerating the bioremediation of contaminant mixtures. It will also be necessary to develop a sufficient understanding of biostimulation and bioaugmentation processes relevant to the field research centers so that methods for accelerating bioremediation (and phytoremediation) can be tested at the field research centers. The ultimate goal of this program element is completion of the development and testing of promising strategies for accelerating bioremediation processes for contaminant mixtures at DOE sites.

\section{Subelement 6.1: Microbial and Chemical Transport Processes}

Fundamental research in hydrogeology, geochemistry, and microbiology focused on understanding bioremediation rate-limiting factors associated with subsurface flow and transport of microorganisms, chemical amendments, and contaminants.

Objective

To develop the scientific foundations for understanding transport of microorganisms and chemicals in multiorganism, multicontaminant environments-focused on developing a knowledge base to support the other Acceleration subelements.

Goals

Three-Year

Explore and identify key bioremediation rate-limiting factors associated with chemical diffusion, advection, dispersion, dissolution/precipitation reactions, chemical complexation, volatilization of contaminants, and addition of chemical amendments. Design complementary bench and field experiments that will help provide a mechanistic understanding of key processes.

Identify key bioremediation rate-limiting factors associated with microbial transport, attachment and detachment, clogging, filtration, sedimentation, and biofilm formation in natural systems. Design 
complementary bench and field experiments that will help to resolve the key issues identified above.

Five-Year

Develop strategies for overcoming the bioremediation rate-limiting factors identified by efforts outlined in the three-year goals. Design complementary and iterative laboratory and field experiments to test and evaluate strategies for overcoming these rate-limiting factors.

Ten-Year

Provide a thorough scientific understanding of the factors that influence transport of microorganisms, contaminants, and additivesand how these factors can be overcome to accelerate bioremediation rates.

\section{Subelement 6.2: Biostimulation and Bioaugmentation Processes}

Fundamental research in geochemistry, hydrogeology, and microbiology, focused on improving implementation of bioremediation strategies that optimize specific biotransformations of contaminant mixtures by microorganisms and/or plants in field environments.

To understand the effectiveness, fate, and transport of biostimulation agents. To understand the interaction of added organisms with the target contaminants in geologic media. To develop, in collaboration with other program elements, robust field methods for implementing and optimizing biostimulation (increasing desired activities of endogenous microorganisms and plants) and bioaugmentation (introducing microorganisms or plants with desired biotransformation capabilities).

\section{Three Year}

Identify key limitations associated with carbon, nutrient, electron donor/acceptors, or other amendments for biostimulation and the scientific issues that need to be addressed to resolve them. Design complementary bench and field experiments that will improve understanding of these issues.

Identify key limitations of methods currently used for bioaugmentation in natural systems and the scientific issues that need to be addressed to resolve them. Design complementary bench and field experiments that will improve understanding of these issues. 
Develop biostimulation and bioaugmentation strategies for the Phase II experiments (Fig. 6) at the first field research center.

\section{Five-Year}

Develop methods for implementing and optimizing newly discovered biotransformation and biodegradation processes for mixtures of metals, organics, and radionuclides.

Develop experiments for field testing new biotransformation or degradation pathways created by the Biomolecular Engineering program element.

Design biostimulation and bioaugmentation strategies for the Phase III experiments at the field research centers.

Develop methods for biostimulation and bioaugmentation to optimize the effectiveness of microbial consortia for biodegradation of contaminant mixtures.

\section{Ten-Year}

Develop and test a suite of new or improved methods of biostimulation and bioaugmentation to bioremediate priority contaminant mixtures at DOE sites.

\section{Subelement 6.3: Delivery Strategies for Chemical and Biological Additives}

Fundamental research in hydrogeology, geochemistry, and microbiology focused on developing effective methods that can be used in the field to deliver amendments to the subsurface for biostimulation, bioaugmentation, and increasing the bioavailability of contaminants.

To develop new and improved strategies to deliver chemical amendments and microorganisms to the subsurface environment for the purpose of bioremediation. Specific objectives include methods for delivery of multiple stimulatory compounds, systems effectively delivering agents to various types of geological media, gaseous and liquid injection schemes, the potential for use of electric and electromagnetic fields to steer amendments to the optimal locations, and methods to create sequential aerobic/anaerobic systems. Explicit consideration of the flow and transport properties of the subsurface media, documentation of flow pathways through the subsurface (e.g., using appropriate physical and chemical tracers), and explicit attention to the heterogeneous nature of natural systems is essential. Researchers in this program element will work closely with the System Integration, Prediction, and Optimization element to develop engineering design tools and models for delivery systems. 


\section{Three-Year}

Identify alternatives for nutrient and microorganism delivery and select one or more schemes for use in the Phase II experiments (Fig. 6) at the first field research center. Design, engineer, and implement delivery schemes for implementation in the Phase II experiments at the first field research center.

Identify key limitations associated with delivering amendments for the range of geochemical and hydrogeological conditions and priority contaminant mixtures at the DOE sites.

Five-Year

Test and evaluate preliminary delivery processes, identify limiting factors, and iterate design improvements between the laboratory and the field to overcome potential bottlenecks.

Identify remedies to overcome the drawbacks associated with displacement of pollutants from the treatment region when amendments are added.

Identify alternatives and select one or more delivery schemes for use in the Phase III experiments (Fig. 6) at the field research center.

Design delivery schemes for implementation in the Phase III experiments at the first field research center.

\section{Ten-Year}

Develop a suite of standardized delivery schemes that address the geologic and chemical diversity anticipated at DOE sites and enable implementation of bioremediation for priority contaminant mixtures. 


\section{Program Element 7: System Integration, Prediction, and Optimization}

Fundamental research to develop conceptual and quantitative methods for describing community dynamics, biotransformation, biodegradation, and biogeochemical dynamics processes in complex geologic systems.

\section{PROGRAM OBJECTIVES}

To integrate scientific concepts and data from different program elements and to develop a hierarchy of improved mathematical methods for describing coupled biological, geochemical, geological, and transport processes. These methods will be used, together with visualization techniques, to design and interpret laboratory and field experiments, to establish bioremediation design principles, to predict and optimize the effectiveness of bioremediation under many different conditions, and to identify and quantify the largest sources of uncertainty. The overall goal is to synthesize this information so that the effectiveness of bioremediation at sites with complex contaminant mixtures can be predicted and optimized. Further, bioremediation strategies can be compared with conventional remediation through a cost-benefit analysis.

Knowledge gained in the scientific disciplines of microbiology, hydrology, and geochemistry provides a strong scientific foundation for bioremediation. However, the effectiveness of bioremediation cannot yet be predicted with a high degree of confidence for complex contaminant mixtures and heterogeneous geology (Miller and Poindexter, 1994). A key component in the inability to make accurate predictions is the lack of a robust understanding of the dynamics that interrelate biological, hydrological, and geochemical processes as well 


The effectiveness
of bioremediation
cannot yet be
predicted with a
high degree of
confidence for
complex
contaminant
mixtures and
heterogeneous
geology.

The effectiveness

of bioremediation

cannot yet be

predicted with a

high degree of

confidence for

complex

contaminant

mixtures and

heterogeneous as the quantitative tools needed to synthesize them. Examples of such coupled or interrelated phenomena include the correlation among local geochemistry, moisture variation, and biological activities; the dependence of biological activities on soil chemistry and fluid advection and dispersion; and the transient processes involving water recharge, nutrient transport, biological activity, chemical transformation, and migration of products from biological activities (AgBiotech, 1991; Alfoldi, 1991). These activities are further complicated by the heterogeneity or variability of the physical, chemical, and biological properties of natural systems. Advances in understanding the relationship of such activities and in dealing with heterogeneities will provide the foundations for predicting and improving the effectiveness of existing bioremediation technologies and for developing new and innovative ones.

Because of the multidisciplinary nature of the program, there will be a diversity of scientific data (biological, chemical, geological, etc.). Fortunately there have been many efforts in recent years on databases and informatics. These will be used to support rapid evolution of data and information from the program elements to promote the sharing of data among projects and with the larger scientific community.

\section{APPROACH}

The System Integration, Prediction, and Optimization element will develop strategies to represent mathematically the key microbial, biotransformation, and biogeochemical processes identified in other program elements, and to identify, adapt, or develop where necessary predictive models (including statistical models) that can design and interpret laboratory and field-scale experiments for intrinsic and enhanced bioremediation. In parallel, an information system will be developed to facilitate the synthesis of experimental data gathered by the program at one site, preferably using existing software where feasible. The final products of this program element are expected to include predictive models that have been successfully tested and that can be used to design and interpret laboratory and field-scale experiments for intrinsic and enhanced bioremediation.

To address the need for systematic methods of integrating biological, geochemical, geological, and transport processes associated with contaminant mixtures in complex geologic systems, research will focus on three areas:

1. Scientific Data Integration and Informatics. In order to support the synthesis of data from various program elements, it will be necessary to identify (or develop) information systems which can support diverse scientific data, including biochemical, molecular biology, metabolic, geochemical, and microbiological. 
2. Mathematical Representation of Community Dynamics, Biotransformation, and Biogeochemical Processes. Develop new mathematical and statistical methods for the mechanistic representation of community dynamics, ecology, biotransformation, and biogeochemical processes.

3. Integrative and Scalable Models. Develop a hierarchy of improved, coupled dynamic models that integrate, predict, and optimize these processes in many different environments using improved mathematical and statistical methods. This could include the adoption or development of software tools to support model development and model management.

These research activities will build on information gained from all program elements and will be essential for interpreting phenomena observed in complex natural systems. At any time, the integrated models and associated databases will represent the current state of knowledge and will be available for predicting optimal bioremediation strategies for a given site and site conditions and for comparing bioremediation strategies with conventional remediation methods through a cost-benefit analysis.

\section{Subelement 7.1: Scientific Data Integration and Informatics}

Fundamental research on integration and informatics for multidisciplinary data and on evaluation techniques for data quality, consistency, and validity ranges.

\section{Objectives}

To develop methods to organize, integrate, and evaluate scientific data and information from all program elements. To provide a networkaccessible information system to support the research program.

Goals

Three-Year

Define the information description and data organization, i.e., schema definition, for different program elements and for a selected field site. Design and implement an efficient, remotely accessible information system to support the diverse data, using existing software where feasible.

Design and implement appropriate, accessible, and efficient information-management systems and mechanisms. 
Five-Year

Deploy and adapt the site information system at all sites. Provide networked, shared, on-line access to public database systems for data derived from the program elements. In addition, provide networked access to appropriate databases managed by various program elements.

Synthesize and evaluate information and data from the various program elements, using the accumulated data and information systems. Identify knowledge gaps and prioritize future research activities.

\section{Ten-Year}

Maintain and provide access to a comprehensive information system that archives experimental results related to the scientific elements of bioremediation (e.g., microbial community dynamics, biotransformation and biodegradation, biomolecular engineering, and assessment methods).

\section{Subelement 7.2: Mathematical Representation of Community Dynamics, Biotransformation, and Biogeochemical Processes}

Fundamental research on mathematical representation of processes related to bioremediation and the couplings and interrelationships among these processes.

\section{Objectives}

To enhance or develop mathematical (numerical and statistical) representations of microbial community dynamics, biodegradation, biotransformation, and biogeochemical processes as they interrelate in terrestrial environments, and to develop integrative and scalable models.

\section{Three-Year}

Develop improved mathematical representations (or new representations where needed) of microbial community dynamics, biodegradation, biotransformation, and biogeochemical processes.

Develop improved or new strategies for describing mathematically how community dynamics, biodegradation, biotransformation, and biogeochemical processes influence and interrelate to each other. 


\section{Five-Year}

Develop mathematical and stochastic representations of microbial community dynamics, biodegradation, biotransformation, and biogeochemical processes in heterogeneous systems and their couplings for selected microbial communities and contaminant mixtures.

Develop and validate larger-scale models of community dynamics, biotransformation, and biogeochemical processes.

\section{Ten-Year}

Develop and test mathematical and stochastic representations of microbial community dynamics, biodegradation, biotransformation, and biogeochemical processes for many different microbial communities and contaminant mixtures.

\section{Subelement 7.3: Integrative and Scalable Models}

Fundamental research on mathematical (numerical and statistical) models to simulate integrated bioremediation processes in soils and geologic formations, accounting for biological, chemical, and physical variabilities.

\section{Objectives}

Enhance or develop predictive computational and statistical models for designing, integrating, and evaluating laboratory and field experiments. Develop inversion methods to obtain parameter estimates from field and laboratory experiments. Obtain or develop improved software tools for model development and model management to cope with the increasingly complex models.

A three-tier hierarchy of models will be constructed, with systematic methods linking results from one model to another. The first set of models will predict bench-scale biodegradation and biotransformation rates in complex subsurface environments contaminated with contaminant mixtures. The second set will focus on the coupling between in situ transport processes and biotransformation and biodegradation at a scale that captures the relevant biogeochemical processes and heterogeneities of natural environments. The third set will focus on the engineering calculations needed to implement and optimize bioremediation on a field scale. These models will include a strong statistical component to account for biological and chemical variabilities as a function of both space and time. Equally important to developing the models is the design of the scaling-up concepts and processes that will link them together. Once the models are successfully tested, they will be made available to the environmental bioremediation industry. 


\section{Three-Year}

Identify and adapt or develop where necessary predictive models-for designing and interpreting initial interdisciplinary, multi-investigator laboratory and field experiments-that can support the program. Develop concepts and strategies for designing the next generation of predictive models in cooperation with researchers from other program elements.

Develop concepts and strategies for scaling up from bench- and intermediate-scale models to field-scale models by evaluating appropriate system parameters, measurement capabilities, and computational requirements.

\section{Five-Year}

Develop next-generation predictive models for bench-, intermediate-, and field-scale bioremediation. Evaluate these models by comparison with observations made from intrinsic and enhanced bioremediation laboratory and field experiments, thus testing the methods for increasing the scale from bench- and intermediate-scale models to field-scale models.

Adopt or develop model development tools which would permit rapid, concise specification of models in terms of symbolic mathematics, and subsequent automatic code generation. Adopt or develop model management systems for managing collections of models and simulation runs.

Develop and apply inversion procedures for evaluating parameters from laboratory and field experiments on bioremediation processes.

\section{Ten-Year}

Use tested predictive and inverse models for designing, optimizing, and evaluating intrinsic and enhanced bioremediation at DOE and other mixed-contaminant sites. 
\begin{tabular}{l} 
Program Management, \\
Partnerships, ELSI Issues, \\
and Implementaton Plan \\
\hline
\end{tabular} 


\section{Program Management, Partnerships, ELSI Issues, and Implementation Plan}

The management, partnerships, and implementation plan for the Natural and Accelerated Bioremediation Research Program is described in this section. The description includes the DOE oversight and management structure; the management approach for the program; partnerships to identify needed research and disseminate information; research to address ethical, legal, and social impacts; procedures for selecting the field sites; the formation of the scientific team; and peer review.

\section{DOE OVERSIGHT AND MANAGEMENT STRUCTURE}

The management structure for the program is presented in Figs. 7 and 8. Figure 7 shows the direct management of the program by OHER. DOE management will include fiscal oversight of the science team, field research centers, and the R\&D shared infrastructure. The program will be supported by an interagency steering committee to ensure coordination with complementary programs and to identify opportunities for leveraging scientific and infrastructure investments.

Figure 8 illustrates the internal structure of the program. The DOE management will be supported by a program office that will manage the program on a day-to-day basis. The program office will be responsible for scientific coordination within and among program elements, scheduling of major activities at the test sites, communication and database management, and facilitating access to the R\&D shared infrastructure. Final management approval and oversight will be retained by OHER. 


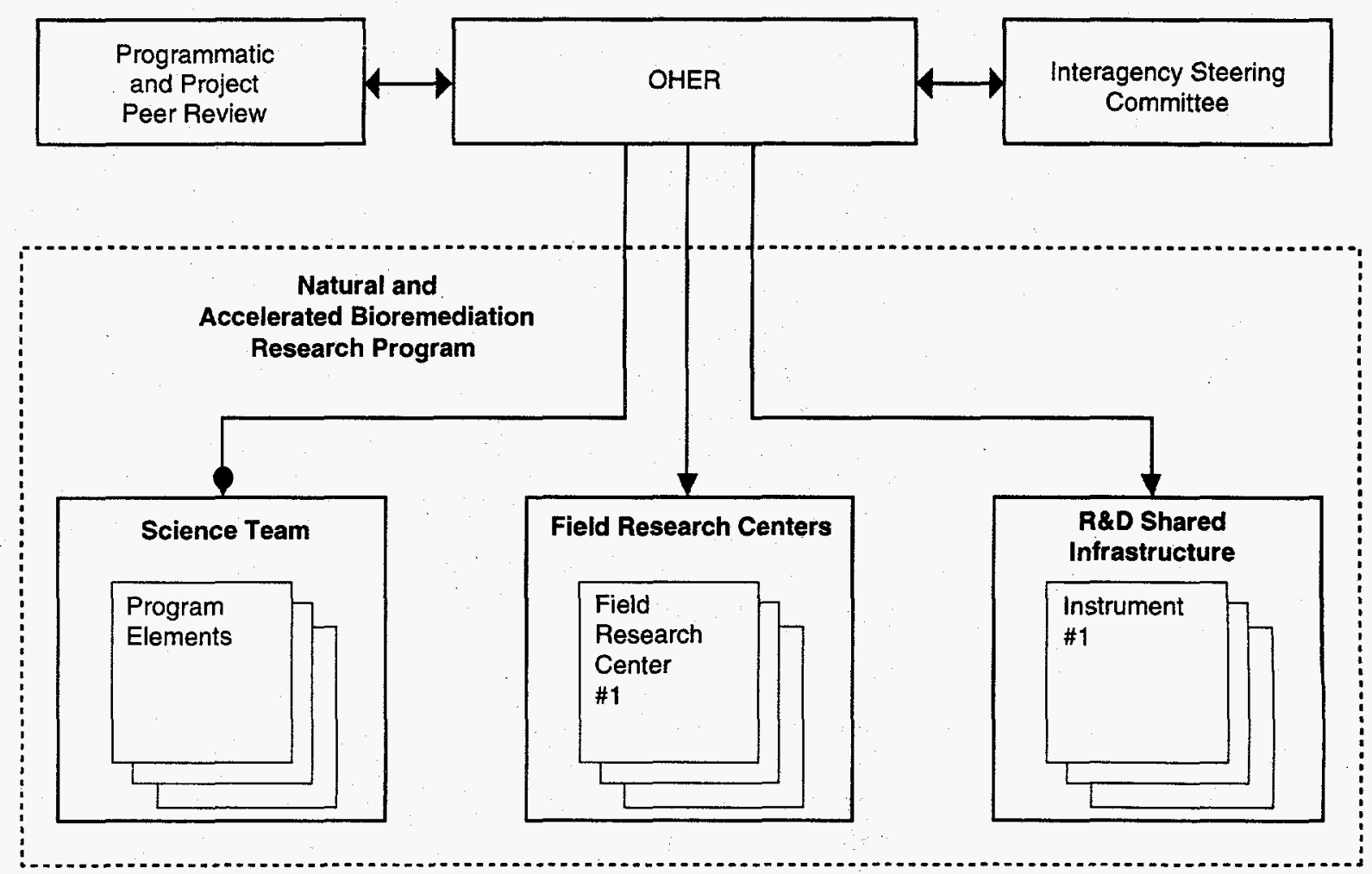

Figure 7. Direct oversight of the three major activities of the NABIR program.

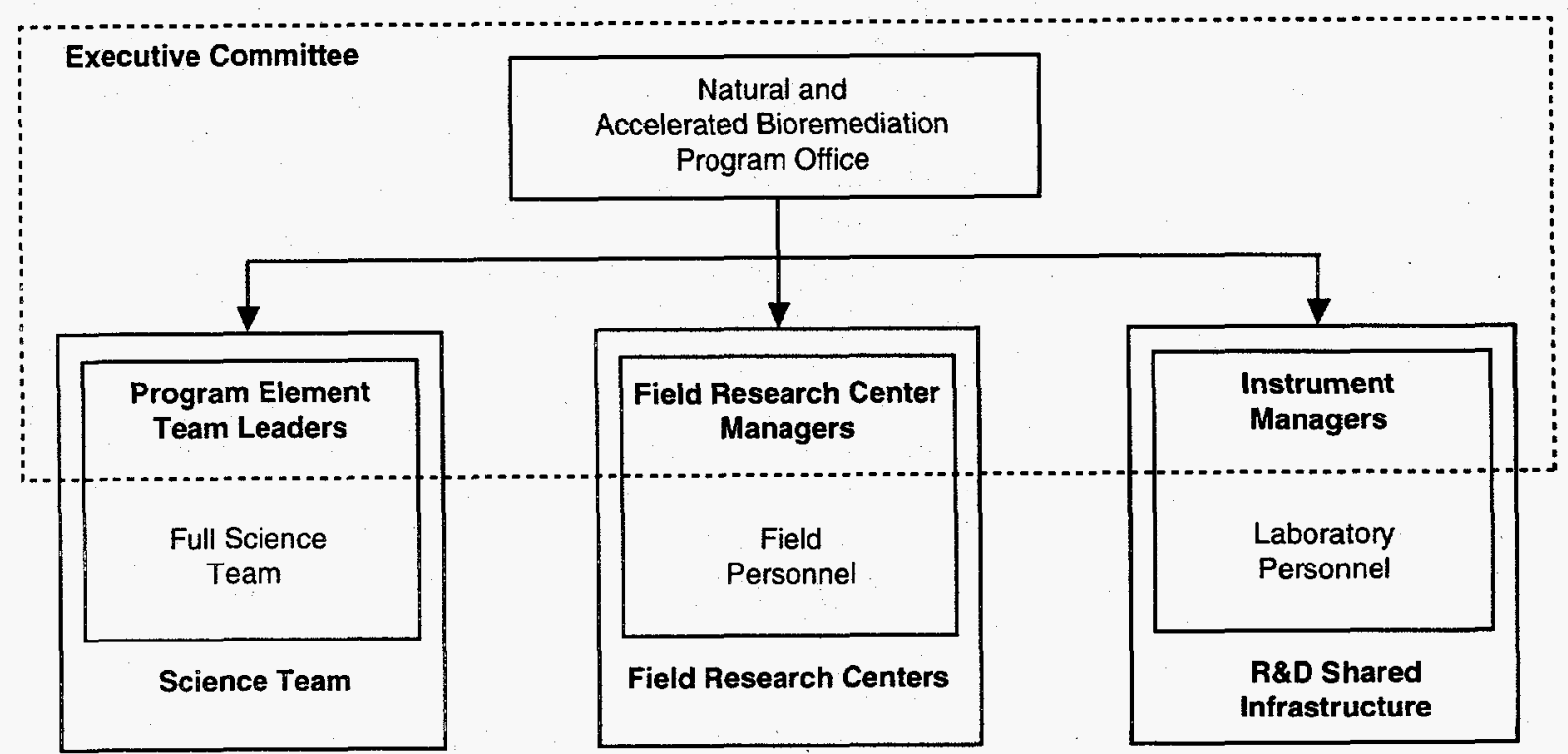

Figure 8. Internal structure of the Natural and Accelerated Bioremediation Research Program. 
An executive committee will be responsible for coordinating the scientific program, making recommendations for the locations of the field research centers; and identifying the highest priority needs for R\&D shared infrastructure. The executive committee will consist of the program office manager, team leaders for each of the program elements, field research center managers, and managers of major instrumentation facilities.

element will have

a scientific team

leader who is

responsible for

scientific direction

and coordination

within the

program element,

as well as

facilitating

collaboration with

other program

elements.

The science team will be responsible for setting the scientific direction of the program and for carrying out research activities. The scientific team will consist of DOE laboratory scientists, academic researchers, industry researchers, postdoctoral fellows, graduate students, and technicians. Each program element will have a scientific team leader who is responsible for scientific direction and coordination within the program element. The team leaders will also be responsible for identifying opportunities and facilitating collaboration with other program elements. The team leader for each program element will be a member of the executive committee.

Each field research center will have an on-site manager who will be responsible for obtaining permits, developing and implementing a site safety plan, day-to-day scheduling of field activities, and site operations. The field research center managers will supervise a staff of technicians and other support personnel at the site. The manager of each field research center will be a member of the executive committee.

Managers will also be identified for major laboratory measurement facilities. These managers will be responsible for facilitating use of the instruments by a variety of scientific investigators, day-to-day scheduling of activities, developing and implementing a site safety plan, and instrument operation. The manager of each major instrument facility will be a member of the executive committee.

The activities described above will be funded by OHER. The scientific program will be funded primarily by competitive proposals, regardless of the status of the principal investigator-academic, federal laboratories, or industry. The program will seek the best talent available to address the goals identified in the program elements. Managers and staff for field research centers and major instrumentation facilities will be located primarily at the DOE laboratories.

\section{PARTNERSHIPS AND EDUCATION TO ENABLE IMPLEMENTATION}

Too often, scientific development, research, engineering implementation, and social acceptance are poorly synchronized. The focus of scientific research sometimes does not reflect engineering and societal needs and thus contributes little to the mainstream of higher education and/or the solution of immediate and important problems. 


Transfer of
the scientific
knowledge gained
will be the key to
the success of this
program.

At other times, scientific knowledge that could contribute to solutions is overlooked because of poor communication between problem holders, the scientific community, regulatory agencies, and the public. The intent of the Natural and Accelerated Bioremediation Research Program is to overcome these barriers by establishing proactive partnerships and educational vehicles to enable implementation of the scientific knowledge gained over the ten-year effort.

To achieve the goal of a seamlessly integrated research program in which new knowledge is implemented quickly and effectively as well as used for training scientists and engineers of the future, this program is committed to providing sustained support for two types of activities:

\section{Linkage with the EM problem holders.}

Identifying those problems that are most important to solve is the critical key to funding meaningful research. Systematic methods of working with DOE's Environmental Management (EM) program will be established-including ongoing interaction with Headquarters staff, field offices, and site problem-holders-to identify high-priority problems that may be solved through bioremediation. EM staff will participate in programmatic peer reviews and act as advisors to the program. At least one person from EM will be requested to serve as a liaison between this program and the prime focus area. This person will bridge the gap between NABIR's fundamental research and EM's technology development programs.

The program will seek input on directions and priorities from within OHER, from other divisions of DOE, and from other government agencies and bioremediation programs. Program managers performing related research in OHER and DOE's Basic Energy Sciences Program will be asked to act as advisors to the program. Communication will be established and maintained with other federal, state, and private bioremediation research programs to coordinate complementary programs and avoid unnecessary duplication. Managers of related programs will be invited to serve as advisors.

Transfer of the scientific knowledge gained will also be a key to the success of this program. Through peer review and open meetings with the scientific community, results of the program will be communicated and the most promising avenues of research will be identified on an ongoing basis. The field research centers can play a major role in transferring scientific knowledge to the problem holders and students alike. Opportunities for other programs and universities to use the sites will help accomplish this goal, and short courses and summer stipend support for higher education will be provided throughout the DOE complex and through scientific societies and other appropriate venues. 


\section{Information and education outreach programs.}

Implementing technologies based on new scientific knowledge requires effective communication with problem holders, regulatory agencies, and the public. The program will establish and maintain an effective information outreach and education program to accomplish this objective. Several different methods of disseminating information will be used: the World Wide Web to publish program opportunities and accomplishments, a newsletter aimed at DOE sites and regulatory agencies, a curriculum program for higher education, and timely publications to publicize successful programmatic products.

\section{IDENTIFY AND ADDRESS ETHICAL, LEGAL, AND SOCIAL IMPACTS}

If scientific and engineering solutions to environmental problems are to be tested and implemented, they first must be accepted by regulatory agencies and the public. To gain acceptance, a host of ethical, legal (including regulatory), and social questions must be identified and addressed. Some examples are:

- How does the public perceive bioremediation?

- Is it safe to introduce bioengineered organisms into the environment?

- Will bioremediation lower contaminant levels enough to protect human health and the ecological systems?

- Is containment through microbial sequestration of metals and radionuclides an acceptable long-term solution?

- Is intrinsic bioremediation an acceptable alternative to a more aggressive remediation strategy?

- What are the implications of bioremediation for environmental justice concerns?

The list of such questions is long and certain to change as our knowledge increases. The Natural and Accelerated Bioremediation Research Program will support research and establish partnerships that address these questions. The program will work with regulatory agencies to develop guidelines for testing new bioremediation procedures. It will also develop strategies for safely testing the effectiveness of bioengineered organisms and for assessing environmentally acceptable end points for bioremediation. 
The startup and implementation of the program will begin in FY96. FY96 activities will include (1) broad and general announcement of the NABIR program, (2) selection of the scientific team leaders, (3) formation of the initial scientific team through a competitive process, (4) selection of the first field research center site, (5) evaluation of R\&D shared infrastructure requirements, (6) identification of ethical, legal, and social issues that must be addressed immediately, and (7) identification of the interagency steering committee. By FY97, the management structure will have evolved from the startup mode to the model described above.

\section{Announcement of the NABIR Program}

Announcement of the NABIR program will be made through the Commerce Business Daily (CBD), direct mailing to research organizations and other federal agencies, presentations at technical meetings, and the World Wide Web.

\section{Selection of Scientific Team Leaders}

Scientific team leaders will be selected through a competitive process. A solicitation requesting a statement of qualifications will be distributed to the scientific community for each of the program elements. Responses will be reviewed by OHER with assistance from the program office. Team leaders will be selected based on their scientific qualifications, ability and desire to lead and work in a team, and level of commitment to the program.

\section{Formation of the Initial Science Team}

The initial science team will be formed by a competitive solicitation for projects within each of the program elements. Panels of scientific peers will review and rank proposals and make recommendations to OHER. Proposals will be selected based on the scientific quality of the proposed work and relevance of the work to the goals of the program.

To ensure the maximum relevance of all proposals, detailed information on contaminants and hydrogeologic settings of interest will be provided in the requests for proposals.

\section{Selection of the First Field Research Center}

Selection of the first field research center will be completed during FY96. It will involve a three-step process. First, through interviews with EM headquarters and field office personnel, high priority mixtures of contaminants will be identified that are likely to be remediated by natural or accelerated bioremediation. Next, a set of 
requirements for the field research centers will be identified. Examples of requirements for the field research center include:

1. Level of interest of the site managers.

2. Nature and composition of the contaminant mixture.

3. Geologic/hydrologic setting.

4. Availability of site for long-term research.

5. Likelihood of co-locating a technology demonstration project nearby.

6. Infrastructure needs and costs.

7. Regulatory relationships and motivation for innovation.

8. Opportunities or commitments for cost sharing.

9. Qualifications of the field research center manager.

Finally, OHER will issue a call for statements of interest from DOE sites. A subset of these statements will be selected for further discussion and negotiations, and one or more will be selected.

\section{Evaluation of R\&D Shared Infrastructure Requirements}

The program office will sponsor a workshop for the scientific community where instrumentation, database, and shared-model needs will be identified and prioritized. Based on the results of the workshop, the program office will make recommendations to OHER for infrastructure and equipment investments.

\section{Identification of Ethical, Legal, and Social Impacts}

In the first quarter of FY 1996, a solicitation for proposals to identify ethical, legal, and social issues relevant to bioremediation will be distributed to universities, the private sector, and public interest groups. A team will be selected and asked to identify key issues that must be addressed immediately and those that must be addressed over the life of the program. A workshop will then be held to provide broad participation and input into the program by interested parties.

\section{Identification of the Interagency Steering Committee Members}

Members of the interagency steering committee will be identified and engaged in the planning and implementation process. Members may include participants from EM's Office of Technology Development, 
Environmental Remediation and Waste Management, the Environmental Protection Agency, the United States Geological Survey, the U.S. Bureau of Mines, the National Science Foundation, the Department of Agriculture, the Department of Defense, and other agencies with related programs.

\section{PEER REVIEW AND PERFORMANCE MEASURES}

Two types of peer review will be incorporated into the program management-programmatic peer review and project peer review. Both of these peer review processes will be used to encourage and create interdisciplinary teams.

Programmatic peer review will be used to evaluate the overall effectiveness of the program and how well the program is achieving the goals identified in the program element section. Programmatic peer reviewers will make recommendations about how the content and structure of the program can be improved. Programmatic peer reviews will take place one, three, five, and ten years into the program.

Project peer review will consist of conventional scientific peer review of individual projects conducted by members of the scientific community from academia, government agencies, and industry. Peer review will take place for initial selection of projects and biannually thereafter.

In addition to peer review; other performance measures will be used to evaluate if the program is successful. These will include:

1. Quality and quantity of new knowledge generated by the program

2. Effectiveness of the interdisciplinary teams

3. Timely accomplishments of programmatic goals

4. Application of knowledge or techniques to bioremediation or to otherwise help solve DOE problems

5. Spin-off to other areas such as pollution prevention, ecosystem studies, biomedical applications, ecotoxicity, and human genome.

A program of this scale and complexity may require midcourse changes or corrections. The mechanisms described above will provide an early warning of the need for such changes or corrections and help focus the program to maintain its effectiveness. 


\section{Schedule and Budget}




\section{Schedule and Budget}

The major components of the schedule for this program and key dates are illustrated in Fig. 9. The first milestone, to be completed after six months, is to select the scientific team leaders. Six months later, the initial portfolio of research projects and investigators will be selected by a competitive solicitation. Other important dates include identifying the locations of the field research centers and completing Phase I, II, and III activities at the field research centers. The first field research center will be selected at the end of the first year, the second by the middle of year three, and the third by year five. The remainder of the schedule is driven by the goals outlined in the various program elements. As indicated in Fig. 9, programmatic peer reviews will take place at the end of years one, three, five, and seven. A final review will take place at ten years.

The projected budget for this program is shown in Table 3 and illustrated in Fig. 10. This budget represents a preliminary assessment based on our current understanding of the program and assessment of the expenses associated with operating field research centers. The budget projections for the field research centers are based on the assumption that scientific effort related to the field experiments will be paid for out of the budgets of the individual program elements.

The budget for each field research center provides funding for a field site manager, an administrative assistant, and six technicians. In addition, a significant fraction of NABIR's S\&E budget listed in Table 3 will be used to drill wells, purchase chemical additives for the Phase II and Phase III acceleration experiments, and provide support for utilities and other site infrastructure. Equipment required to support on-site activities will be purchased from NABIR's equipment budget as shown in Table 3. The total annual operating cost for each field research center is approximately 5 million dollars during the startup, declining to about 2 million dollars once the site is fully established.

The budgets for the scientific program elements were determined by resource loading each with a mixture of DOE laboratory scientists, academic researchers, students, and technicians. These budget projections are sufficiently accurate to encompass the effort necessary to achieve the goals outlined in the program elements. However, as more is learned, the emphasis on different program elements may shift 
to reflect revised program priorities. The programmatic peer reviews scheduled to occur at one, three, five, and seven years will assist in reevaluating program priorities. The budget projections reflect the schedule described above and illustrated in Fig. 9. 


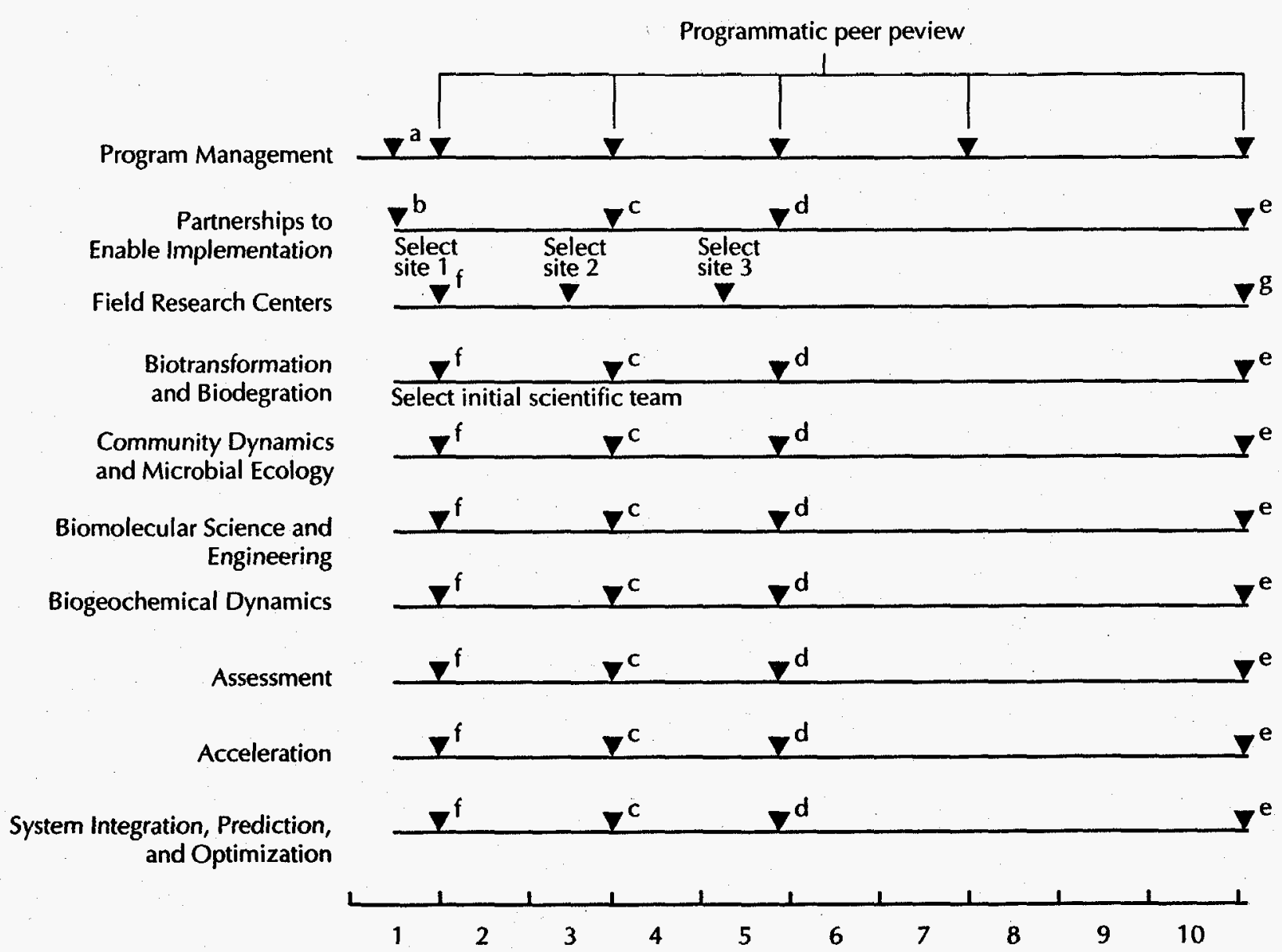

Program year

Figure 9. Schedule of key activities for the Intrinsic and Enhanced Bioremediation Research Program.

a Select scientific executive team. b Identify ethical, legal, and social issues that must be addressed to implement the program plan. c Achieve three-year goals outlined in the program element descriptions. $\mathrm{d}$ Achieve five-year goals outlined in the program element descriptions. e Achieve ten-year goals outlined in the program element descriptions. ${ }^{f}$ Select initial scientific team. g Complete Phase I, II, and III experiments at field research centers. 
Table 3. Program budget in $\$ M$ (in 1996 dollars).

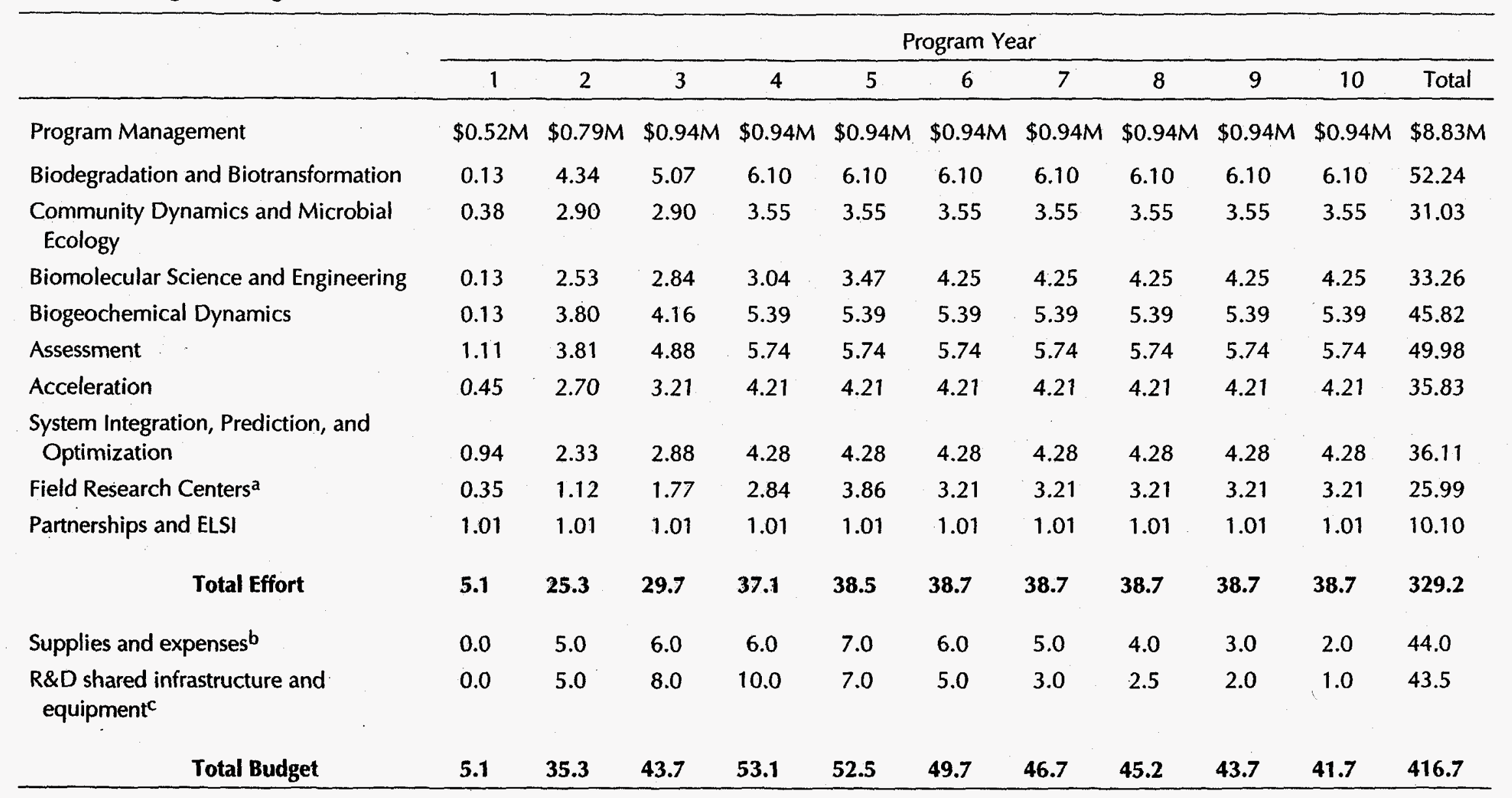

aNote that cost reflects effort only.

b Most expenses will be used to develop and operate the field research centers.

$\mathrm{C}_{\text {Approximately }} 50 \%$ of the equipment funds will be used for the field research centers, the remainder will support R\&D shared infrastructure and single-investigator equipment needs. 
Schedule and Budget
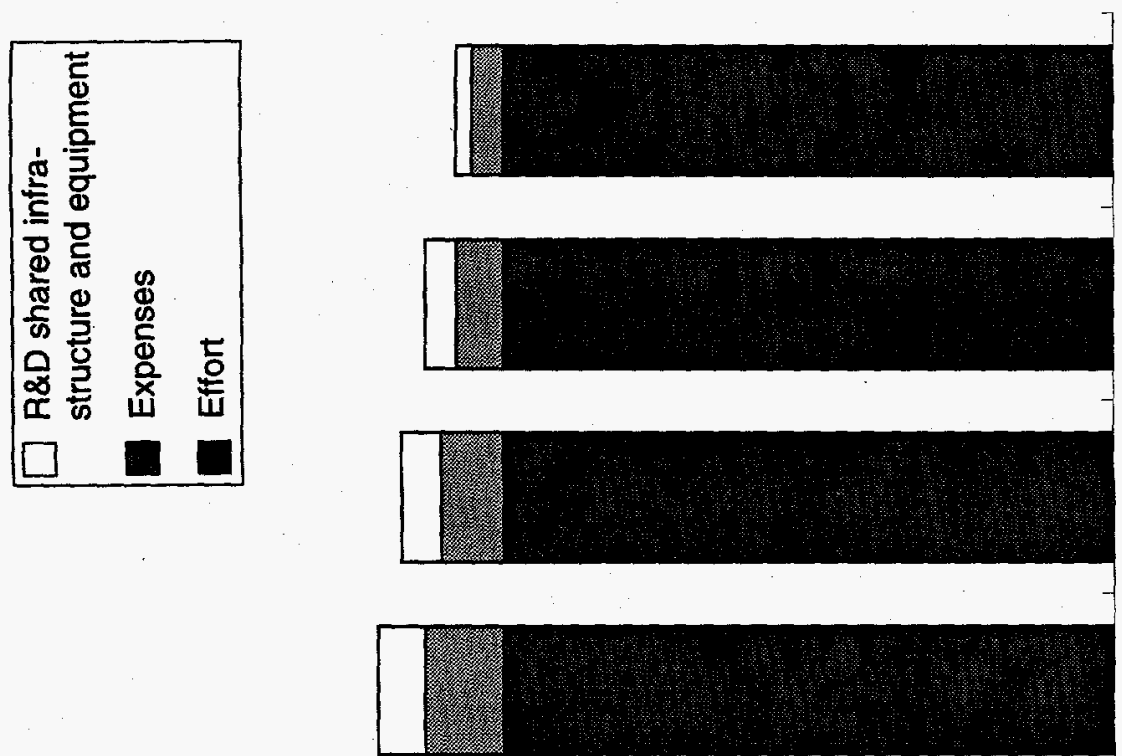

오

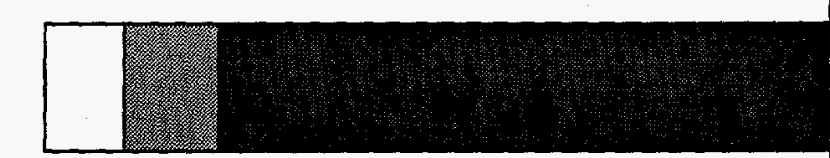

$a$

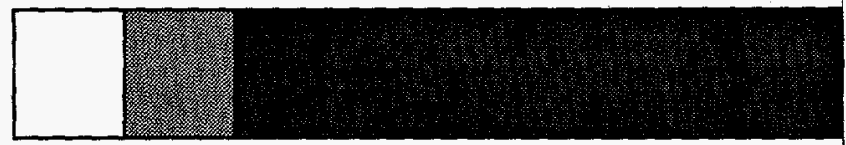

$\infty$

苞

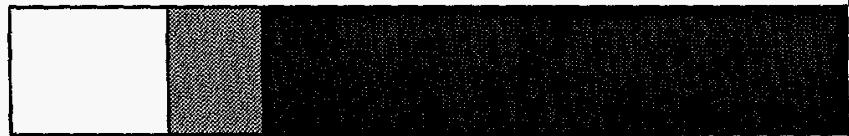

$\sim \quad$ d

$\infty$

홍

ํํㄹ

0

홍

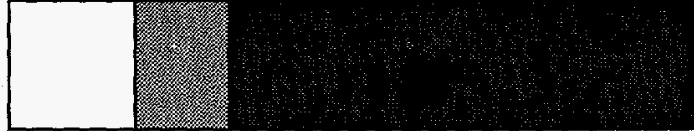

$m$

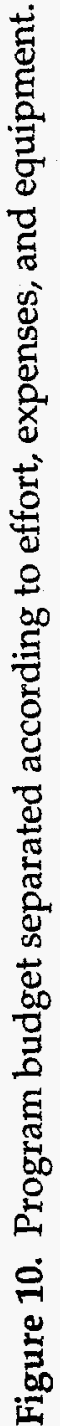

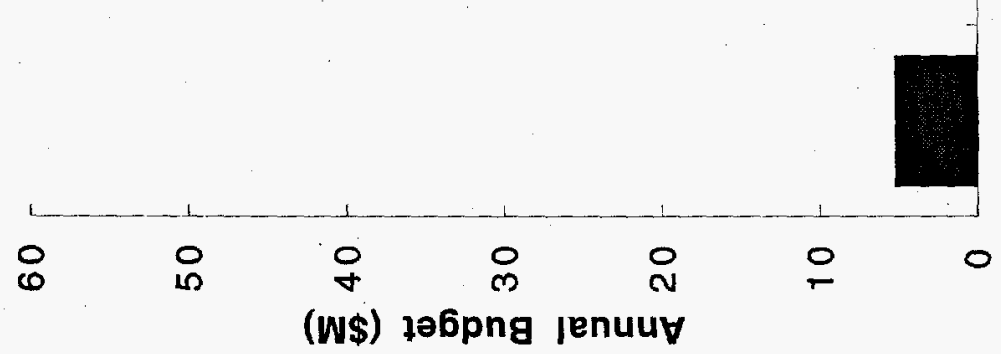


Bibliography 


\section{Bibliography}

AgBiotech: see Center for Agricultural Molecular Biology.

Alföldi, L. (1991). Hydrogeologic considerations for in situ bioremediation, in "In Situ Bioreclamation" (R.E. Hinchee and R.F. Olfenbuttel, eds.), 33-50. Butterworth-Heinemann Publishers, Stoneham, Massachusetts.

Anderson, T.A., and Coats, J.R., eds. (1994). "Bioremediation through Rhizosphere Technology." ACS Symposium Series No. 563. American Chemical Society, Washington, D.C.

Atlas, R.M. (1995). Bioremediation. Chemical and Engineering News, April, 32-42.

Benson, S.M., Delamore, M., and Hoffman, S. (1993). Kesterson crises. Irrigation and Drainage Engineering 119, 471-483.

Biosystems Technology Development Program (BTDP). (1992). "Bioremediation of Hazardous Wastes." U.S. Environmental Protection Agency, EPA/600/R-92/126, Cincinnati, Ohio.

Biotechnology Research Subcommittee (BRS). (1995). "Biotechnology for the 21st Century: New Horizons." Committee in Fundamental Science and Research, National Science and Technology Council, Washington, D.C.

Center for Agricultural Molecular Biology (AgBiotech). (1991). "Utilizing Bioremediation Technologies: Difficulties and Approaches. Report from a National Workshop, New Brunswick, N.J., July 12-14." Cook College, New Jersey Agricultural Experiment Station, Rutgers, The State University, New Brunswick, N.J.

Cirpka, O., and Bisch, G. (1995). Development of a model aquifer for reduction dechlorination of chlorinated ethenes: Technical design of the aquifer model and influence of spatial variability. Presented at the Third International Symposium on In-Situ and On-Site Bioreclamation, San Diego, California, April 24-27. 
Committee on In Situ Bioremediation (CISB). (1993). "In Situ Bioremediation: When Does It Work?" Water Science and Technology Board, Commission on Engineering and Technical Systems, National Research Council. National Academy Press, Washington, D.C.

Cooney, J.J., and Gadd, G.M. (1995). Metals and microorganisms. Journal of Industrial Microbiology 14(2, 3, 4), 59-353.

de Lorenzo, V. (1992). Genetic engineering strategies for environmental applications. Current Opinion in Biotechnology 3 , $227-231$.

(1993). Genetic tools for constructing predictable genetic modified organisms, in "In Situ Bioremediation: When Does It Work?" 73-77. Committee on In Situ Bioremediation, Water Science and Technology Board, Commission on Engineering and Technical Systems, National Research Council. National Academy Press, Washington, D.C.

Department of Energy (DOE). (1989). "Evaluation of Mid- to LongTerm Basic Research for Environmental Restoration." DOE/ER0419 .

. (1990). "Basic Research for Environmental Restoration." DOE/ER-0482T.

(1994a). "EM's Action Plan for a New Approach to Environmental Restoration in DOE." Unpublished report.

(1994b). "Summary Report of a Workshop on Phytoremediation Research Needs, December, 1994." DOE/EM0224.

(1994c). "Subsurface Science Program: Program Overview." DOE/ER-0640.

(1995). "Estimating the Cold War Mortgage: The 1995

Baseline Environmental Management Report" (2 vol.). DOE/EM0230 .

Economidis, I., and Palmisano, A., eds. (1995). "Proceedings: Environmental Biotechnology: EC-US Task Force on Biotechnology Research." Brussels, Belgium.

Ehrlich, H.L. (1990). "Geomicrobiology." Marcel Dekker, Inc., New York. 
Francis, A.J. (1990). Microbial dissolution and stabilization of toxic metals and radionuclides in mixed wastes. Experientia 46, 840-851.

Frankenberger, Jr., W.T., and Benson, S.M., eds. (1994). "Selenium in the Environment." Marcel Dekker, Inc., New York.

Gibson, D.T., and Sayler, G.S. (1992). "Scientific Foundations of Bioremediation: Current Status and Future Needs." American Academy of Microbiology, Washington, D.C.

Grimes, D.J. (1995). Validation of reliability and predictability of environmental biotechnologies, in "Proceedings of the 1994 OECD Workshop on Bioremediation." Tokyo, Japan.

Harkness, M.R., McDermott, J.B., and Abramowicz, D.A. (1993). In situ stimulation of aerobic degradation of PCB biodegradation in Hudson River sediments. Science 259, 503-507.

Hinchee, R.E., Anderson, D.B., Metting, Jr., F.B., and Sayles, G.D., eds. (1994). "Applied Biotechnology for Site Remediation." Lewis Publishers, Boca Raton, Florida.

King, R.B., Mihony, G., and Sheldon, J.K. (1992). "Practical Environmental Bioremediation." Lewis Publishers, Boca Raton, Florida.

Li, Y., Yang, C.-Y., Lee, V.-I., and Yen, T.F. (1994). In situ biological encapsulation: Biopolymer shields, in "Applied Biotechnology for Site Remediation" (R.E. Hinchee et al., eds.), 275-286. Lewis Publishers, Boca Raton, Florida.

Lovley, D.R. (1993). Dissimilatory metal reduction. Annual Review of Microbiology 47, 263-290.

Lynch, J.M., and Hobbie, J.E. (1988). "Micro-organisms in Action: Concepts and Applications in Microbial Ecology." Blackwell Scientific Publications, Oxford, England.

Macaskie, L.E. (1991). The application of biotechnology to the treatment of waste products produced from the nuclear fuel cycle: Biodegradation and bioaccumulation as a means of treating radionuclide-containing streams. Critical Reviews in Biotechnology $11,41-112$.

Metting, Jr., F.B., ed. (1992). "Soil Microbial Ecology: Applications in Agricultural and Environmental Management." Marcel Dekker, Inc., New York. 
Miller, R.V., and Poindexter, J.S. (1994). "Strategies and Mechanisms for Field Research in Environmental Bioremediation." American Academy of Microbiology, Washington, D.C.

Mueller, J.G. (1995). Model studies of bioremediation strategies and monitoring technologies, in "Proceedings: Environmental Biotechnology: EC-US Task Force on Biotechnology Research" (I. Economidis and A. Palmisano, eds.). Brussels, Belgium.

National Research Council (NRC). (1994). "Alternatives for Ground Water Cleanup." National Academy Press, Washington, D.C.

Riley, R.G., Zachara, J.M., and Wobber, F.J. (1992). "Chemical Contaminants on DOE Lands and Selection of Contaminant Mixtures for Subsurface Science Research." Department of Energy, DOE/ER-0547T.

Saaty, R.P., and Booth, S.R. (1994). "In Situ Bioremediation: Cost Effectiveness of a Remediation Technology Field Tested at the Savannah River Integrated Demonstration Site." LA-UR-94-1714. Los Alamos National Laboratory, Los Alamos, New Mexico.

Sayler, G.S. (1995). Biodegradation process analysis: Molecular application in simulations and environmental verification, in "Proceedings: Environmental Biotechnology: EC-US Task Force on Biotechnology Research" (I. Economidis and A. Palmisano, eds.), 47-54. Brussels, Belgium.

Sayler, G.S., Fox, R., and Blackburn, J.W. (1991). "Environmental Biotechnology for Waste Treatment." Plenum Press, New York.

Shannon, M.J.R., and Unterman, R. (1993). Evaluating bioremediation. Annual Review of Microbiology 47, 715-730.

Skladany, G.J., and Metting, Jr., F.B. (1992). Bioremediation of contaminated soil, in "Soil Microbial Ecology: Applications in Agricultural and Environmental Management" (F.B. Metting, Jr., ed.), 483-513. Marcel Dekker, Inc., New York.

Taylor, R.T., Hanna, M.L., Shah, N.N., Shonnard, D.R., Duba, A.G., Durham, W.B., Jackson, K.J., Knapp, R.B., Wijesinghe, A.M., Knezovich, J.P., and Jovanovich, M.C. (1993). In situ bioremediation of trichloroethylene-contaminated water by a resting-cell methanotrophic microbial filter. Hydrological Science Journal 38, 323-342.

Thomas, J.M., and Ward, C.H. (1989). In situ biorestoration of organic contaminants in the subsurface. Environmental Science and Technology 23, 760-766. 
Tunlid, A., and White, D.C. (1992). Biochemical analysis of biomass, community structure, nutritional status, and metabolic activity of microbial communities in soil, in "Soil Biochemistry" (G. Stotzky and J.M. Bollag, eds.), vol. 7, 229-262. Marcel Dekker, Inc., New York.

Wijesinghe, A.M., Knapp, R.B., Taylor, R.T., and Carman, L.M. (1992). "Preliminary Feasibility and Cost Analysis of the In-Situ Microbial Filter Concept." UCRL-ID-111021. Lawrence Livermore National Laboratory, Livermore, California. 


\title{
Appendix A: Acronyms and Initialisms
}

\author{
AAM American Academy of Microbiology \\ ALS Advanced Light Source \\ APS Advanced Photon Source \\ BES Basic Energy Science Program \\ BRS Biotechnology Research Subcommittee, Committee in \\ Fundamental Science and Research, National Science and \\ Technology Council \\ BTDP Biosystems Technology Development Program, \\ Environmental Protection Agency \\ CBD Commerce Business Daily \\ CISB Committee on In Situ Bioremediation, Water Science and \\ Technology Board, Commission on Engineering and \\ Technical Systems, National Research Council \\ DNA Deoxyribonucleić acid \\ DOC Department of Commerce \\ DOD Department of Defense \\ DOE Department of Energy \\ DPTA Diethylenetriaminepentaacetic acid \\ EDTA Ethylenediaminetetraacetic acid \\ ELSI Ethical, legal, and social impacts \\ EM Office of Environmental Management \\ EPA Environmental Protection Agency \\ FST Fractionation separation technology \\ GC/MS Gas chromatography/mass spectroscopy. \\ GEMS Genetically engineered microorganisms \\ GRI Gas Research Institute
}


HPLC/MS High-pressure liquid chromatography/mass spectroscopy MPN Most probable number

NAPL Nonaqueous phase liquid

NIST National Institute of Standards and Technology Division

NMR Nuclear magnetic resonance spectroscopy

NOAA National Oceanic and Atmospheric Administration

NRC National Research Council

NSF National Science Foundation

NSLS National Synchrotron Light Source

NTA Nitrilotriacetic acid

OHER Office of Health and Environmental Research

ONR Office of Naval Research

ORNL Oak Ridge National Laboratory

PAHs Polycyclic aromatic hydrocarbons

PCBs Polychlorinated biphenyls

PCE Perchloroethylene

PCR Polymerase chain reaction

PERF Petroleum Environmental Research Fund

PHB Polyhydroxy butyrate

PLFA Phospholipid ester-lined fatty acids

RNA Ribonucleic acid

SLB Signature lipid biomarker analysis

SSRL Stanford Synchrotron Radiation Laboratory

TCE Trichloroethylene

USAID Agency for International Development 


\section{Appendix B: Glossary}

Abiotic

Accelerated bioremediation

Actinide

Advection

Aerobic

Amensalism

Anaerobic

Anion

Antibody

Aquifer

Archaebacteria

Assessment

Autochthonous

Bioaccumulation

Bioaugmentation
Not biotic or living.

Bioremediation within the subsurface at a given site that is accelerated beyond the normal actions of the naturally occurring microbial population and naturally occurring chemical, biological, and geological conditions.

Any element in the series of elements with atomic numbers in the range beginning with actinium (89) or thorium (90) and ending with lawrencium (103).

The process by which solutes are transported by the bulk motion of the flowing groundwater.

Living, active, or occurring only in the presence of oxygen.

An interspecific interaction in which one species population is inhibited, typically by toxin produced by the other, which is unaffected.

Living, active, or occurring in the absence of free oxygen.

A negatively charged ion. The ion in an electrolyzed solution that migrates to the anode.

Any of the body globulins that combine specifically with antigens and neutralize toxins, agglutinate bacteria or cells, and precipitate soluble antigens.

Water-bearing stratum of permeable rock, sand, or gravel.

A group of prokaryotic microorganisms that are only distantly related to eukaryotes and the other prokaryotes and are members of the domain Archaea.

An appraisal or evaluation (e.g., assessment of the degree of success of a remediation procedure at a contamination site).

Indigenous, natural, aboriginal; formed or occurring in the place where found.

Intracellular accumulation of environmental pollutants such as heavy metals by living organisms, including microorganisms, plants, and humans.

The addition to the environment of bacteria or fungi that can metabolize and grow on specific organic compounds. 
Bioavailability

Bio-barrier

Bio-chelator

Biocolloid

Biodegradation

Biogeochemical dynamics

Biomass

Biomolecular engineering

Biopolymer

Bioreactor

Bioremediation

Biosequestration

Biostimulation

Biosurfactant

Biota

Biotic

Biotransformation

Cell-free extracts

Chelator
The availability of chemicals to microorganisms, which will influence the degradation of the chemicals.

A biologically active zone that is placed in the subsurface perpendicular to the normal flow of a contaminant plume so that the contaminant can be adsorbed and biologically degraded.

A biochemical compound (synthesized by living organisms) that binds and forms complexes with trace elements and polyvalent cations.

A colloid or colloidal mixture of biological components (see Colloid).

The breakdown of substances by microorganisms.

The temporal behavior of coupled biological, hydrological, and geochemical processes in geologic media.

The amount of living matter present in a particular habitat, usually expressed as dry weight per unit area or as volume or weight per unit volume.

The application of engineering technology to the solution of problems pertaining to organic molecules occurring in living organisms, especially macromolecules.

Microbial products, either exopolysaccharides or polyhydroxyalkanoates, that can be manufactured commercially from renewable resources, are biodegradable, and provide alternatives to traditional plant and algal gums or to plastics made from hydrocarbons.

Vessel or tank in which whole cells or cell-free enzymes transform raw materials into biochemical products and/or less undesirable by-products.

The process by which microorganisms act to degrade hazardous organic contaminants to environmentally safe levels in soils, subsurface materials, water, sludges, and residues.

The conversion of a compound through biological processes to a form that is chemically or physically isolated.

Addition of nutrients and oxygen so as to increase the number of indigenous microorganisms available for degradation of contaminants. Generally, any process that will increase the rates of biological degradation.

A surface-active agent produced by microorganisms (see Surfactant).

The animal and plant life of a region.

Of or relating to life; induced or caused by the action of living beings.

Alteration of the structure of a compound by a living organism or enzyme.

Components (e.g., enzymes and biochelators) produced in living systems (either plant or animal) that can be removed from those systems and then used in bioremedial activities.

An agent that causes formation of a chelate-a heterocyclic molecule in which a metal ion is bound to at least two nonmetal ions in the same molecule. 
Chemotaxis

Chemotropism

Chromatography

Colloid

Cometabolism

Commensalism

Community

Community dynamics

Complexing agent

Conjugation

Cytochrome

Dehalogenate

Ecology

Ecotoxicity

Eh

Electromagnetic

Electron acceptor

Electron donor

ELISA
Movement of cells or organisms toward or away from chemical stimuli.

Orientation response of cells or organisms in relation to chemical stimuli.

A process of separating gases, liquids, or solids in a mixture or solution by adsorption, as selective adsorption on clay, silica gel, alumina, or paper.

Any gas, solid, or liquid in a fine state of subdivision, with particles too small to be visible in an ordinary optical microscope, that is dispersed in a continuous gaseous, liquid, or solid medium and does not settle or settles very slowly.

Biotransformation of a compound by a microorganism that is incapable of using the compound as a source of energy or growth.

A close and permanent association between two populations of organisms in which one population benefits without damaging or benefiting the other.

Assemblage of species of microorganisms that occur and interact within a given habitat

Temporal changes in the structure and function of a community.

A dissolved ligand that binds with a simple charged or uncharged molecular species in a liquid solution to form a complex chemical species.

The transfer of genetic material, in particular the transfer of microbial genomes or genes either between or within species to enhance enzymatic activity for bioremedial purposes.

Any of several respiratory pigments that occur in animal and plant cells, play a major role in intracellular oxidations, and are related chemically to hemoglobin.

To remove halogen atoms from a molecule.

The study of the relationships between living organisms and between organisms and their environment.

The quality, state, or relative degree of being toxic or poisonous to the environment and the ecological system.

Standard oxidation-reduction potential (redox potential); the energy gained in the transfer of $1 \mathrm{~mol}$ of electrons from an oxidant to $\mathrm{H}_{2}$.

Of, relating to, or produced by electromagnetism, magnetism developed by a current of electricity.

Small inorganic or organic compound that is reduced to complete an electron transport chain. Compound that is reduced in a metabolic redox reaction.

Small inorganic or organic compound that is oxidized to initiate an electron transport chain. Compound from which electrons are derived in a metabolic redox reaction.

Enzyme-linked immunosorbent assay based on enzyme-labeled immunoreactants for use in the detection of analytes in clinical specimens 
Endogenous

Energetics

Eubacteria

Eukaryotes

Expression system

Extremophiles

Ex situ

Feedback inhibition

Gene

Genetic engineering

Genome

Genotype

Geohydrological

Geology

Geomechanics

Geophysical

Heavy metals
Growing from or on the inside. Developing within the cell wall. Constituting or relating to metabolism of the nitrogenous constituents of cells or tissues. Arising from internal structural or functional causes.

The physics of energy and its transformations.

Prokaryotes other than archaebacteria (see their respective definitions).

Organisms that maintain their genome within a defined nucleus. (Not used in any formal taxonomic system, but now may be used to refer to members of the domain Eucarya.)

A system in which a cloned gene can be expressed. Elements used to evaluate the quality of an expression system include the number of copies of the gene per cell, the strength of the transcriptional promoter, the presence of the bacterial ribosome binding site, codon usage, and the fate of the protein.

A group of organisms whose growth is dependent on extreme environmental conditions, e.g., extreme halophiles, extreme psychrophiles, extreme thermophiles.

In a position or location other than the natural or original one.

Mechanism by which the end product of the cell's biosynthetic pathway inhibits the activity of the first enzymes in the same pathway. This mechanism controls enzymatic activity so that resources can be conserved and regulated.

A section of DNA coding for a single polypeptide chain, a particular species of transfer or ribosomal RNA, or a sequence that is recognized by and interacts with regulatory proteins.

The application of engineering technology to the isolation and study of single genes, and the reintroduction of these genes into cells of the same or different species.

The sum of all chromosomal genes in a haploid cell (including prokaryotes), or the haploid set of chromosomes in a eukaryotic cell.

The type species of a genus. The genetic constitution of an individual or group. The totality of genes possessed by an individual or group.

Referring to the character, source, and mode of the occurrence and flow of underground water.

The geologic features of an area. The science that deals with the history of the earth and its life, especially as recorded in the rocks.

A branch of geology that embraces the basic fundamentals of structural geology and a knowledge of the response of natural materials to deformation or changes due to the application of stress or strain energy.

Of, relating to, or based on the physics of the earth, including the fields of meteorology, hydrology, oceanography, seismology, volcanology, magnetism, radioactivity, and geodesy.

Metals of high specific gravity (5.0 or higher). 
Heterocyst

Heterogeneity

Heterologous

Horizontal gene transfer

Hydrocarbons

Hydrology

In situ

Interfacial

Interlayer transfer

Ketone

Kinetics

Leaching

Mass spectroscopy

Mesocosm

Metazoans

Methanotroph

Microaggregate transfer
One of three types of specialized cells that form in filamentous cyanobacteria in response to environmental conditions, involved in the fixation of atmospheric nitrogen.

The quality or state of being heterogeneous, i.e., varying in space or time.

Consisting of different elements or of like elements in different proportions.

An evolutionary event involving the transfer of genes, from one species to another, in which the viable offspring gain genetic diversity.

Any of a large class of organic compounds containing only carbon and hydrogen.

A science dealing with the properties, distribution, and circulation of water; the study of water on the surface of the land, in the soil and underlying rocks, and in the atmosphere, particularly with respect to evaporation and precipitation.

In place; in the natural or original position or location.

Included between two plane surfaces or faces. Relating to or situated at the boundary between two phases, such as liquid-liquid, liquid-solid, and gasliquid interfaces.

The transfer of chemicals and living organisms over a distance between layers of mineral surfaces in soil.

Organic compound characterized by a carbonyl group attached to two carbon atoms, usually contained in hydrocarbon radicals or in a single bivalent radical, similar to an aldehyde but less reactive.

A branch of science that focuses on biological, physical, or chemical changes.

The process or an instance of separating the soluble components from some material by percolation. The process or an instance of removing nutritive or harmful elements from soil by percolation.

The measurement and interpretation of electromagnetic spectra generated when a beam of ions is sent through a combination of electric and magnetic fields such that the ions are deflected according to their masses. Used to determine the masses of atoms or molecules.

A field-scale model utilized to understand the interactive relationship of microbial communities and the roles played by microbial populations within ecosystems.

A group that comprises all animals having an adult body composed of numerous cells differentiated into tissues and organs and usually a digestive cavity lined with specialized cells, usually including the Coelenterata and all higher animals but sometimes extended to include the Parazoa and Mesozoa.

A methane-oxidizing bacterium.

The transfer of chemicals and living organisms in soil aggregates $50-200 \mu \mathrm{m}$ in size. 
Microautoradiography

Microbial ecology

Microbiology

Microcosm

Microorganism

Mineralization

Molecular biology

Molecular evolution

Morphology

Mutualism

Natural bioremediation

Nuclear magnetic resonance

(NMR) spectroscopy

Parasitism

Pathway engineering

$\mathrm{pH}$

Phenotypic

Photon
The technique of obtaining photographic images of microscopic samples by using neutron, $x$, or $\gamma$ radiation emitted from the sample.

The field of study that examines the interactions of microorganisms with their biotic and abiotic surroundings.

A branch of biology dealing especially with microscopic forms of life (bacteria, protozoa, viruses, and fungi).

A laboratory-scale model used to understand the interactive relationships of microbial communities and the roles played by microbial populations within ecosystems.

An organism of microscopic or ultramicroscopic size.

The microbial breakdown of organic materials into inorganic materials brought about by microorganisms.

A branch of biology dealing with the ultimate physicochemical organization of living matter at the molecular level.

The divergence of genes in sequence as they evolve from a common ancestor. The evolution of genomes through such genetic mechanisms as mutation, recombination, and gene duplication.

A branch of biology that deals with the form and structure of animals and plants. Alternately, the external structure of rocks in relation to the development of erosional forms or topographic features.

A stable condition in which two organisms of different species live in close physical association, each organism deriving some benefit from the other.

Bioremediation within the subsurface at a given site as a function of the naturally occurring microbial population and naturally occurring chemical, biological, and geological conditions.

The use of nuclear magnetic resonance (NMR) over a wide frequency range to analyze protons and nuclei and to study changes in the chemical and physical quantities of materials.

A relationship in which an organism of one kind lives in, on, or in intimate association with an organism of another kind at the expense of which it obtains food and usually other benefits.

The application of engineering technology to alter or construct a sequence of enzymatically catalyzed chemical reactions.

The negative logarithm of the effective hydrogen-ion concentration or hydrogen-ion activity in gram equivalents per liter.

Of, relating to, or constituting a detectable expression of the interaction of genotype and the environment.

A massless elementary particle that is the carrier of radiant energy (as light or $x$ rays). 
Phototropism

Phototaxis

Phylogeny

Phthalate

Physiochemical

Physiology

Physiological ecology

Phytoremediation

Plume

Predation

Prokaryotes

Promoter

Radionuclides

Random mutagenesis

Recalcitrant

Redox reactions

Regulatory elements

Respiration

Rhizosphere

Secondary metabolism
A growth-mediated response of plants or microorganisms to stimulation by visible light.

The ability of bacteria to detect changes in light intensity and respond by moving away from or toward the light.

The evolutionary history of a group of organisms. The sign and evolution of higher taka; phylogenesis.

A salt or ester of phthalic acid.

Of or relating to physiological chemistry, a branch of science dealing with the chemical aspects of physiological and biological systems.

Study of the processes, activities, and phenomena incidental to and characteristic of life or of living organisms.

The study of biophysical, biochemical, and physiological processes used by living organisms to cope with factors of their physical environment and which are employed during ecological interactions with other organisms.

Remediation performed by plants.

An elongated body of fluid, usually mobile and varying in shape.

A mode of life in which food is primarily obtained by killing and consuming.

Organisms that maintain their genome dispersed throughout the cytoplasm. (Not used in any formal taxonomic system, but previously used interchangeably with the term bacteria.)

A substance that in very small amounts is able to increase the activity of a catalyst. A DNA sequence that directs RNA polymerase to bind and initiate, transcription of genes or operons.

Nuclides that emit radioactivity ( $\alpha, \beta$, or $\gamma$ particles) or fission into smaller nuclides.

The random occurrence or induction of mutation.

Resistant to microbial attack.

Reactions of oxidation and reduction.

The relatively short nucleotide sequences in DNA that play important roles in controlling gene expression.

Any of various energy-yielding oxidative reactions in living matter that typically involve transfer of oxygen and production of carbon dioxide and water.

Soil that surrounds and is influenced by the roots of a plant.

A metabolic process that produces a metabolite, which peaks only after the main growth phase of the cell is completed. 
Sequence

Soil matrix

Spatial heterogeneity

Sporulation

Stochastic

Subsurface

Surfactant

Synchrotron

Taxonomy

Temporal heterogeneity

Thermodynamics

Transduction

Transformation

Transposon
The succession of one thing or event after another, as of genes along a strand of DNA or geological events in time.

An assemblage of mineral particles of various sizes, shapes, and chemical characteristics, together with organic materials, in various stages of decomposition and living soil populations.

A condition or state that varies with position in space.

The formation of spores. Division into many small spores.

Involving a random variable. Involving chance or probability.

The geologic zone below the surface of the earth. Rock and soil materials lying near, but not exposed at, the Earth's surface.

A natural or synthetic chemical that promotes the wetting, solubilization, and emulsification of various types of organic chemicals.

An apparatus for imparting very high speeds to charged particles by means of a high-frequency electric field and a low-frequency magnetic field.

Study of the classification of organisms according to standard rules. Most modern taxonomies are phylogenetic (or natural); they attempt to group organisms according to evolutionary descent.

A condition or state that changes in time.

A branch of physics that deals with the mechanical actions or relationships of heat.

The transfer of genetic determinants from one microorganism to another or from one strain of microorganisms to another by a viral agent.

In microbiology, genetic transfer wherein DNA from a donor cell enters a recipient cell and is incorporated into the recipient DNA by genetic recombination.

A segment of DNA with a repeat of an insertion sequence element at each end and which can migrate from one plasmid to another within the same bacterium, to a bacterial chromosome, or to a bacteriophage. 


\section{Appendix C: Developers and Reviewers of the Program Plan}

Lisa Alverez-Cohen, University of California, Berkeley William Apel, Lockheed Martin Idaho Technologies David H. Attaway, National Oceanic and Atmospheric Administration Sally Benson, Lawrence Berkeley National Laboratory Pragna Bhakta, U.S. Bureau of Mines Gerald Boyd, Department of Energy Jim Brainard, Los Alamos National Laboratory Michelle Broido, U.S. Department of Energy Carl E. Cerniglia, U.S. Food and Drug Administration Rita Colwell, University of Maryland Geoffrey Compeau, Enviros Gregory Dilworth, U.S. Department of Energy T.H. Dunning, Jr., Pacific Northwest Laboratory A.J. Francis, Brookhaven National Laboratory Stanley Goldman, Lawrence Berkeley National Laboratory Darrell J. Grimes, U.S. Department of Energy Frank Harris, University of Tennessee Terry Hazen, Savannah River Technology Center Michael Heeb, U.S. Department of Energy Dennis Hjeresen, Los Alamos National Laboratory Joanne Horn, Lawrence Livermore National Laboratory Jennie Hunter-Cevera, Lawrence Berkeley National Laboratory Ken Jackson, Lawrence Livermore National Laboratory Lamar Johnson, Idaho National Engineering Laboratory Michael Klug, Michigan State University Allen Laskin, Laskin/Lawrence Associates Stephen C.T. Lien, U.S. Department of Energy Carol Litchfield, George Mason University Janice Longstreth, Waste Policy Institute William Luth, U.S. Department of Energy Don Maiers, Idaho National Engineering Laboratory John Manning, Argonne National Laboratory 
Bob Menzer, Environmental Protection Agency

F. Blaine Metting, Jr., Pacific Northwest Laboratory

Geri Moline, Oak Ridge National Laboratory

Frank Olken, Lawrence Berkeley National Laboratory

Anna C. Palmisano, Office of Naval Research

Tony Palumbo, Oak Ridge National Laboratory

Frank Parker, Vanderbilt University

Ari Patrinos, U.S. Department of Energy

Mary Peterson, Pacific Northwest Laboratory

George Pierce, CYTEC Industries, Inc.

Jeanne S. Pointdexter, Barnard College/Columbia University

Parmely H. Pritchard, Environmental Protection Agency

Chris Reilly, Argonne National Laboratory

Christopher Rivard, National Renewable Energy Laboratory

James Romesser, Betz Laboratories, Inc.

Gary Sayler, University of Tennessee

Tetsu K. Kokunaga, Lawrence Berkeley National Laboratory

Phil Sayre, Environmental Protection Agency

David Smith, U.S. Department of Energy

Gary Sposito, University of California, Berkeley

Joseph M. Suflita, University of Oklahoma

Anne O. Summers, University of Georgia

Tetsu Tokunaga, Lawrence Berkeley National Laboratory

Jonathan Trent, Argonne National Laboratory

Chin-Fu Tsang, Lawrence Berkeley National Laboratory

Peter Van Voris, Pacific Northwest Laboratory

Jef Walker, U.S. Department of Energy

Barbara Walton, Oak Ridge National Laboratory

Paul Wichlacz, Idaho National Engineering Laboratory

Raymond E. Wildung, Pacific Northwest Laboratory

Frank Wobber, U.S. Department of Energy 